\title{
A TEST OF FUSIBLE INSULATION FOR A PROPOSED ISOTOPE POWER UNIT
}

\author{
M. E. Lackey
}

\section{OAK RIDGE NATIONAL LABORATORY}

OPERATED BY UNION CARBIDE CORPORATION - FOR THE U.S. ATOMIC ENERGY COMMISSION 


\section{DISCLAIMER}

This report was prepared as an account of work sponsored by an agency of the United States Government. Neither the United States Government nor any agency Thereof, nor any of their employees, makes any warranty, express or implied, or assumes any legal liability or responsibility for the accuracy, completeness, or usefulness of any information, apparatus, product, or process disclosed, or represents that its use would not infringe privately owned rights. Reference herein to any specific commercial product, process, or service by trade name, trademark, manufacturer, or otherwise does not necessarily constitute or imply its endorsement, recommendation, or favoring by the United States Government or any agency thereof. The views and opinions of authors expressed herein do not necessarily state or reflect those of the United States Government or any agency thereof. 


\section{DISCLAIMER}

Portions of this document may be illegible in electronic image products. Images are produced from the best available original document. 
This report was prepared as an account of work sponsored by the United States Government. Neither the United States nor the United States Atomic Energy Commission, nor any of their employees, nor any of their contractors, subcontractors, or their employees, makes any warranty, express or implied, or assumes any legal liability or responsibility for the accuracy, completeness or usefulness of any information, apparatus, product or process disclosed, or represents that its use would not infringe privately owned rights. 
Contract No.W-7405-eng-26

Reactor Division

This report was prepared as an account of work sponsored by the United States Government. Neither the United States nor the United States Atomic Energy Commission, nor any of their employees, nor any of their contractors, subcontractors, or their employees, makes any warranty, express or implied, or assumes any legal liability or responsibility for the accuracy, completeness or usefulness of any information, apparatus, product or process disclosed, or represents that its use would not infringe privately owned rights.

A TEST OF FUSIBLE INSULATION FOR A PROPOSED ISOTOPE POWER UNIT

M. E。 Lackey

APRIL 1974

OAK RIDGE NATIONAL IABORATORY

Oak Ridge, Tennessee 37830

operated by

UNION CARBIDE CORPORATION

for the

U.S. ATOMIC ENERGY COMMISSION 
Blank Page 


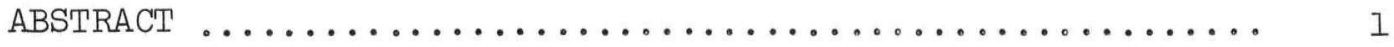

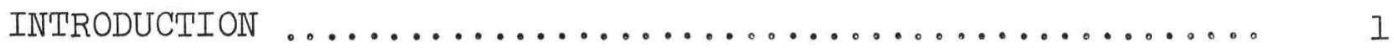

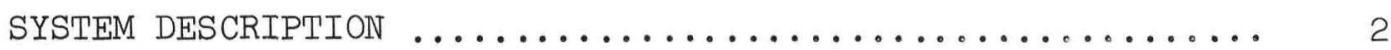

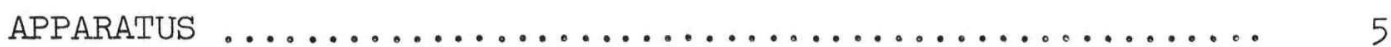

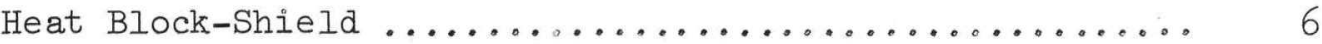

Electrical Heaters $\ldots \ldots \ldots \ldots \ldots \ldots \ldots \ldots \ldots \ldots \ldots \ldots \ldots$

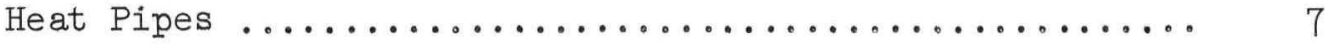

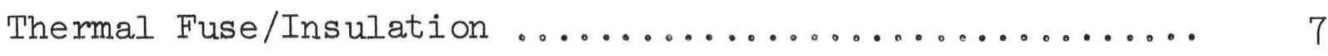

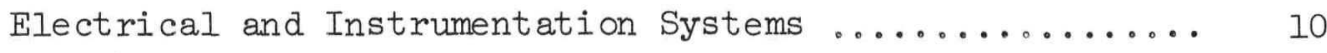

Cooling System .............................. 10

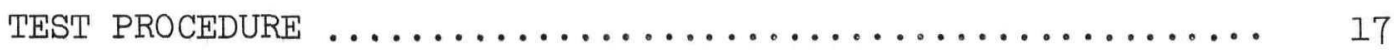

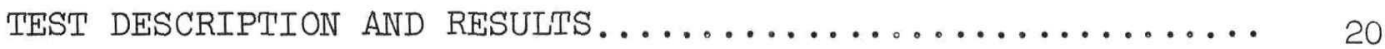

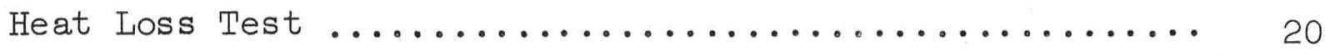

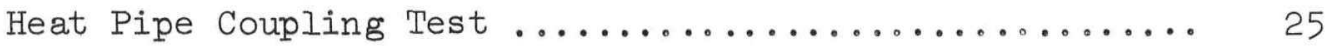

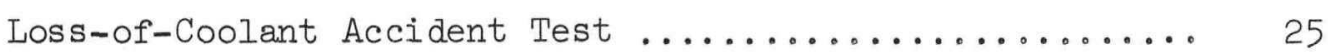

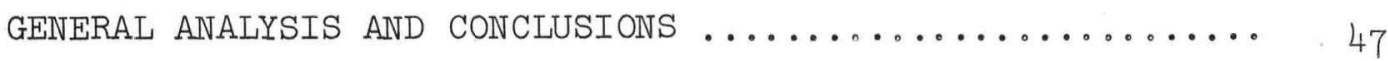

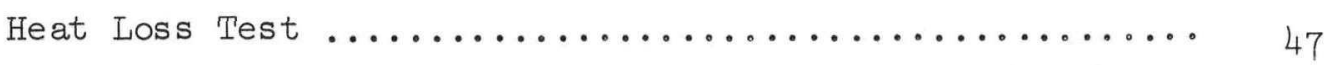

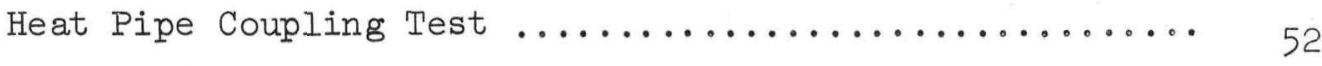

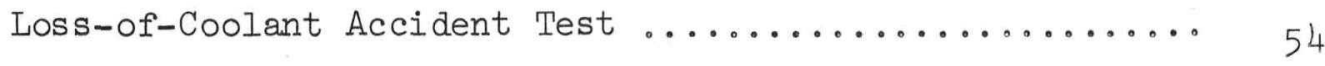

APPENDIX A - HEAT BLOCK-SHIELD TEST DATA .............. 58

APPENDIX B - HEAT PIPE DESIGN, FABRICATION, AND TESTING ... 65

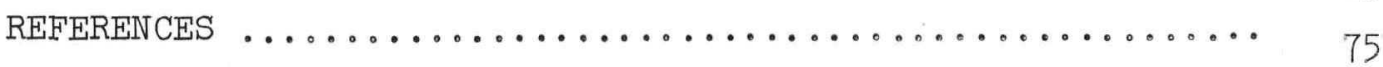


Blank Page 
List of Figures

\section{Figure}

1. Full-scale fusible insulation evaluation test.

2. Components used to simulate the isotope capsules for the fullscale heat block-shield test. The parts shown are the electric heater element (bottom), the shield plug (right middle), and the assembled heater (top).

3. Completed fusible insulation with the outer layer of expanded metal installed.

4. Completed fusible insulation with the bottom cross supports installed.

5. Completed fusible insulation with the top cross supports installed.

6. The top thermal insulation and the top retainers for the fusible insulation bundle installed in the simulated pressure vessel.

7. The double sheathed, grounded junction thermocouples attached to the vertical surface of the heat block-shield.

8. Bottom feed-through for the double sheathed grounded junction thermocouples.

9. Simulated 54.5 in. diameter pressure vessel for the heat blockshield test.

10. Location of cooling coils on the heat pipe condensers.

11. Total heat losses from the full scale heat block-shield with 6.5 in. of fusible insulation operating in 1 psig argon.

12. Adjusted heat losses from a full scale heat block-shield with 6.5 in. of fusible insulation operating in 1 psig argon.

13. The thermal conductivity of combined aluminum foil-screen insulation operating in an atmosphere of argon at a pressure of 1.0 psig.

14. Heat block-shield before the installation of the fusible insulation.

15. Performance of the simulated thermoelectric power generation system. 
Figure

16. Adjusted performance of the simulated thermoelectric power generation system.

17. Time-temperature history of the full scale meltdown.

18. Vertical view of the fused insulation at $\theta=0^{\circ}$.

19. Vertical view of the fused insulation at $\theta=90^{\circ}$.

20. Vertical view of the fused insulation at $\theta=180^{\circ}$.

21. Vertical view of the fused insulation at $\theta=270^{\circ}$.

22. The inner expanded metal insulation support after fusion of the insulation.

23. An area with a complete radial fusion of the aluminum-foil insulation.

24. An overall view of the fusible insulation after the removal of simulated pressure vessel.

25. Close-up view of the complete radial fusion shown in Fig. 24.

26. Close-up view of a radial fusion complete except for the outer screen layer.

27. Molten aluminum spillover occuring at approximately 13 hours into the meltdown.

28. Close-up of the 13-hour spillover showing a layering effect indicating successive spillover.

29. Molten aluminum spillover occuring at approximately 40 hours into the meltdown.

30. Top view of the fusible insulation bundle after removal from the heat block-shield.

31. Bottom view of the fusible insulation bundle after removal from the heat block-shield.

32. Bottom view of the fusible insulation bundle showing the debris buildup.

33. Bottom section of the heat block-shield after the removal of the fusible insulation bundle. 


\section{Figure}

34. Deflector cone after the removal of the fusible insulation bundle.

35. Bottom section of the heat block-shield showing the maximum height of the molten aluminum to be approximately one foot.

36. The temperature difference, the heat pipe vapor and the heat pipe hole surface temperature distribution in the heat blockshield at a power level of $34 \mathrm{~kW}$.

37. Estimated time-temperature history of the full scale meltdown.

A-1. Thermocouple coordinate system.

A-2. Location of the thermocouples in the fusible insulation.

B-1. Fabrication technique for a 200-400-200 mesh wick.

B-2. Internal cleanup system in the evaporator end of a heat pipe.

B-3. External cleanup system on the evaporator end of a heat pipe.

B-4. Potassium charging system.

B-5a. Heat pipe arrangement in the furnace during cleanup.

B-5b. Heat pipe temperature distribution during cleanup.

B-6. Cross-section of heat pipe test assembly. 
A TEST OF FUSIBLE INSULATION FOR A PROPOSED ISOTOPE POWER UNIT

M. E。 Lackey

A BSTRACT

In support of the Isotope Kilowatt Program, an evaluation test of the full-scale simulated thermoelectric power generation system was made. The test was run with 6.5 in. of fusible insulation around the heat block-shield to determine the system heat losses. A loss of $10 \%$ of full power was obtained with the system operation at a heat block-shield surface temperature of $1100^{\circ} \mathrm{F}$ and an argon pressure of 1.0 psig.

A test was run to determine the thermal coupling between the heat block-shield and 12 heat pipes with 12 simulated thermoelectric generators. A heat pipe condenser temperature of $1040^{\circ} \mathrm{F}$ was obtained at a heat block-shield surface temperature of $1150^{\circ} \mathrm{F}$ at a total power input of $34 \mathrm{~kW}$.

A loss-of-coolant accident test was made to determine the maximum fuel capsule surface temperature reached during a meltdown of the fusible insulation. The meltdown results yielded a maximum fuel capsule surface temperature of $2175^{\circ} \mathrm{F}$ and an equilibrium temperature of $2070^{\circ} \mathrm{F}$.

\section{INTRODUCTION}

The isotope power unit reference designs evolved in the Isotope Kilowatt Program entailed the use of a mild steel heat block-shield to serve both as a radiation shield and as a heat conduction medium between the radioisotopic heat source and the electric power conversion system. The electric power can be produced from either a thermoelectric ${ }^{1}$ or a Rankine ${ }^{2}, 3$ cycle power conversion system. The thermoelectric power unit makes use of potassium-filled heat pipes to transport heat to the thermoelectric modules from the heat block-shield. The Rankine cycle system employs a turbine-generator unit driven by either steam or Dowtherm-A vapor that is generated in the heat block-shield.

The temperature distribution in the heat block-shield and the thermal performance of the fusible insulation for use with the Rankine cycle 
power conversion system was experimentally evaluated and is reported in Ref. 4.

The thermal performance of the heat block-shield and the fusible insulation for use with the thermoelectric power conversion system was determined experimentally in this test. Integrated with this work was a test with twelve heat pipes in the heat block-shield (operating with electric heaters simulating the ${ }^{90} \mathrm{SrTiO}_{3}$ fuel) to determine the temperature distribution in the complete full-scale system when operating under the full-power conditions of $34 \mathrm{~kW}$.

The test consisted of three major subtasks. The first was the determination of the performance of the thermal coupling between the heat pipes and the heat block-shield. The second subtask was the determination of the insulating value of the fusible insulation under the operating conditions of the thermoelectric system. The final subtask was a test of the fusion characteristics of the aluminum screen-foil insulation operating under simulated loss-of-coolant accident conditions.

\section{SYSTEM DESCRIPTION}

A full-scale steel heat block-shield with electric heaters to simulate the full capsules was used to determine the temperature distribution under various modes of operation. Seven heaters clad with Type 310 stainless steel to allow operation at $2000^{\circ} \mathrm{F}$ in air were used to simulate the fuel capsules. The heaters were located in the center of the heat block-shield in seven 4.153 in. ID holes in an hexagonal array, with a web thickness of 1.5 in. The heaters were sized to deliver a total of $34 \mathrm{~kW}$.

The heat block-shield has twelve holes for boiler tubes, and twelve holes for heat pipes. There are 45 vertical fins on the outer circumference and the unit is supported by a stainless steel skirt the bottom of which is attached to an iron plate that simulates an elliptical head for the hull that would enclose the unit (see Fig. 1). The major design and dimensional data for the full-scale heat block-shield are given in Table 1 . 
ORNL DWG 72-9629

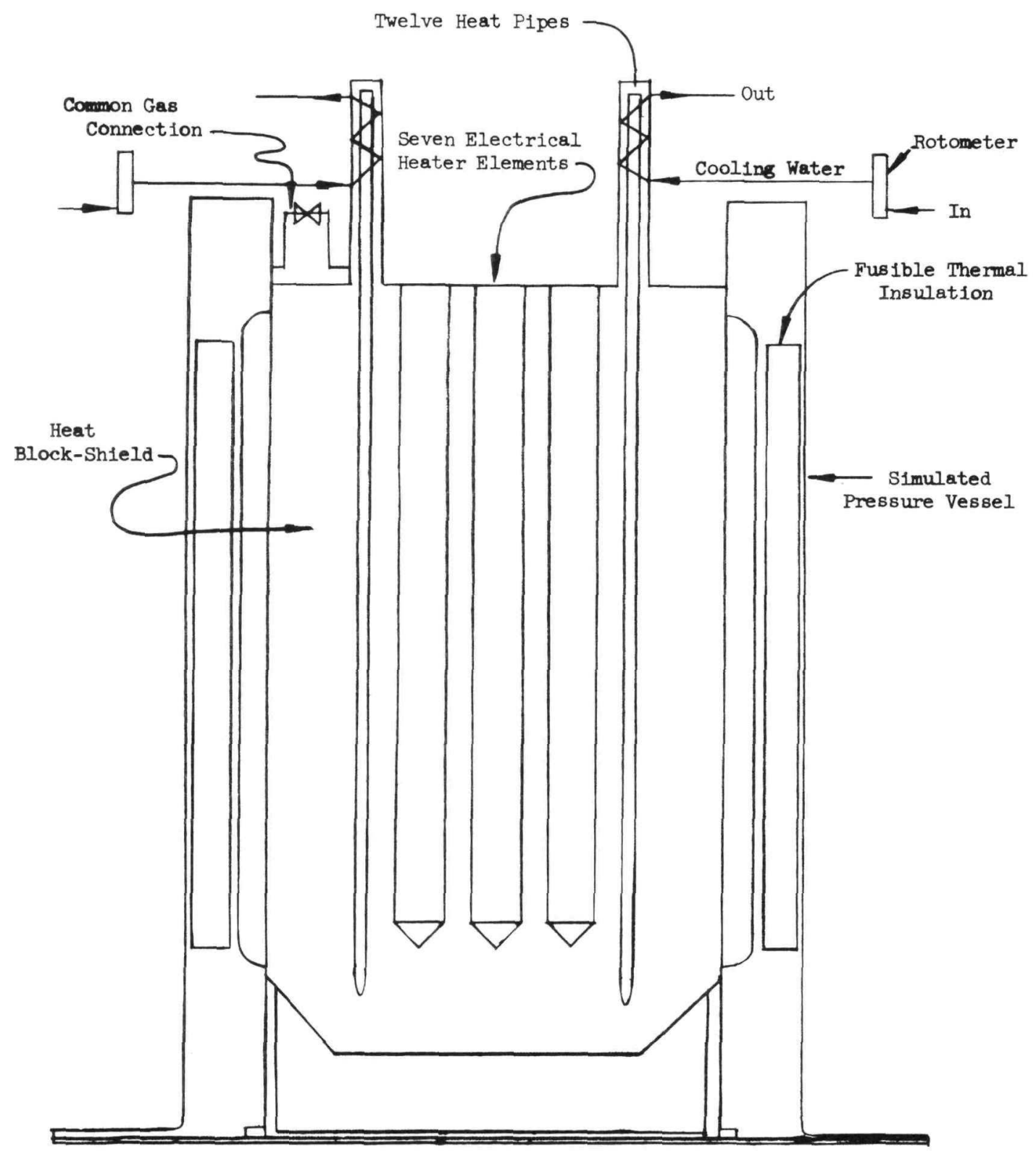

Fig. 1. Full-scale fusible insulation evaluation test. 
Table 1. Design and Dimensional Data for the Full-Scale Heat Block-Shield Test

Material

Diameter

Fin root, in.

Fin tip, in.

Height, in.

Number of fins

Fin height, in.

Fin thickness, in.

Holes for heat pipes

Number

Diameter, in.

Length, in.

Centerline circle, in.

Holes for electric heaters

Number

Diameter, in.

Length, in.

Centerline spacing, in.
SAE 1010 steel

35.5

40.5

60

45

2.5

0.5

12

1.008

55

21.25

7

4.153

50.25

5.653

\section{Heaters}

Number

Outside diameter, in.

Inside diameter, in.

Assembled length, in.

Heated length, in.

Power @ 227 volts, kW

Power@ 208 volts, kW

7

4.090

3.500

40.300

38.33

5.67

4.85

Heat block-shield assembly shipping weight 16,500 without heaters, Ib 
To determine the performance of the thermal coupling between the heat pipes and the heat block-shield when operating in an atmosphere of argon at 15.4 psia a test was run at power inputs up to $34 \mathrm{~kW}$ with the unit in an upright position with 6.5 in. of fusible insulation around the outside diameter. The temperature distribution in the heat block-shield and the heat pipe condenser temperatures were determined for these operating conditions.

The normal operating heat losses were determined without the heat pipes in the heat block-shield and with 6.5 in. of fusible insulation around the outside diameter with an argon atmosphere at a pressure of 15.4 psia. The heat losses were determined for a range of heat blockshield surface temperatures up to $1100^{\circ} \mathrm{F}$.

To simulate a complete failure of the primary heat removal system, the test to determine the fusion characteristics of the aluminum screen-foil insulation was run in an argon atmosphere at a pressure of 15.4 psia without the heat pipes in the heat block-shield. The 6.5 in. of fusible insulation around the outside of the heat block-shield was allowed to melt. This reduced its thickness and thus its insulating value until the thickness was such that the full power load of $34 \mathrm{~kW}$ was transmitted with the inner surface of the remaining insulation at the melting point. The temperature distribution in the heat block-shield and the fusible insulation were determined for this operating condition.

\section{APPARATUS}

The major components of the full-scale fusible insulation evaluation test facility include the heat block-shield, electrical heaters, heat pipes, and a vacuum vessel containing the fusible insulation. The system operation entailed the arrangement of various components to simulate a specific test condition, adjusting the power level of the heaters, and allowing the temperature of the block to rise to equilibrium with the environment. 
Heat Block-Shield

The full-scale heat block-shield, which was fabricated from SAE 1010 steel, is 35.5-in. OD by 60-in. long with 45 axial fins on the OD. The fins are $1 / 2-i n$. thick by 2 l/2-in. high and 53-in. in length. The block has two sets of twelve holes each 55-in. deep. The outer set equally spaced around a 31-in. diam circle are 1.067-in. ID and was designed for boiler tubes if the heat is to be extrated from the block by boiling Dowtherm-A to supply the energy for the operation of an organic Rankine cycle. The inner set of holes on a 21.25-in. diam circle are 1.008-in. ID, and was designed for the installation of heat pipes if the heat is to be used for thermoelectric generators.

Seven holes 4.153-in. ID $x$ 50.25-in. deep in a hexagonal array with a web thickness of $1.5 \mathrm{in}$, are located in the center of the block. These holes will normally contain an isotopic heat source in the form of ${ }^{90} \mathrm{SrTiO}_{3}$ in Hastelloy $\mathrm{C}-276$ capsules. In the subject experiments an electrically heated source was used to simulate the isotopic source.

The bottom of the block is a truncated cone with a minor diameter of 25-in. and a slope of $45^{\circ}$. This shape was used to reduce the gross weight of the block and also to allow for better insulation of the block and the support skirt arrangement.

The block is supported by a stainless steel skirt 0.25-in. thick by Il-in. long attached to a 48-in. diam x 1.5-in. thick iron plate that simulates a bottom elliptical head. The skirt has 24 equally spaced 0.125 -in. slots 10.5 -in. long to relieve the thermal stresses induced by the differential expansion of the top and bottom of the skirt resulting from the temperature gradient in the skirt. The skirt is fabricated from stainless steel to take advantage of its low thermal conductivity to reduce heat losses, and its good strength at $1100^{\circ} \mathrm{F}$ avoids difficulty with creep.

\section{Electrical Heaters}

Seven electrical heaters are used to simulate the isotopic heat sources. The heaters are clad with Type 310 stainless steel, and were 
designed to operate for short periods in air at a surface temperature of $2000^{\circ} \mathrm{F}$. The heater cladding was 4.090-in. OD by 40.3-in. long. The heater core was fabricated from 230 turns of 0.1144-in. OD Nichrome $V$ wire on a 2.75-in. OD Alundum core, manufactured by the Norton Company, to give a heated length of 38.33 in. Each heater will deliver approximately $4.85 \mathrm{~kW}$ at $208 \mathrm{~V}$ to simulate the power generation rate of ${ }^{90} \mathrm{SrTiO}_{3}$. The component parts used to simulate the isotopic capsules are shown in Fig. 2 .

\section{Heat Pipes}

The heat pipes are modifications of the type used in the earlier phase of the Thermoelectric Isotope Power Program as reported in Ref. 5. The heat pipes are 79 in. long, have a l-in. diameter, and use potassium as the working fluid. The design, fabrication, and testing of these pipes are summarized in Appendix B.

\section{Thermal Fuse/Insulation}

The thermal fuse/insulation was fabricated from aluminum wire screen and aluminum foil. The wire screen and foil were wrapped around a mandrel made of stainless steel grid of expanded metal. Eight layers of screen were wrapped first and then a layer of foil, and then the process was repeated. This ratio of eight wire screen wraps to one foil wrap was continued until the desired thickness of insulation was obtained. The only exception to this ratio was that the last screen layer was preceded by a foil layer. After the desired insulation thickness was obtained, a final grid of stainless steel expanded metal was affixed around the outer diameter of the insulation bundle.

The screen was woven from Alcoa alloy 1100 wire. The wire diameter was 0.011 in. and the screen mesh $16 \times 16$ wires per in. The foil was 0.002-in. thick Alcoa alloy 5052. The chemical composition and melting range of these alloys as given in the Alcoa Aluminum Handbook are given in Table 2. The dimensions of the fusible insulation are given in Table 3. 


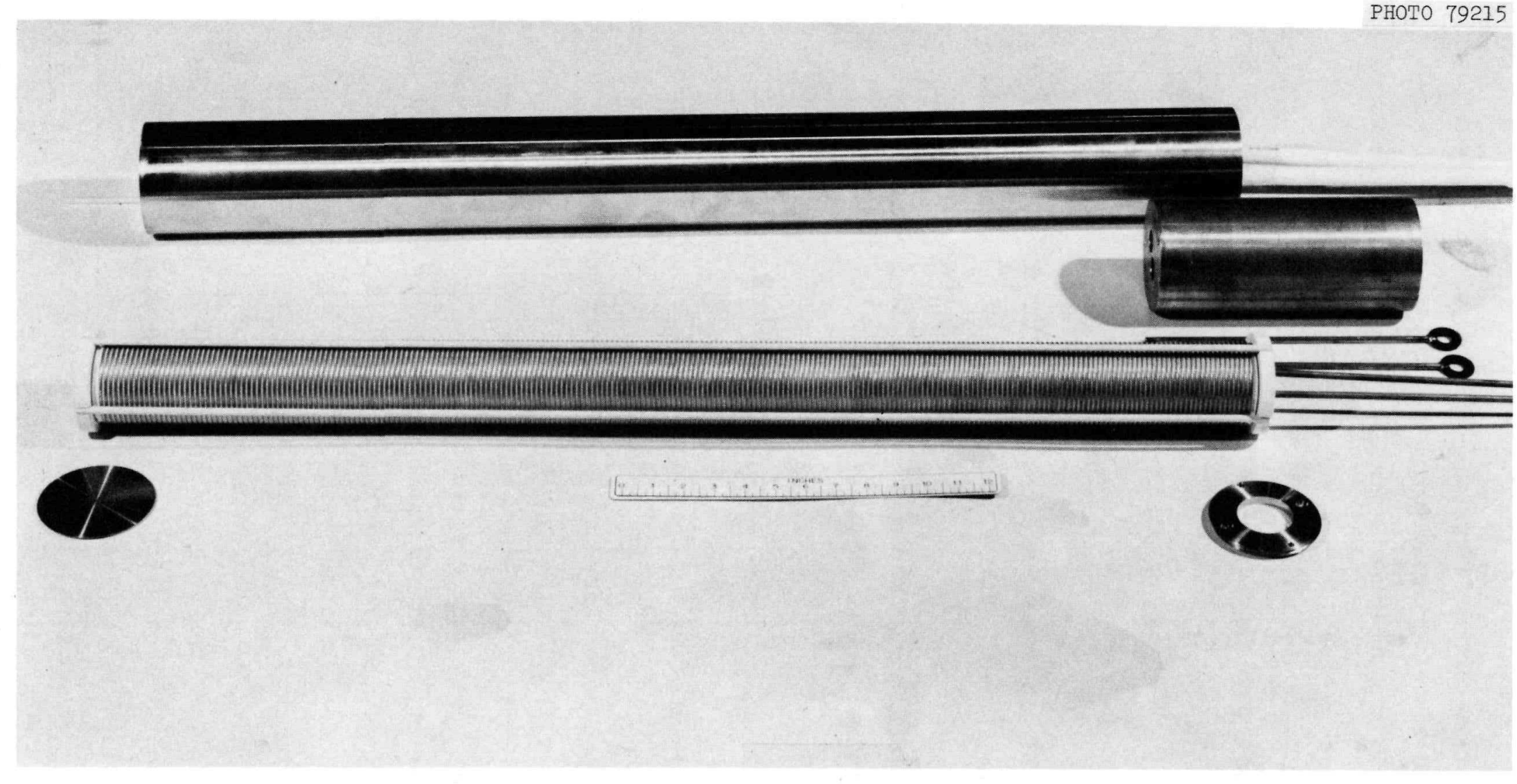

$\infty$

Fig. 2. Components used to simulate the isotope capsules for the full-scale heat block-shield test. The parts shown are the electric heater element (bottom), the shield plug (right midale), and the assembled heater (top). 
Table 2. Chemical Composition and Melting Range of the Fusible Insulation Wire and Foil

\begin{tabular}{|c|c|c|}
\hline \multirow[b]{2}{*}{ Element } & \multicolumn{2}{|c|}{ Alloy } \\
\hline & 1100 & 5052 \\
\hline $\begin{array}{l}\text { Silicon plus iron (max), \% } \\
\text { Copper (max), \% } \\
\text { Manganese (max), \% } \\
\text { Magnesium, \% } \\
\text { Chromium, \% } \\
\text { Zinc (max), \% } \\
\text { Other elements }\end{array}$ & $\begin{array}{l}1.0 \\
0.20 \\
0.05\end{array}$ & $\begin{array}{l}0.45 \\
0.10 \\
0.10 \\
2.2-2.8 \\
0.15-0.35 \\
0.10\end{array}$ \\
\hline $\begin{array}{l}\text { Each, \% } \\
\text { Total, \% }\end{array}$ & $\begin{array}{l}0.05 \\
0.15\end{array}$ & $\begin{array}{l}0.05 \\
0.15\end{array}$ \\
\hline $\begin{array}{l}\text { Aluminum (min), } \% \\
\text { Melting Range, deg F }\end{array}$ & $\begin{array}{l}99.00 \\
1190-1215\end{array}$ & $\begin{array}{l}\text { Remainder } \\
1125-1200\end{array}$ \\
\hline
\end{tabular}

Table 3. Dimensions of the Fusible

Insulation for the Full Scale Heat-Block Test

Expanded Metal Liners

Type

Flattened Expanded

$11 / 2$ in. No.16-18

Metal

Nominal thickness, in.

Width, in.

0.047

Material

48

Inside diameter

Inner liner, in.

Outer liner, in.

Stainless steel

41.375

54.469

Number of Foil Layers

38

301

Number of Screen Layers

6.5

Average Screen Layer Thickness, in.

0.021 
The completed screen with its outer grid of expanded metal installed is shown in Figure 3. The bottom and top of the insulation bundle with the cross supports between the inner and outer expanded metal grids are shown in Fig. 4 and 5, respectively. The Kaowool thermal insulation at the top and the top retainers for the fusible insulation bundle are shown installed in the simulated pressure vessel in Fig. 6.

\section{Electrical and Instrumentation Systems}

Electrical power was supplied to the seven heaters from seven variable transformers which have a range of output voltage from 0 to 270 V. The voltage to each heater was measured with a multirange voltmeter that had full-scale ranges of 15, 30,75, 150, and $300 \mathrm{~V}$. The current to each heater was measured with a multirange ammeter that had full-scale ranges of $2,5,10,20$, and $50 \mathrm{amp}$.

The temperature was measured using chromel-alumel thermocouples. The thermocouples on the heater surfaces and on the upper surface of the heat block-shield were sheathed, grounded junction thermocouples attached to the surface with spotwelded shim stock. The thermocouples on the heat block-shield vertical surface were double sheathed, grounded junction thermocouples attached to the surface with spotwelded shim stock as shown in Fig. 7. Details of the bottom thermocouple feed-through are shown in Fig. 8. The thermocouples used in the fusible insulation were of the sheathed, grounded junction type, and were wired to the screen to fix their positions.

The temperature data were collected with a DEXTIR data acquisition system. Key temperatures were recorded using a 12- and a 24-point Brown recorder to determine when equilibrium temperature conditions were reached。

\section{Cooling System}

The heat transferred through the fusible insulation was transferred to cooling water coils located around the simulated pressure vessel and 


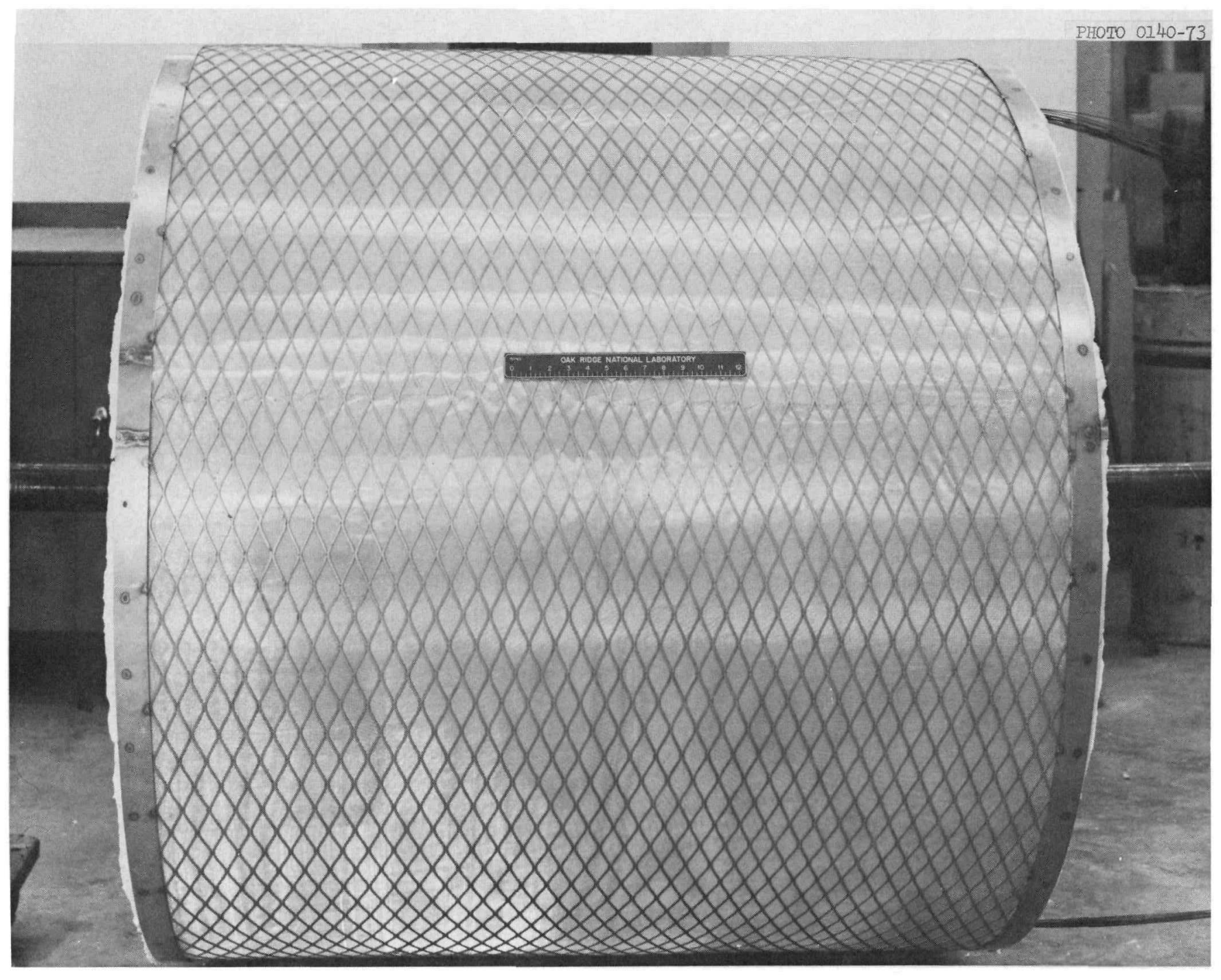

Fig. 3. Completed fusible insulation with the outer layer of expanded metal installed. 
PHOTO 0.142-73

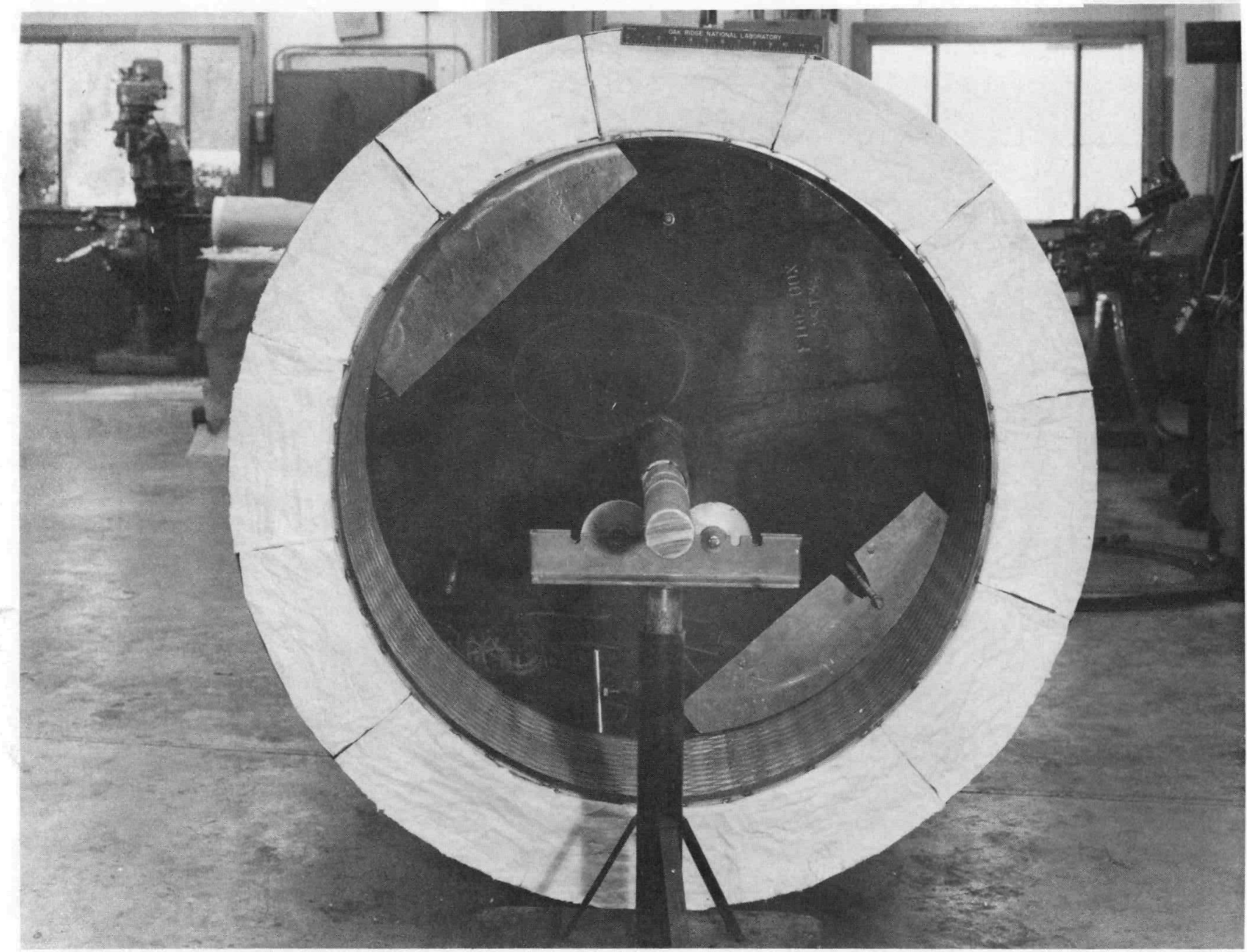

Fig. 4. Completed fusible insulation with the bottom cross supports installed. 


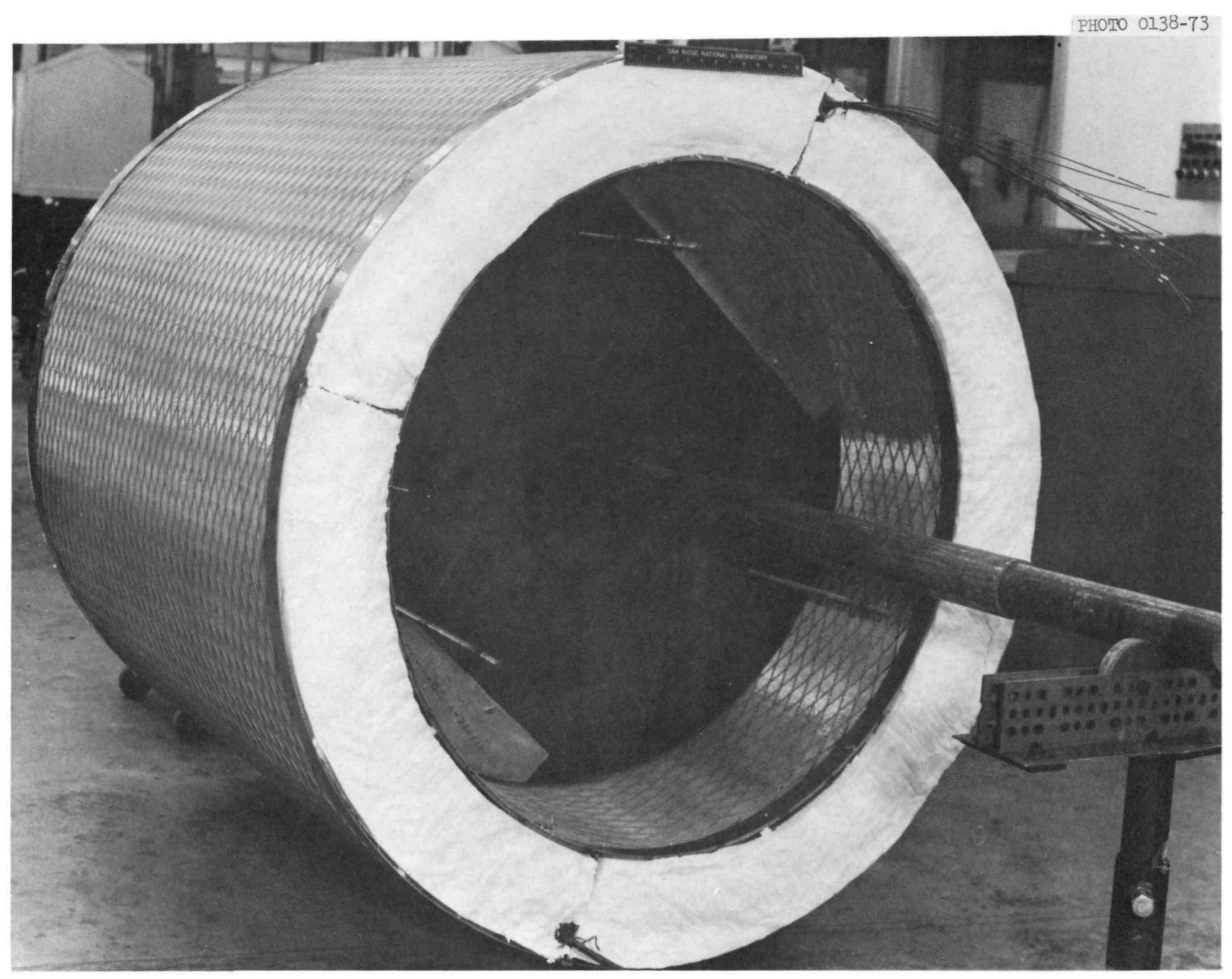

Fig. 5. Completed fusible insulation with the top cross supports installed. 


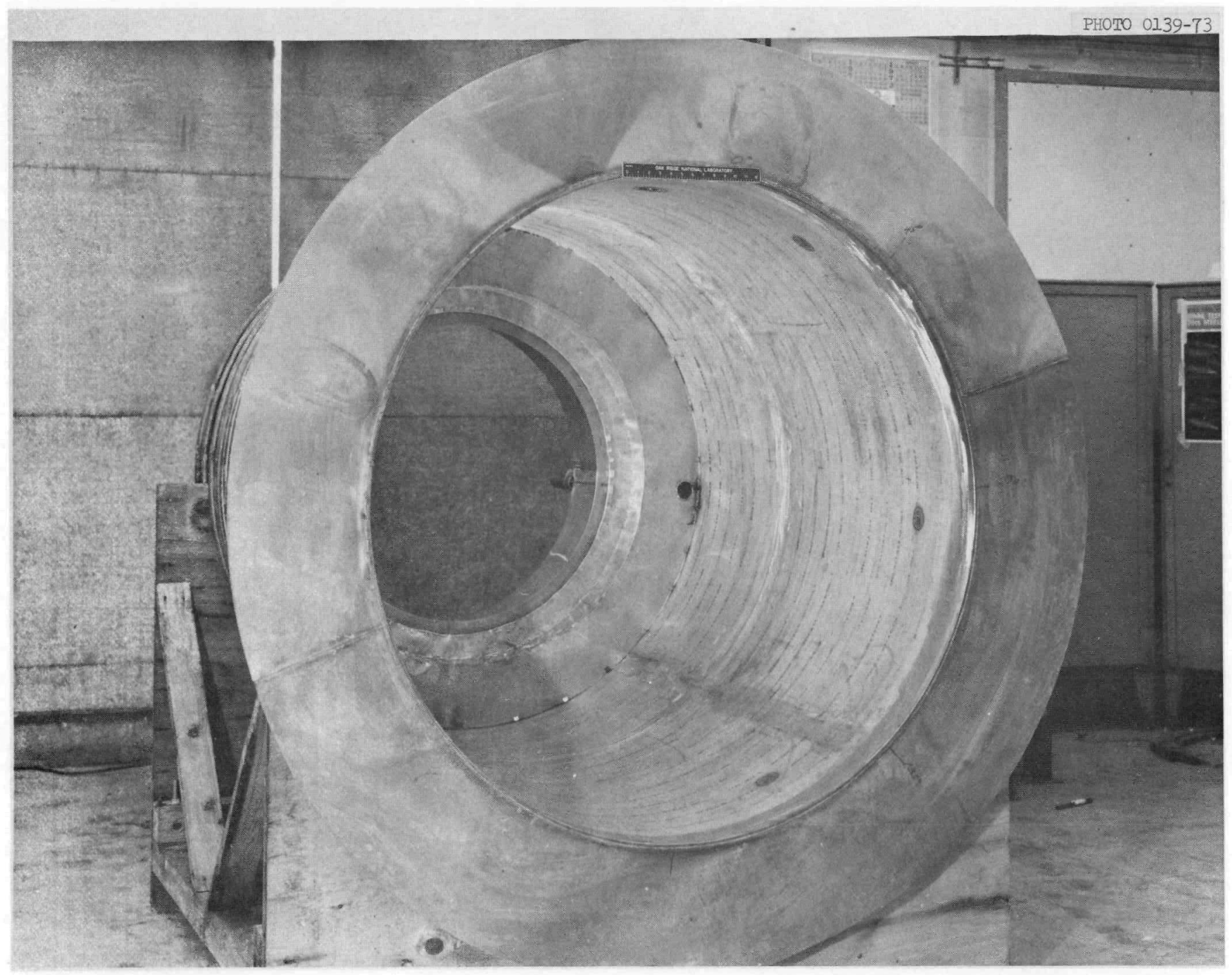

Fig. 6. The top thermal insulation and the top retainer for the fusible insulation bundle installed in the simulated pressure vessel. 


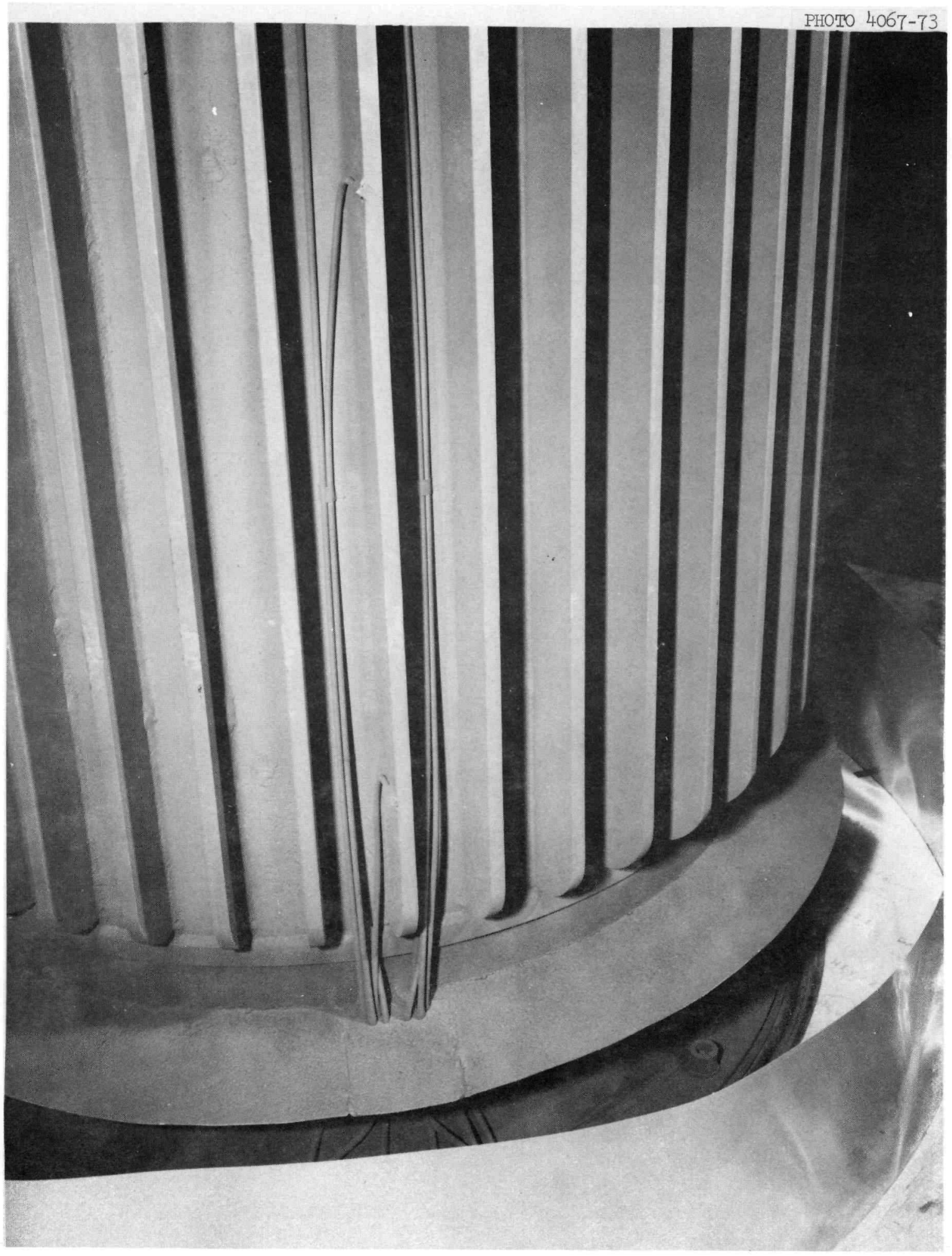

Fig. 7. The double sheathed, grounded junction thermocouples attached to the vertical surface of the heat block-shield. 


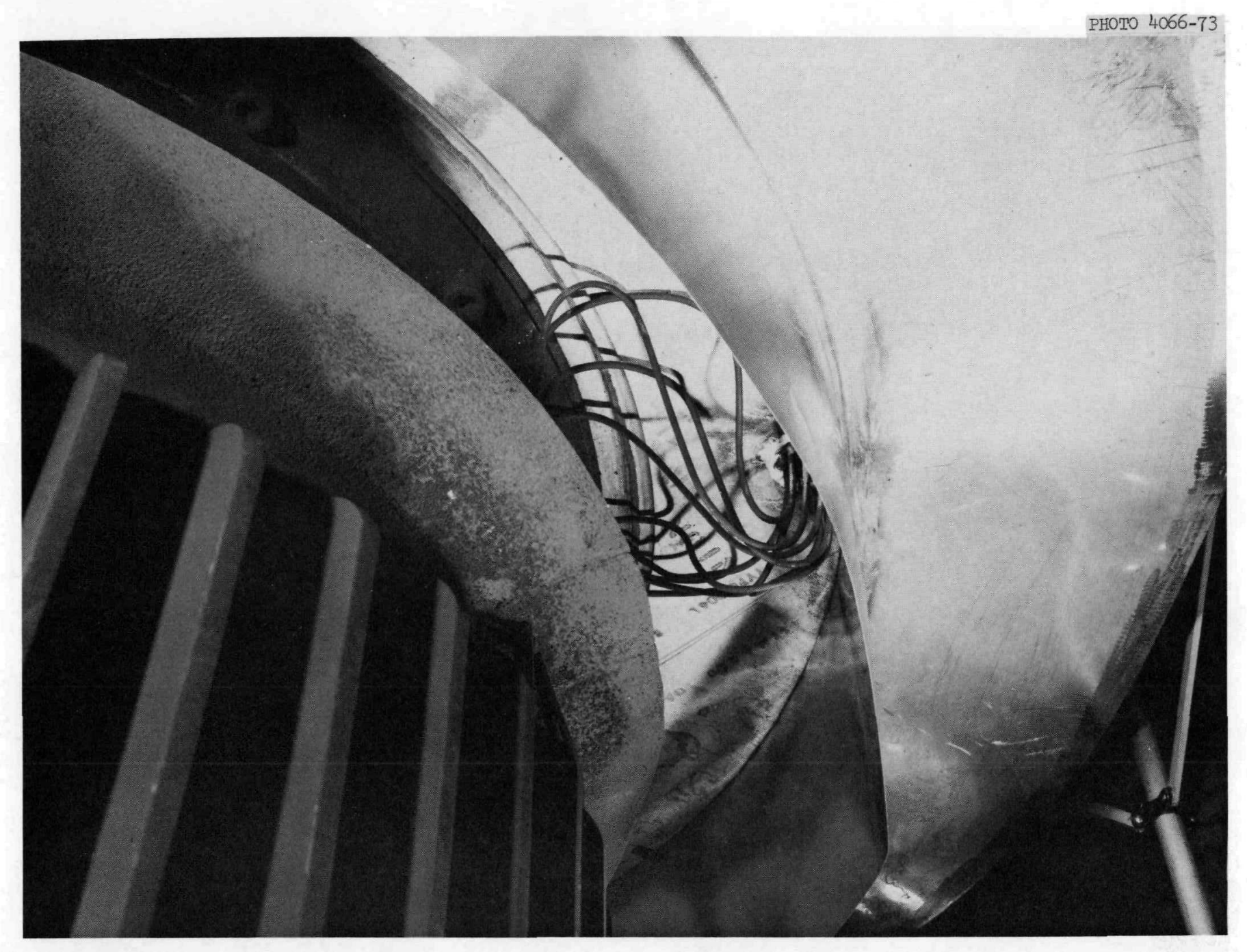

Fig. 8. Bottom feed-through for the double sheathed grounded junction the rmocouples. 
on the simulated bottom elliptical head. The simulated pressure vessel with the cooling coils in place is shown in Fig. 9. The heat removed from the heat block-shield with the heat pipes was transferred by radiation and conduction to cooling coils located around each heat pipe as shown in Fig. 10 .

\section{TEST PROCEDURE}

The independent variables for the test conditions are the power input and the method of heat removal. These factors were combined to determine the temperature profile of the heat block-shield. The power level was varied from approximately $2 \mathrm{~kW}$ to $34 \mathrm{~kW}$. The modes of heat removal with the fully insulated heat block-shield in an upright position were; first, the heat losses through the insulation were determined at normal operating temperatures; second, the heat was removed with 12 heat pipes simulating the thermoelectric power generation system; and third, the heat was removed through the insulation with the system operating at $34 \mathrm{~kW}$ to determine the fusion characteristics of the aluminum screen-foil insulation.

The general procedure for each of the experiments was as follows:

1. The cooling conditions for the heat block-shield were fixed.

2. Power was supplied to the simulated fuel elements.

3. The heat block-shield temperature distribution was allowed to approach equilibrium.

4. As equilibrium was approached, the power was trimmed to compensate for changes in heater resistance.

5. When the heat block-shield appeared to be at thermal equilibrium, as indicated by stabilization of the temperature distribution, the data were recorded. The voltage and current for each heater and the temperatures were read and recorded. 


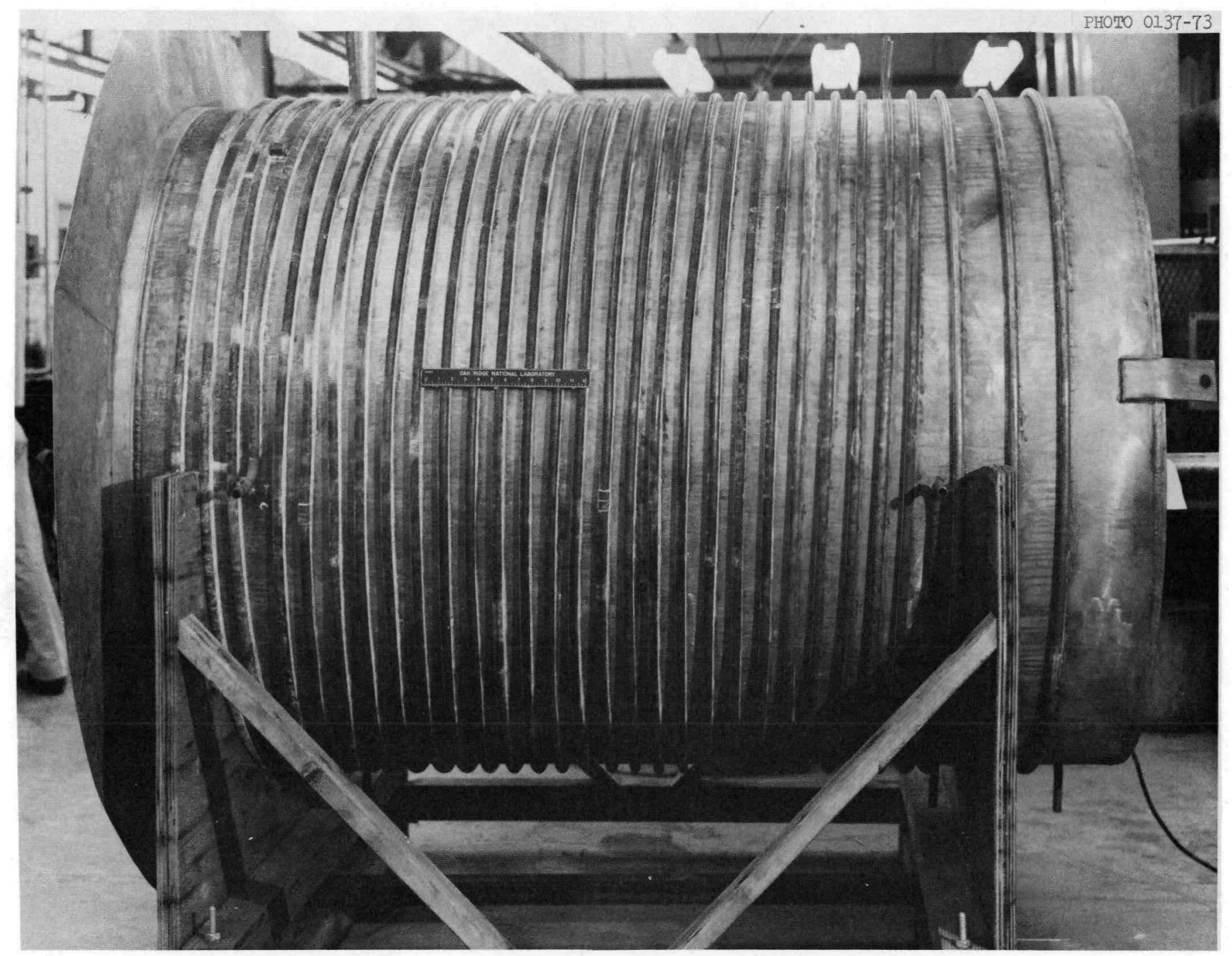

Fig. 9. Simulated 54.5 in. diameter pressure vessel for the heat block-shield test. 


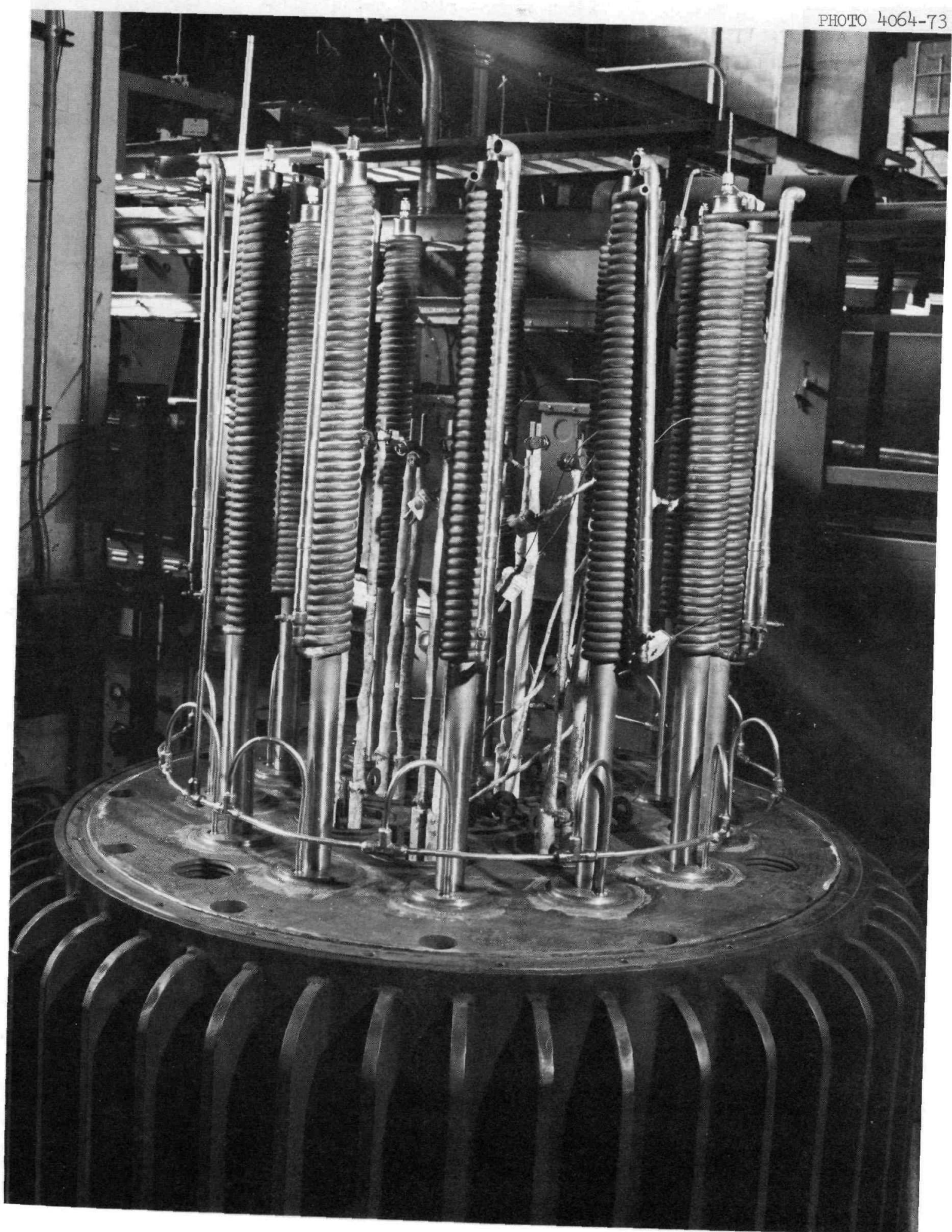

Fig. 10. Location of cooling coils on the heat pipe condensers. 
TEST DESCRIPTION AND RESULTS

The test results are given for the most part in terms of temperature profiles through the heat block-shield and the thermal insulation. Prior to the operation of the system for the temperature determinations, moisture and oxygen were removed from the environs of the heat pipes and the thermal insulation by purging with argon. A moisture content of less than $25 \mathrm{ppm}$, an oxygen concentration of less than $1 \mathrm{ppm}$, and an argon pressure of 1 psig were maintained throughout the entire testing regime.

\section{Heat Loss Test}

To determine the effectiveness of the 6.5 in. fusible insulation, heat loss tests were run with the insulation bundle installed around the full scale heat block-shield. The heat loss tests were run in an argon atmosphere at a pressure of 1.0 psig. The details of these tests (listed as Tests 1 through 4) are given in Appendix A, Table A-1.

The total heat losses are given in Table 4 and are shown in Fig. II as a function of the heat block-shield midplane surface temperature. The losses peculiar to the test rig and not associated with an operational system, such as the heat losses through the top skirt, were estimated and subtracted from the measured values. The adjusted losses are shown in Fig. 12. These adjusted data indicate heat losses of $10 \%$ at a midplane surface temperature of $1150^{\circ} \mathrm{F}$.

From the heat loss test data an estimate of the thermal conductivity of the fusible insulation was made using the method described in Ref. 4. The thermal conductivities are shown in Fig. 13. Also shown in Fig. 13 for comparison are conductivities taken from Fig. 2 of Ref. 6 which were obtained from the full-scale heat block-shield heat loss tests run with 3.0 in. of fusible insulation. As can be seen from Fig. 13, good agreement between the two sets of data was obtained. 
TABLE 4

Heat loss from the full-scale heat block-shield with 6.5 in. of fusible insulation in a 1 psig argon atmosphere.

\begin{tabular}{|c|c|c|}
\hline $\begin{array}{r}\text { TEST } \\
\text { NUMBER }\end{array}$ & $\begin{array}{l}\text { HEAT BLOCK- } \\
\text { SHIELD MID- } \\
\text { PLANE SUR- } \\
\text { FACE TEMP- } \\
\text { ERATURE } \\
\quad\left({ }^{\circ} \mathrm{F}\right)\end{array}$ & $\begin{array}{l}\text { HEAT } \\
\text { LOSS } \\
\text { (\% of } \\
\text { FULL POWER* })\end{array}$ \\
\hline 1 & 489 & 3.17 \\
\hline 2 & 679 & 4.38 \\
\hline 3 & 872 & 6.52 \\
\hline 4 & 1092 & 9.96 \\
\hline
\end{tabular}

*34 kW 


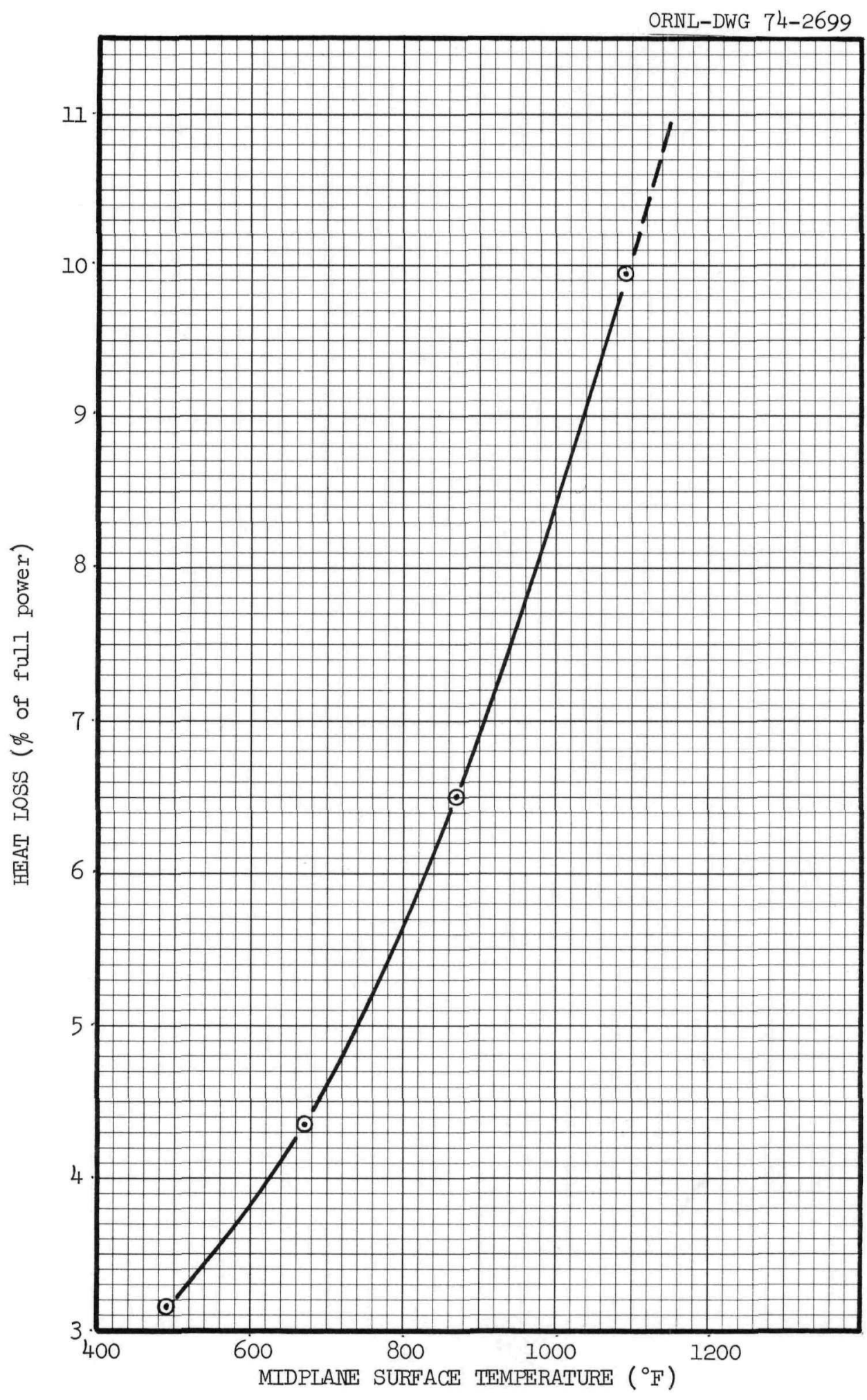

Fig. 11. Total heat losses from the full scale heat block-shield with 6.5 in. of fusible insulation operating in 1 psig argon. 


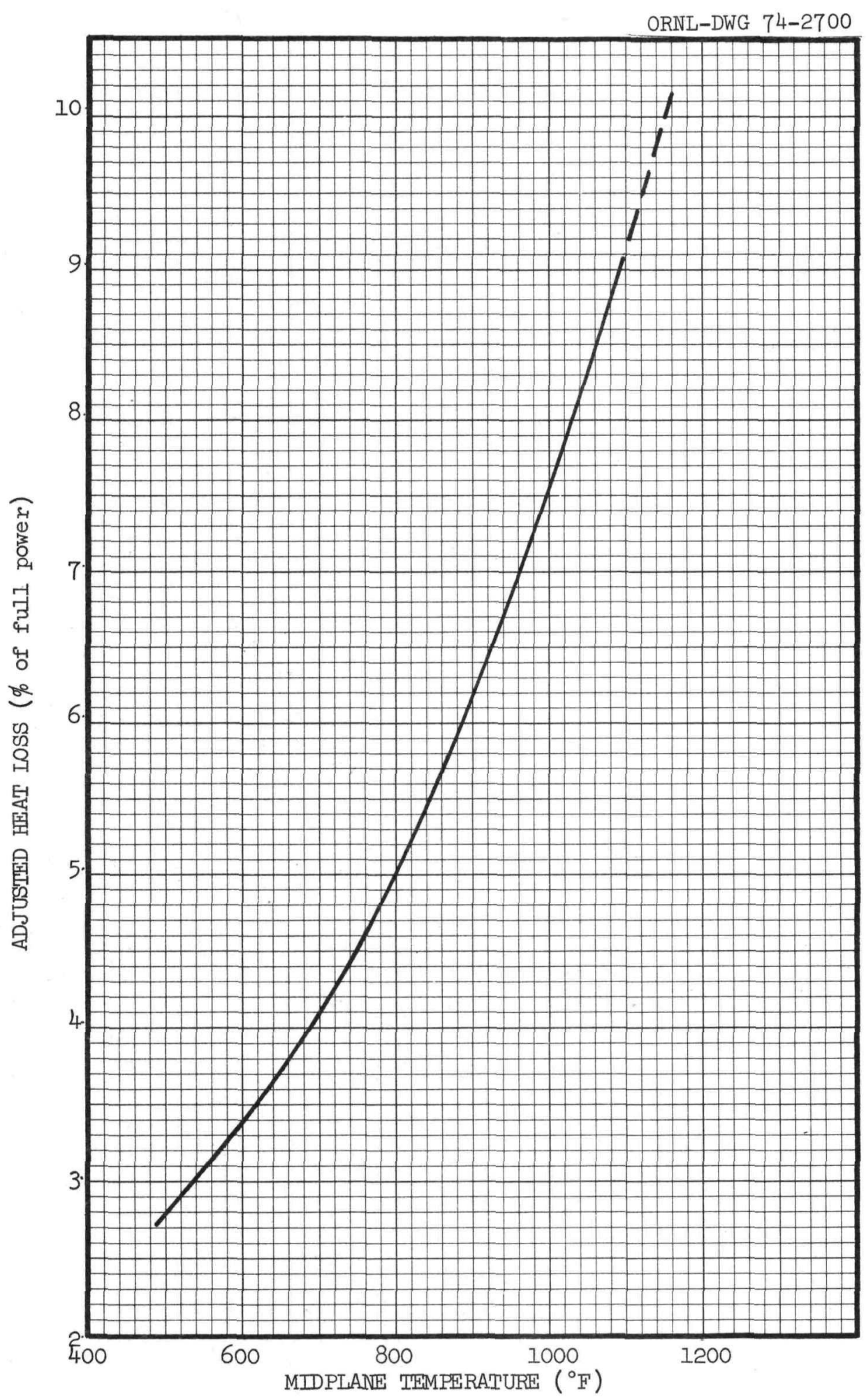

Fig. 12. Adjusted heat losses from a full scale heat block-shield with 6.5 in. of fusible insulation operating in 1 psig argon. 
24

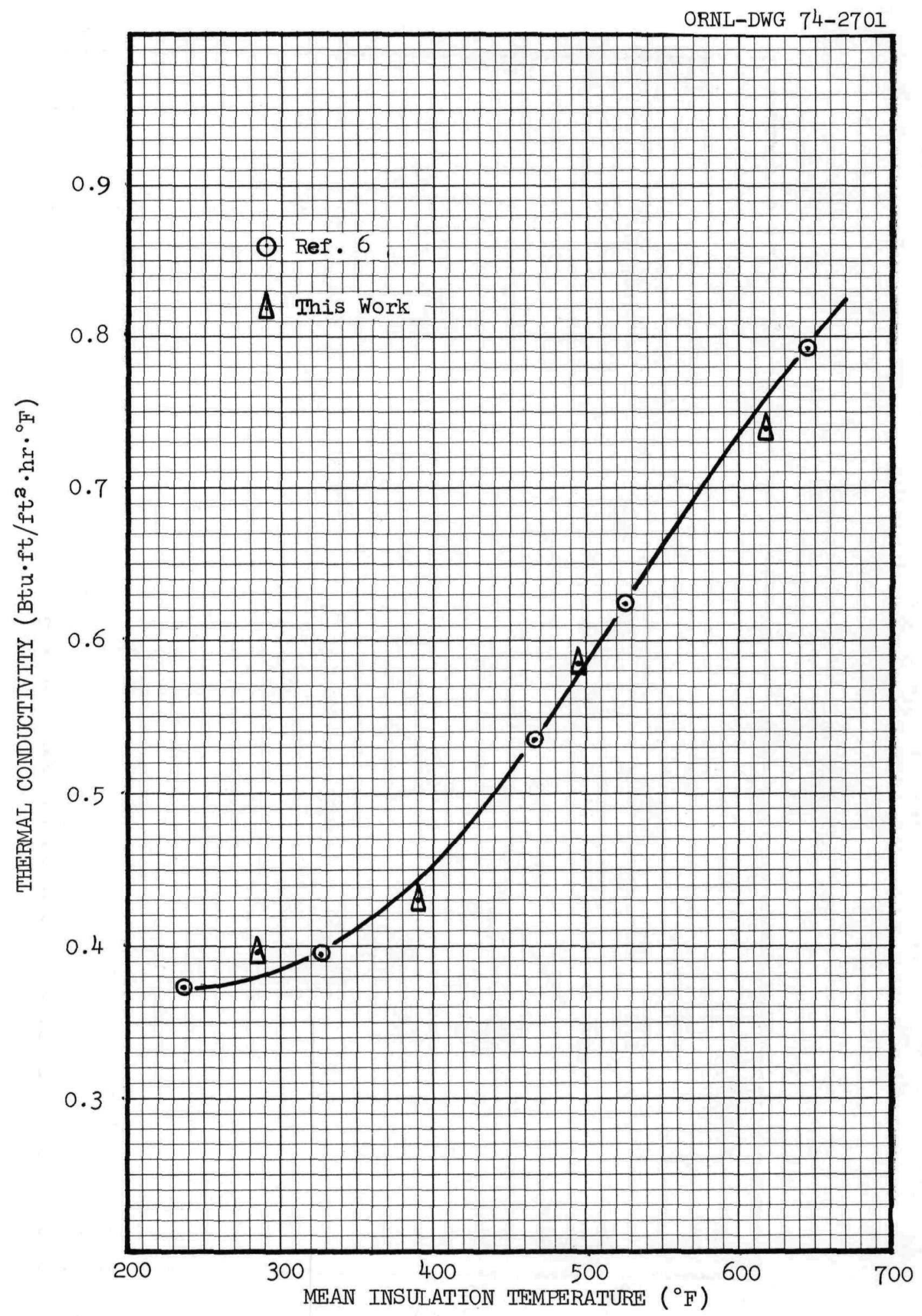

Fig. 13. The thermal conductivity of combined aluminum foil-screen insulation operating in an atmosphere of argon at a pressure of 1.0 psig. 
Heat Pipe Coupling Test

The fully insulated heat block-shield was operated in an upright position with 12 heat pipes to simulate the thermolectric power generation system. The heat block-shield is shown in Fig。 14 as it was being readied for the installation of the fusible insulation. The tests were run in an argon atmosphere at a pressure of 1.0 psig. The details of these tests (listed as Test 5 through 7) are given in Appendix A, Table A-2.

The heat block-shield midplane surface temperature and the average heat pipe condenser temperature are given in Table 5 and are shown in Fig. 15 as a function of the power input to the simulated fuel elements. After adjusting for the losses not associated with an operational system, such as the losses through the top skirt, the performance curves shown in Fig. 16 were obtained. Examination of Figs. 12 and 16 indicates that, at a power input of $34.0 \mathrm{~kW}$ to the heater elements, an average condenser temperature of $1040^{\circ} \mathrm{F}$, a heat block-shield midplane surface temperature of $1150^{\circ} \mathrm{F}$, and a power output of $30.6 \mathrm{~kW}$ would be obtained in an operational system.

A description of the design, fabrication and testing the heat pipes used in this test is covered in detail in Appendix B.

\section{Loss-of-Coolant Accident Test}

The fully insulated heat block-shield was operated in an upright position at a power level of $34 \mathrm{~kW}$ with the 12 heat pipes removed to simulate a complete loss-of-coolant accident. The test was run in argon at a pressure of $I$ psig. The simulated pressure vessel was maintained at a temperature of approximately $100^{\circ} \mathrm{F}$ to simulate conditions under which all of the heat would flow through the thermal insulation and pressure vessel to the ocean.

The test was started at a power level of approximately $3.4 \mathrm{~kW}$ with the heat block-shield midplane surface temperature at $1100^{\circ} \mathrm{F}$. The power level was increased to $34 \mathrm{~kW}$ and the timing of the test was begun when 


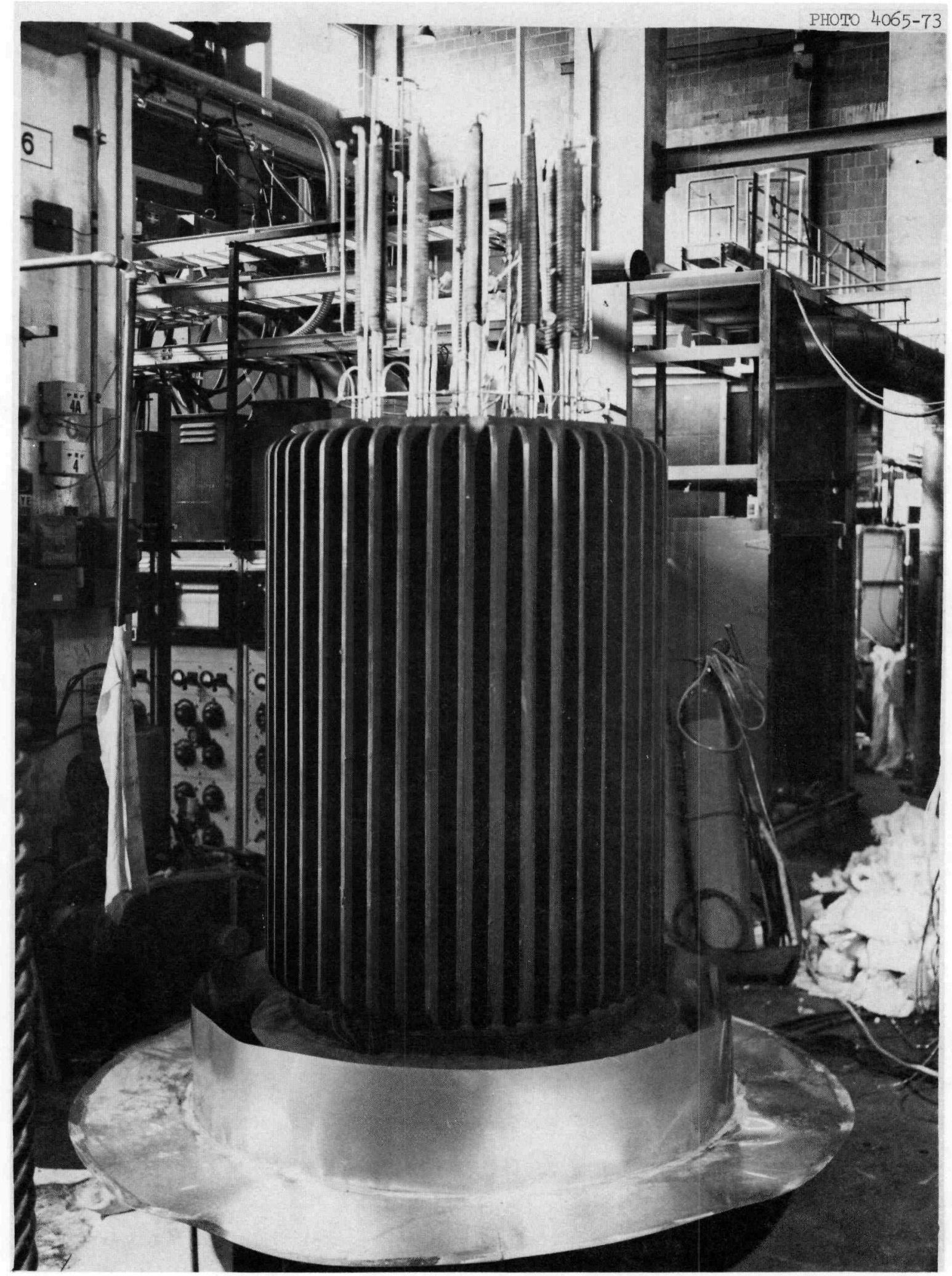

Fig. 14. Heat block-shield before the installation of the fusible insulation. 
Performance of the simulated thermoelectric power generation system.

\begin{tabular}{c|c|c|l}
\hline \multirow{2}{*}{ TEST } & $\begin{array}{c}\text { POWER } \\
\text { LEVEL } \\
\mathrm{kU}\end{array}$ & $\begin{array}{l}\text { HEAT BLOCK- } \\
\text { SHIELD MID- } \\
\text { PLANE SUR- } \\
\text { FACE TEMP- } \\
\text { ERATURE } \\
\left({ }^{\circ} \mathrm{F}\right)\end{array}$ & $\begin{array}{l}\text { AVERAGE HEAT } \\
\text { PIPE CONDENSER } \\
\text { TEMPERATURE ( }\end{array}$ \\
\hline 5 & 27.951 & 1078 & \\
6 & 30.350 & 1111 & 947.1 \\
7 & 34.465 & 1151 & 983.3 \\
\hline
\end{tabular}




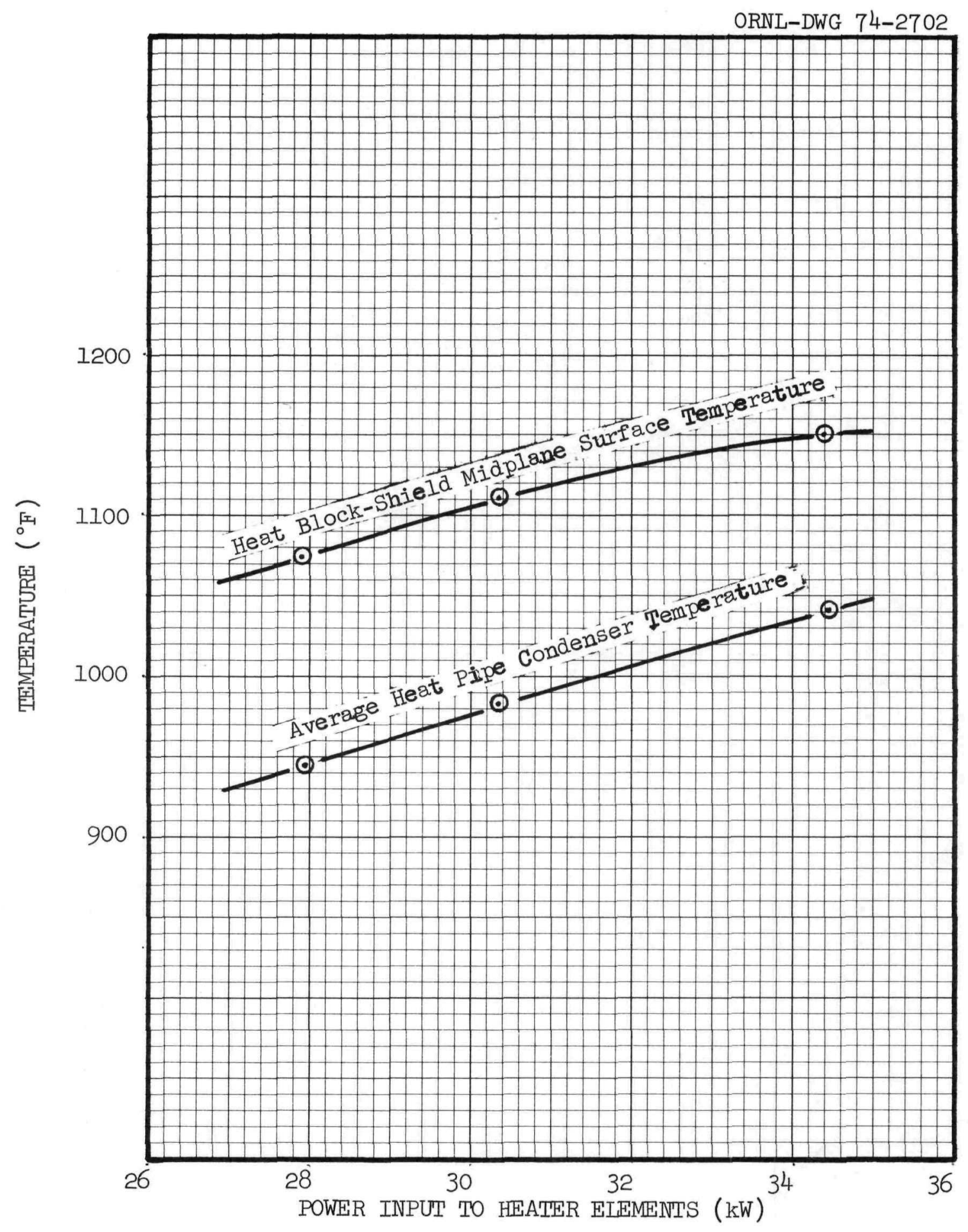

Fig. 15. Performance of the simulated thermoelectric power generation system. 


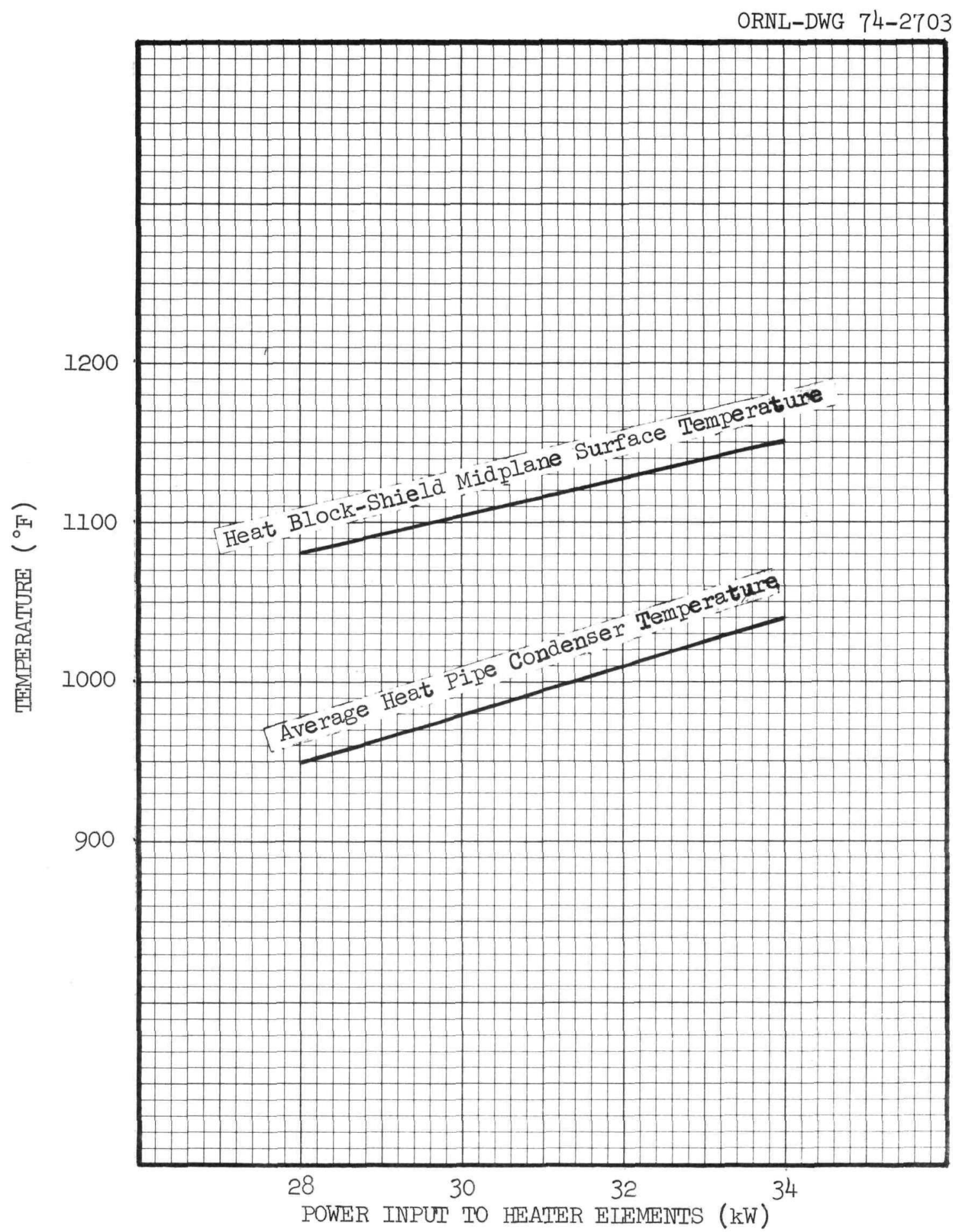

Fig. 16. Adjusted performance of the simulated thermoelectric power generation system. 
the midplane surface temperature of the heat block-shield started to increase. To establish the full power internal temperature gradient required approximately $1.5 \mathrm{hr}$. The time-temperature history of the meltdown of the aluminum-foil insulation is shown in Fig. 17. The peak and equilibrium temperature data are given in Appendix A, Table A-3. The peak temperatures were observed after approximately $45 \mathrm{hr}$ and the equilibrium temperatures after approximately $140 \mathrm{hr}$. The test was terminated after $200 \mathrm{hr}$ with no changes in conditions occuring during the last $60 \mathrm{hr}$ of the test.

Approximately $13 \mathrm{hr}$ into the test a hot spot on the simulated pressure vessel expansion joint was observed. Inspection of Fig. 17 shows that a change in the slope on both the central heater can and the heat block-shield midplane surface temperatures occured at the same time.

Approximately $40 \mathrm{hr}$ into the test a second hot spot was observed on the simulated pressure vessel expansion joint approximately 180 deg removed from the one observed earlier. Inspection of Fig. 17 shows that a change in the slope of the central heater can surface temperature occured at the same time. The melt down was continued without further unusual events. Inspection of Fig. 17 shows the central heater can surface peak and equilibrium temperatures were $2175^{\circ} \mathrm{F}$ and $2067^{\circ} \mathrm{F}$, respectively. The corresponding peak and equilibrium values for the heat block-shield midplane surface temperature were $1690^{\circ} \mathrm{F}$ and $1570^{\circ} \mathrm{F}$, respectively.

The test system was allowed to cool to ambient temperature after the termination of meltdown. The system was disassembled and inspected. The first step in the disassembly involved the removal of the top section of the simulated pressure vessel to allow visual inspection of the condition of the undisturbed fusible insulation. The vessel was cut approximately 1.0 in. above the fusible insulation and the top section of the vessel was removed. Shown in Fig. 18, 19, 20, and 21 are vertical quadrant views of the fused insulation taken at 0, 90, 180, and $270 \mathrm{deg}$, respectively. As can be seen in these photographs, approximately $85 \%$ of the insulation at the top of the matrix had melted 


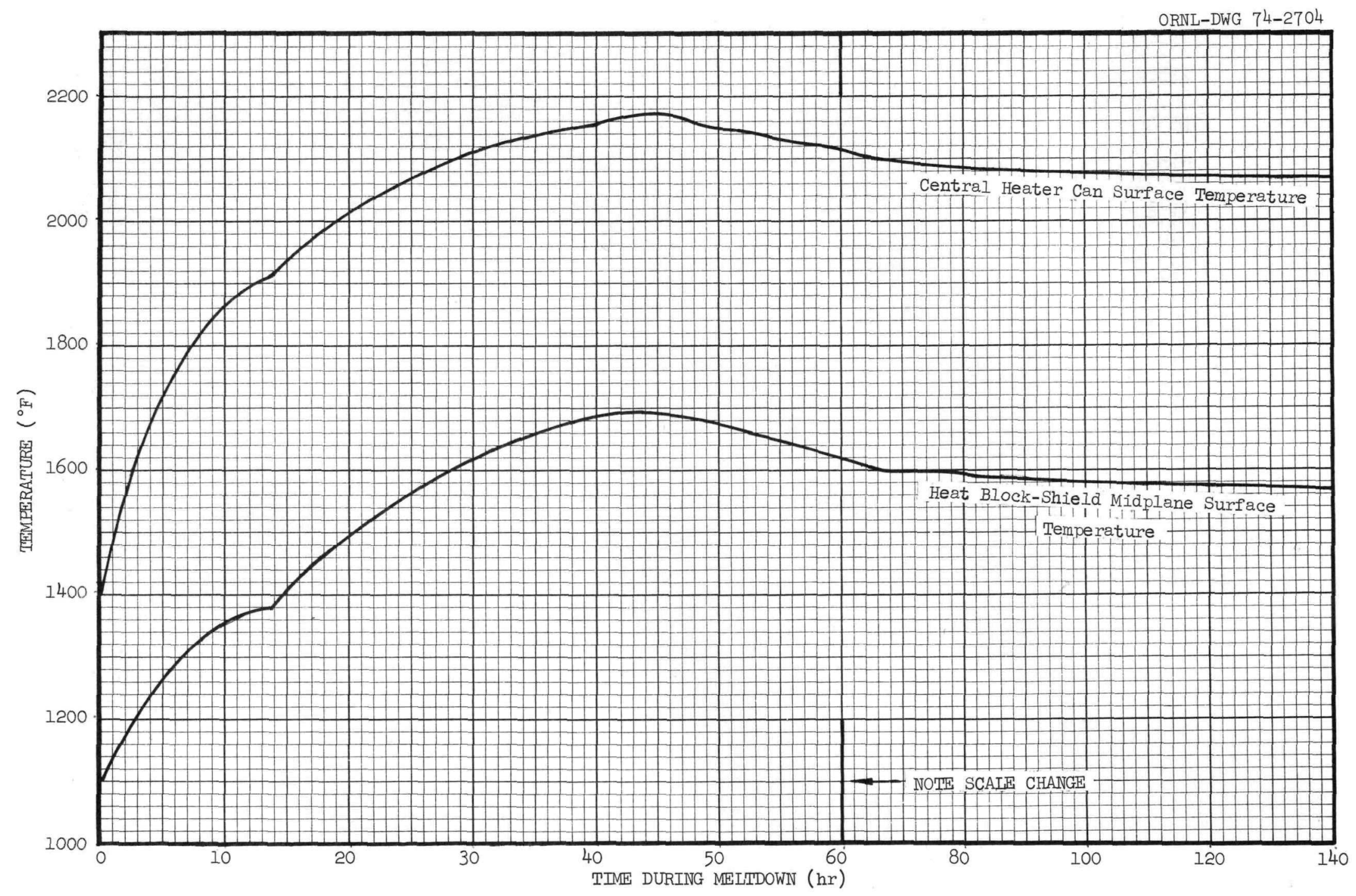

Fig. 17. Time-temperature history of the full scale meltdown. 
PHOTO $1863-73$

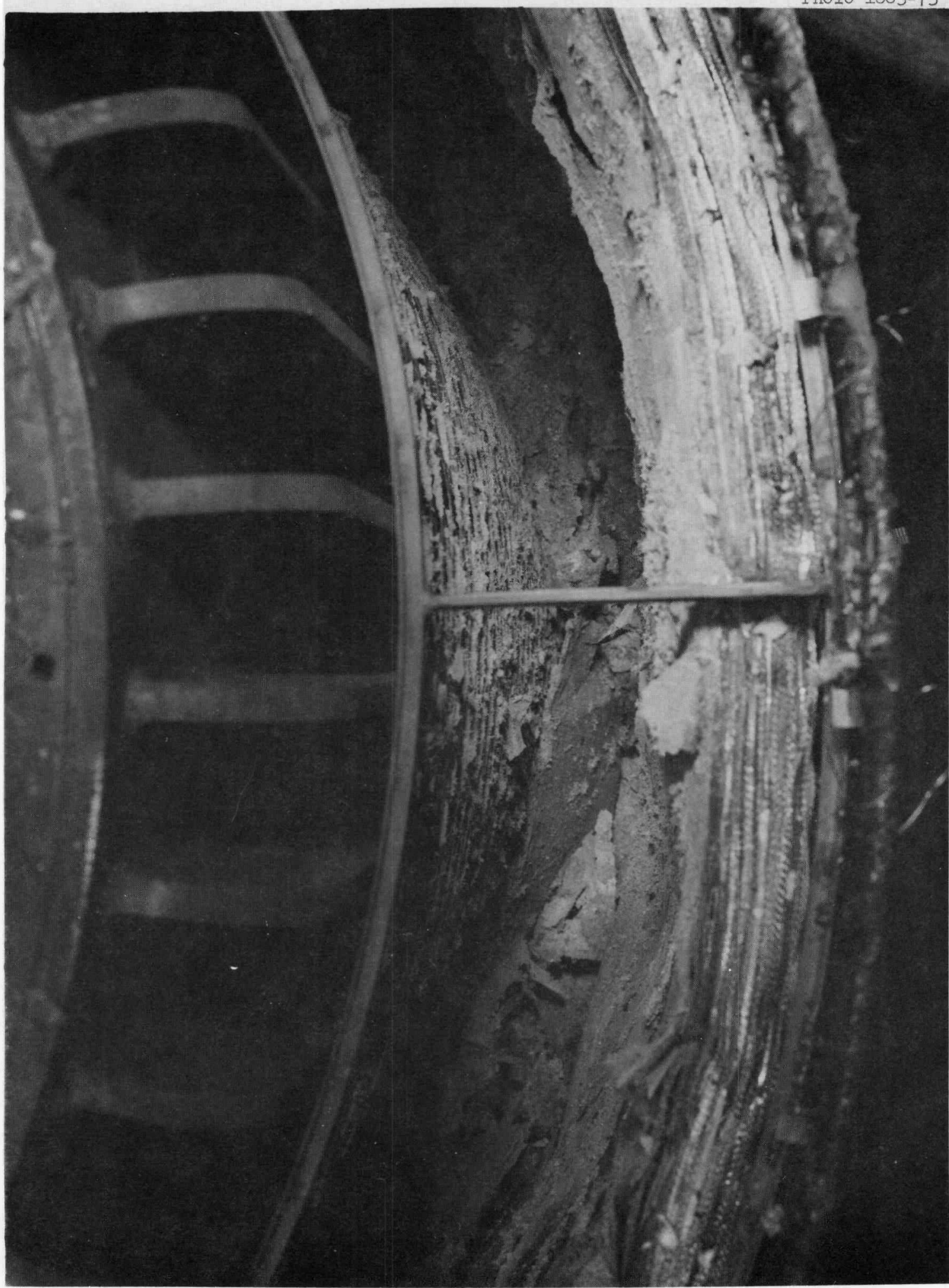

Fig. 18. Vertical view of the fused insulation at $\theta=0^{\circ}$. 


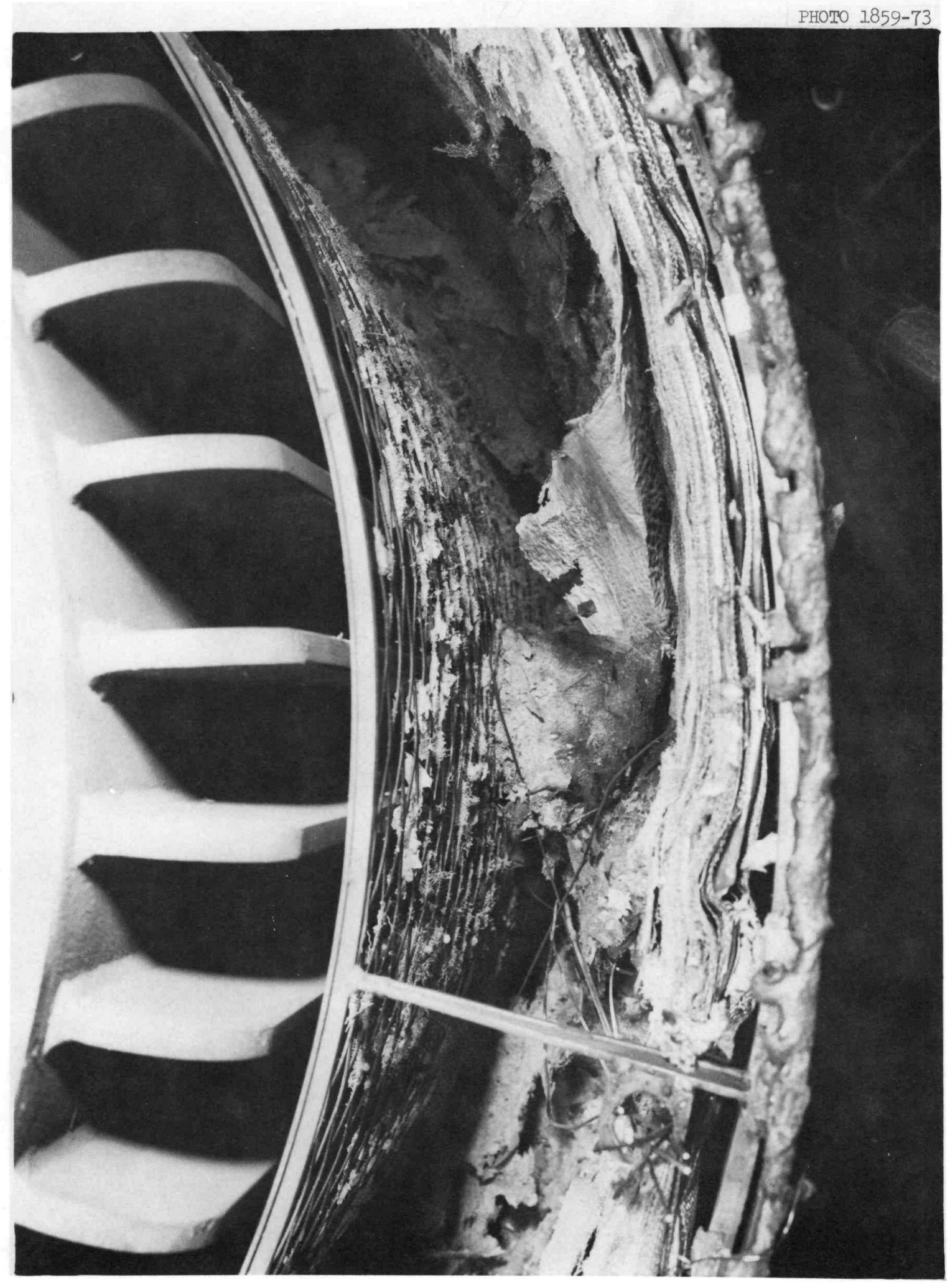

Fig. 19. Vertical view of the fused insulation at $\theta=90^{\circ}$. 


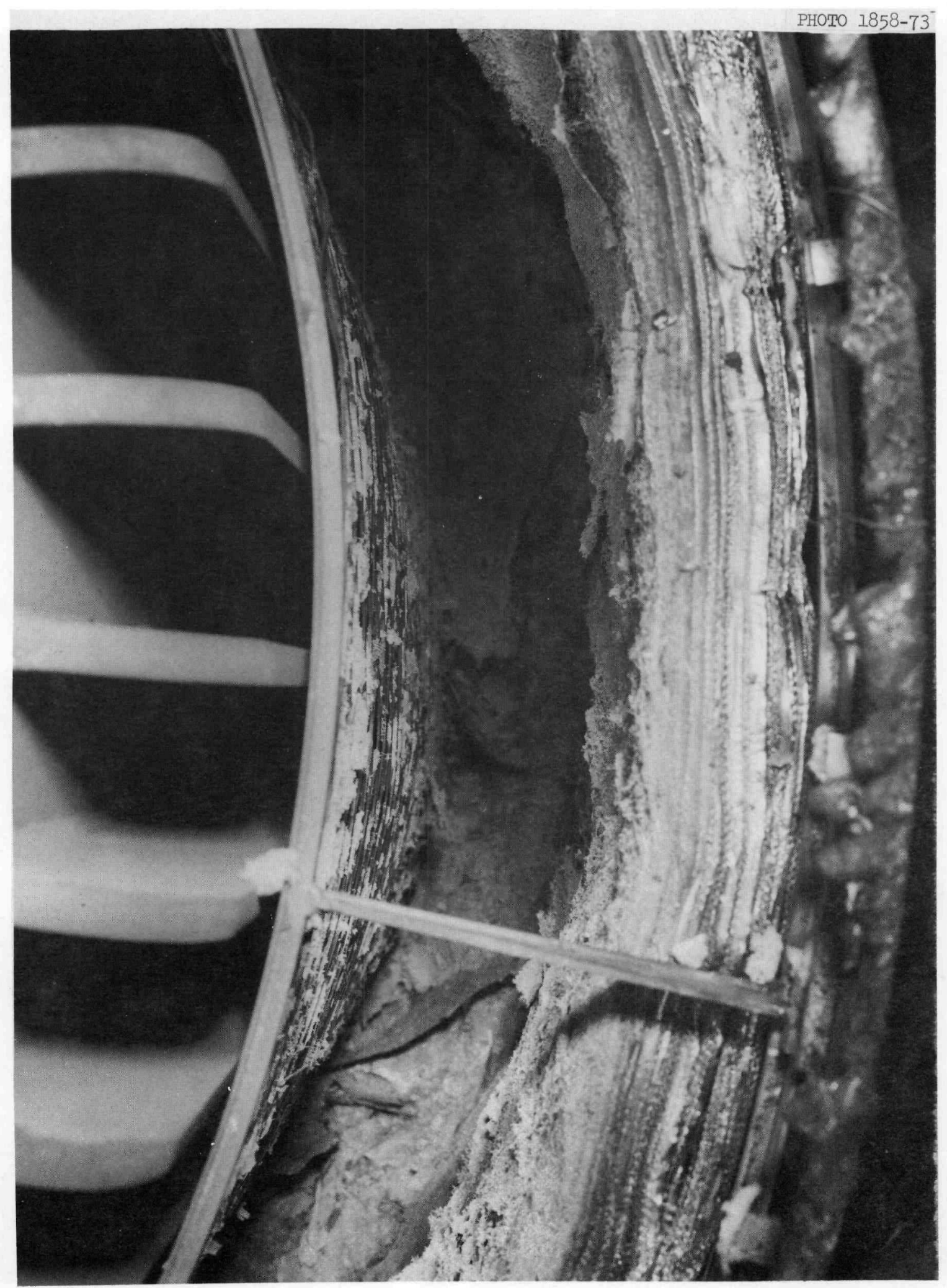

Fig. 20. Vertical view of the fused insulation at $\theta=180^{\circ}$. 


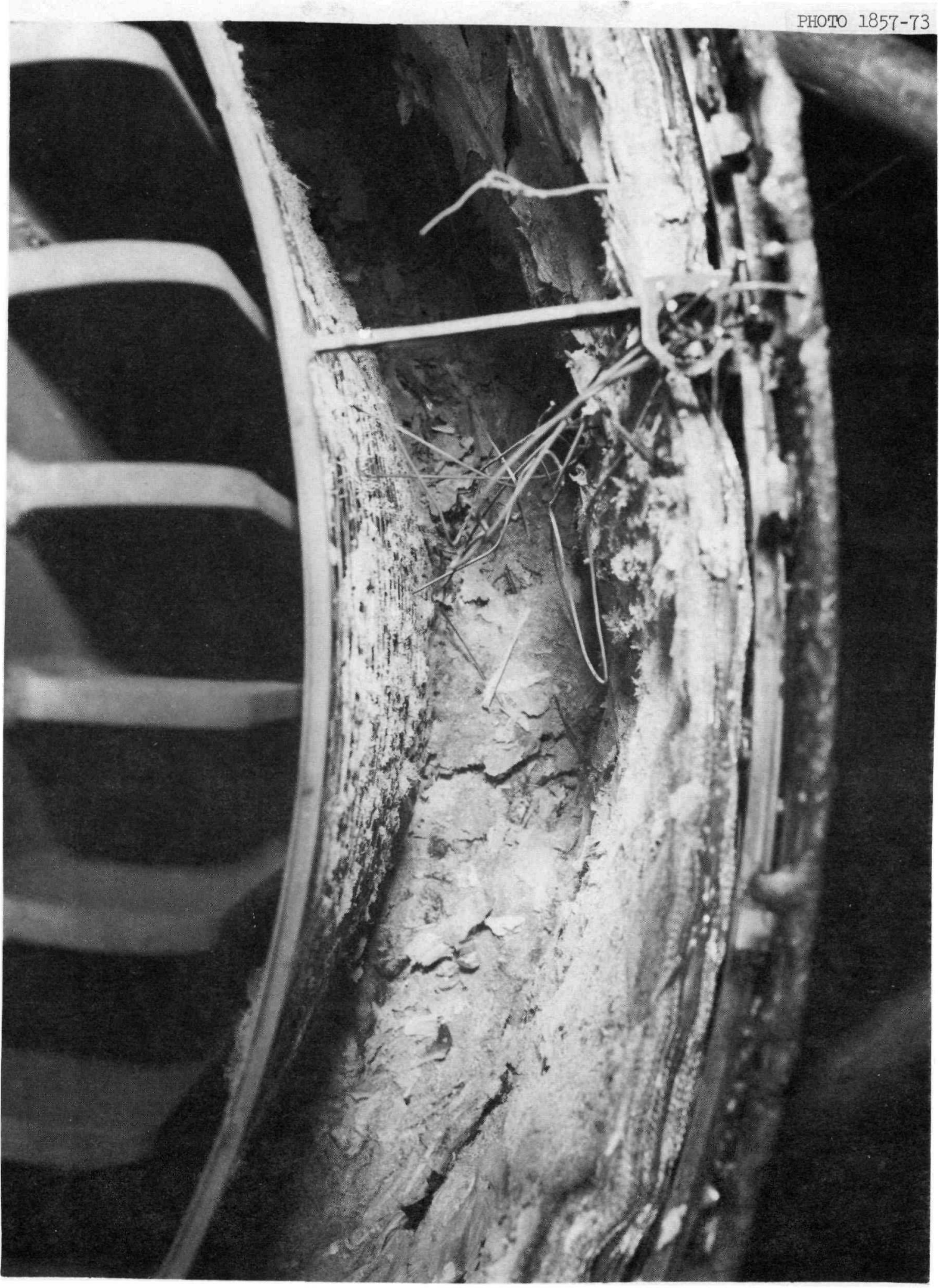

Fig. 2l. Vertical view of the fused insulation at $\theta=270^{\circ}$. 
and the debris had fallen to the bottom and filled approximately 25\% of the free space formed by the fusion of the aluminum-foil insulation.

Figure 22 shows a close-up view of the inner expanded metal insulation support. The support is essentially free of debris, and this allowed free interchange of the radiant heat between the heat block-shield surface and the surface of the unfused insulation.

Figure 23 shows a place in the insulation located approximately 2 ft from the top of the bundle that had complete radial fusion of the insulation. The simulated pressure vessel can be seen through the outer expanded metal insulation support.

The remaining portion of the simulated pressure vessel was removed from the insulation bundle. Figure 24 shows an overall view of the fusible insulation after the removal of the simulated pressure vessel. The area located in the middle left of the photograph is the same area as shown from the inside in Fig. 23. A comparison of Fig. 24 with Fig. 14 shows the molten aluminum that has run over the top of the stainless steel shim stock that was used as a retainer.

Figure 25 shows a close-up view of the complete radial fusion of the insulation shown in Figs. 23 and 24. Figure 26 shows regions of radial fusion that are complete except for the outer layer of screen wire. The areas of complete and partially complete radial fusion cover approximately $80 \%$ of the midplane circumference and average approximately $1.0 \mathrm{ft}$ in length.

Shown in Fig. 27 is the area that manifested a hot spot approximately $13 \mathrm{hr}$ into the test. That this spillover did not occur as one single event is indicated by the layering effect shown in Fig. 28. Figure 29 shows the area that manifested a hot spot approximately $40 \mathrm{hr}$. into the test. This spillover, which is located approximately 180 deg from the one shown in Fig. 27, did not exhibit the layering effect shown in Fig. 27, and probably represents a single event.

The insulation bundle was removed from the heat block-shield. Figure 30 is a top view of the bundle which shows complete removal of the insulation from the major portion of the bundle. Figure 31 shows 


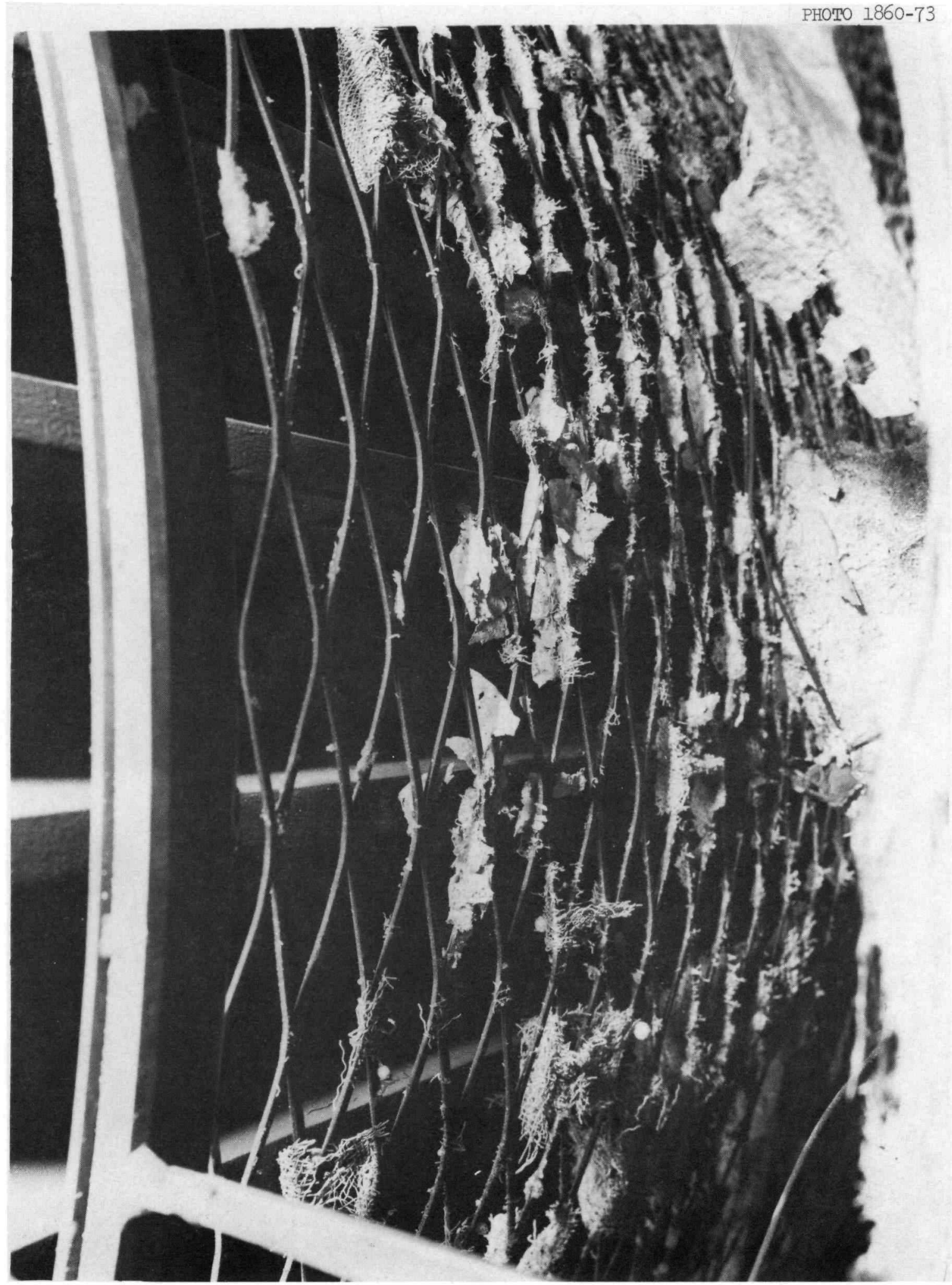

Fig. 22. The inner expanded metal insulation support after fusion of the insulation. 


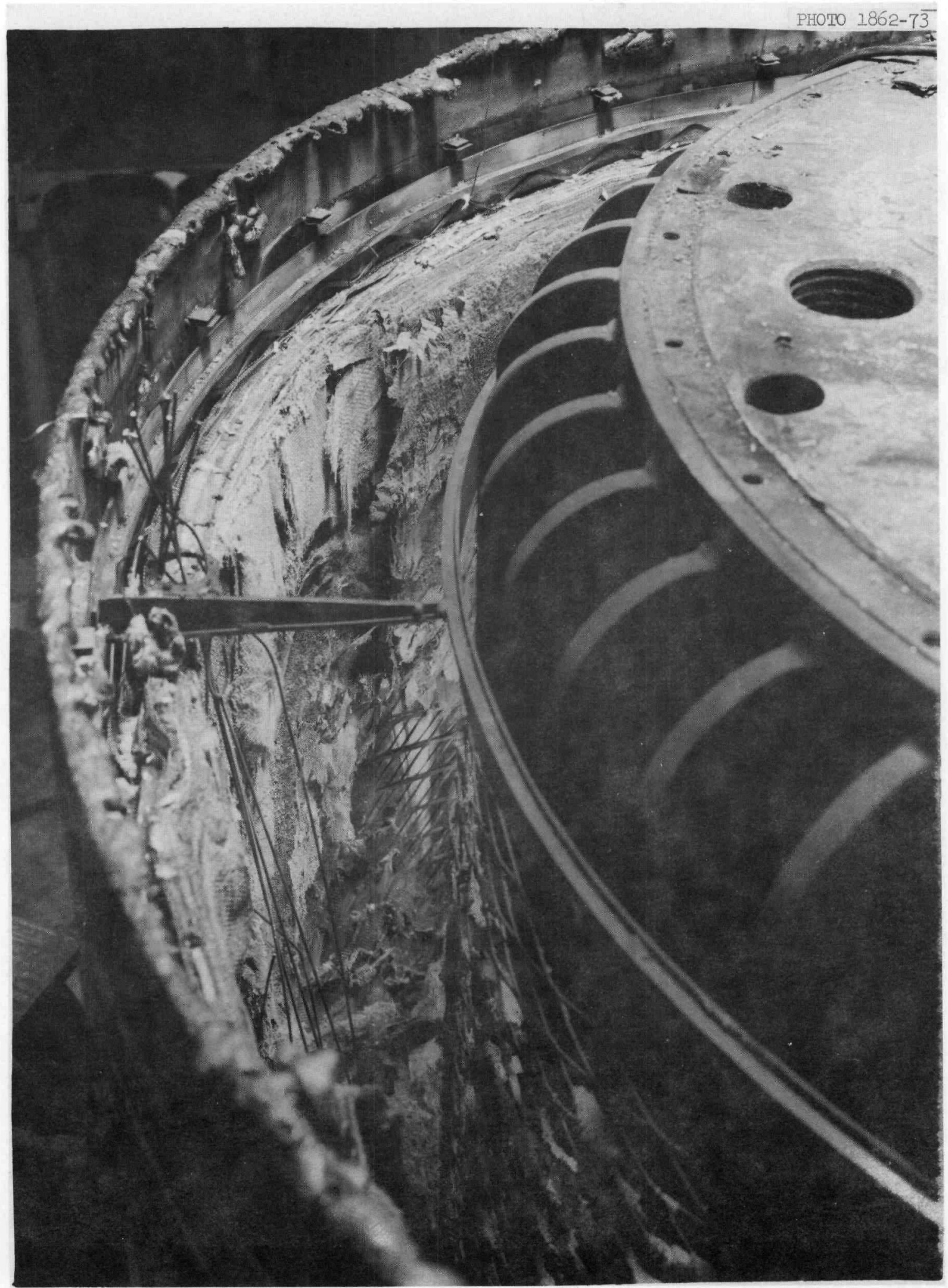

Fig. 23. An area with a complete radial fusion of the aluminum-foil insulation. 


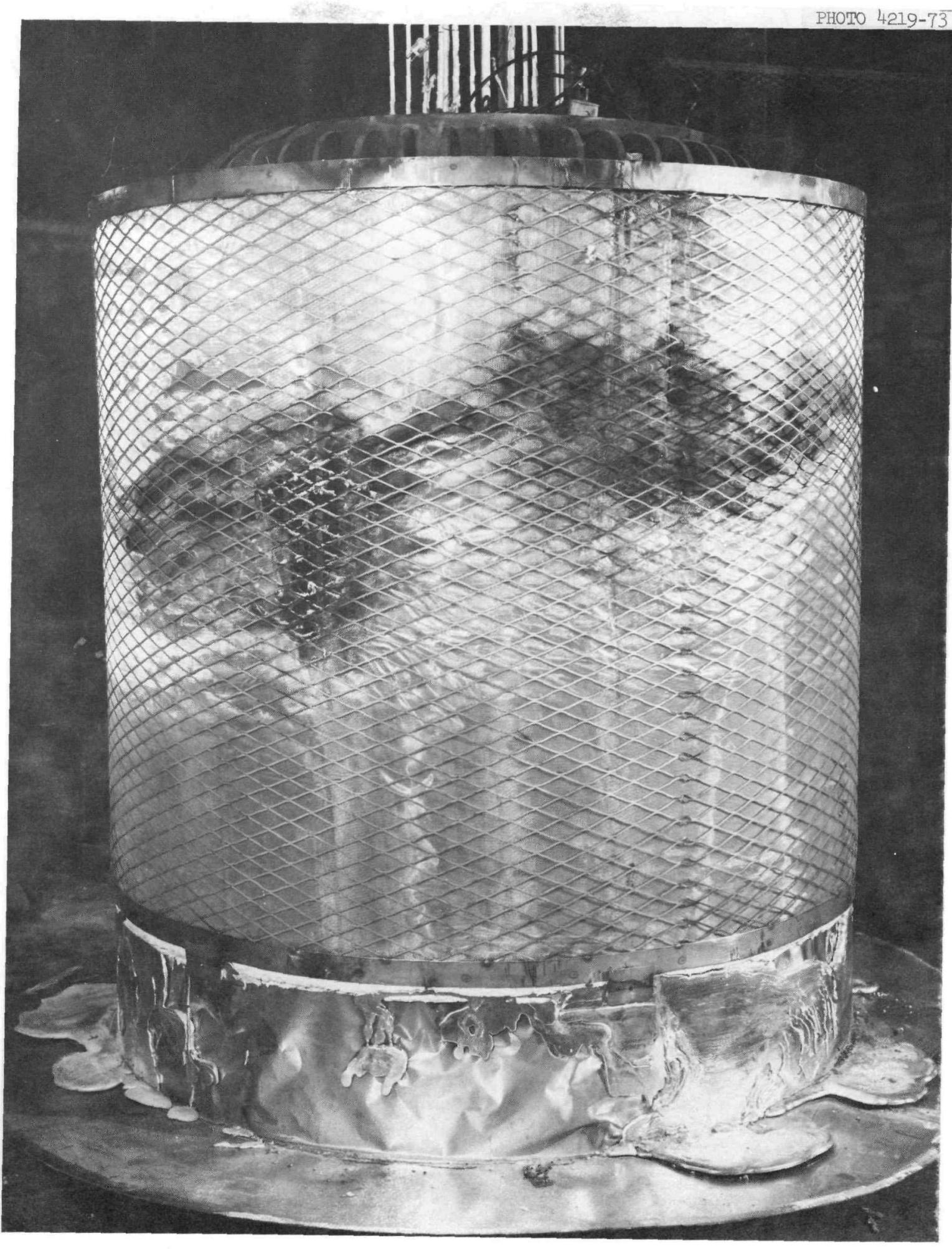

Fig. 24. An overall view of the fusible insulation after the removal of simulated pressure vessel. 


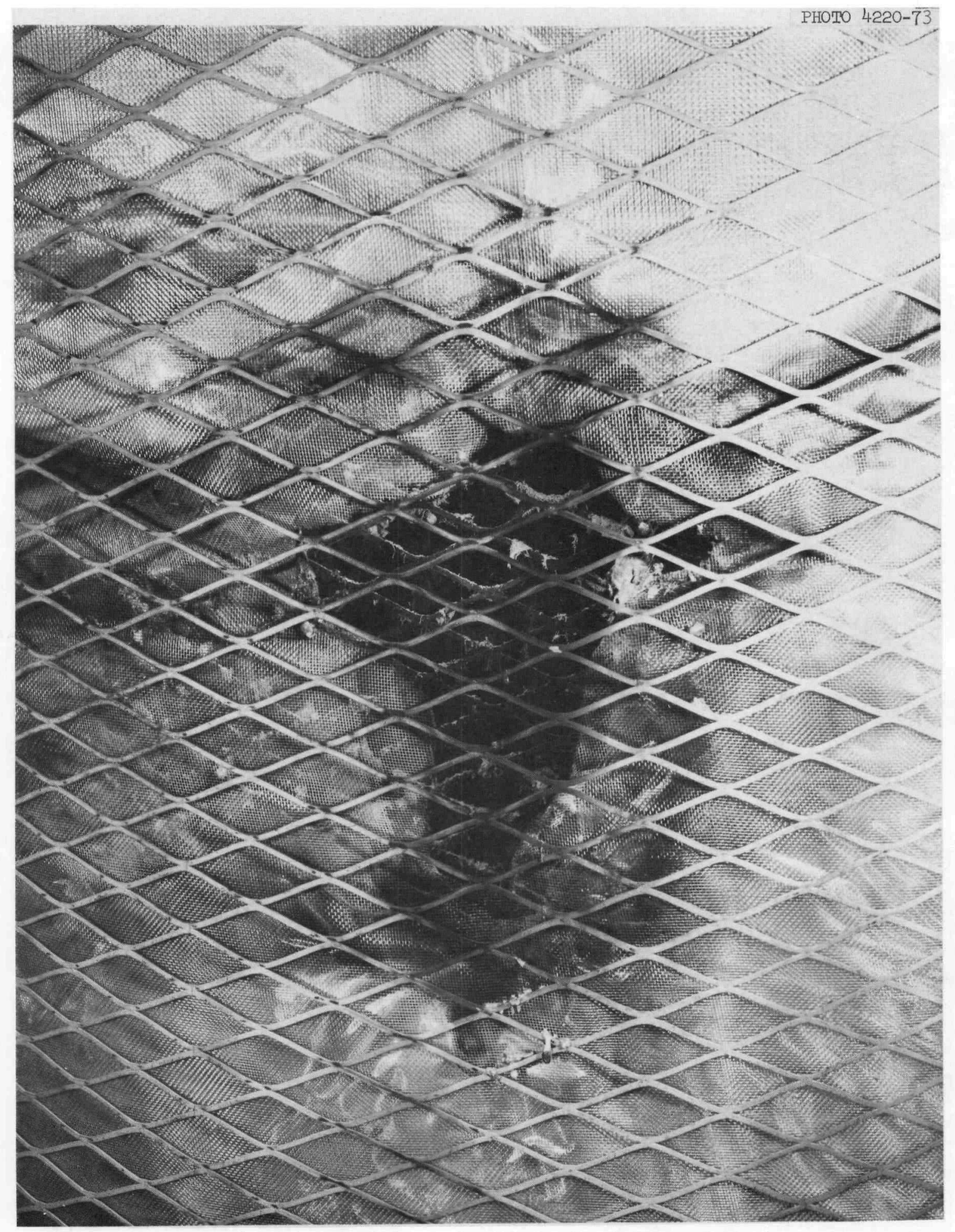

Fig. 25. Close-up view of the complete radial fusion shown in Fig. 24. 


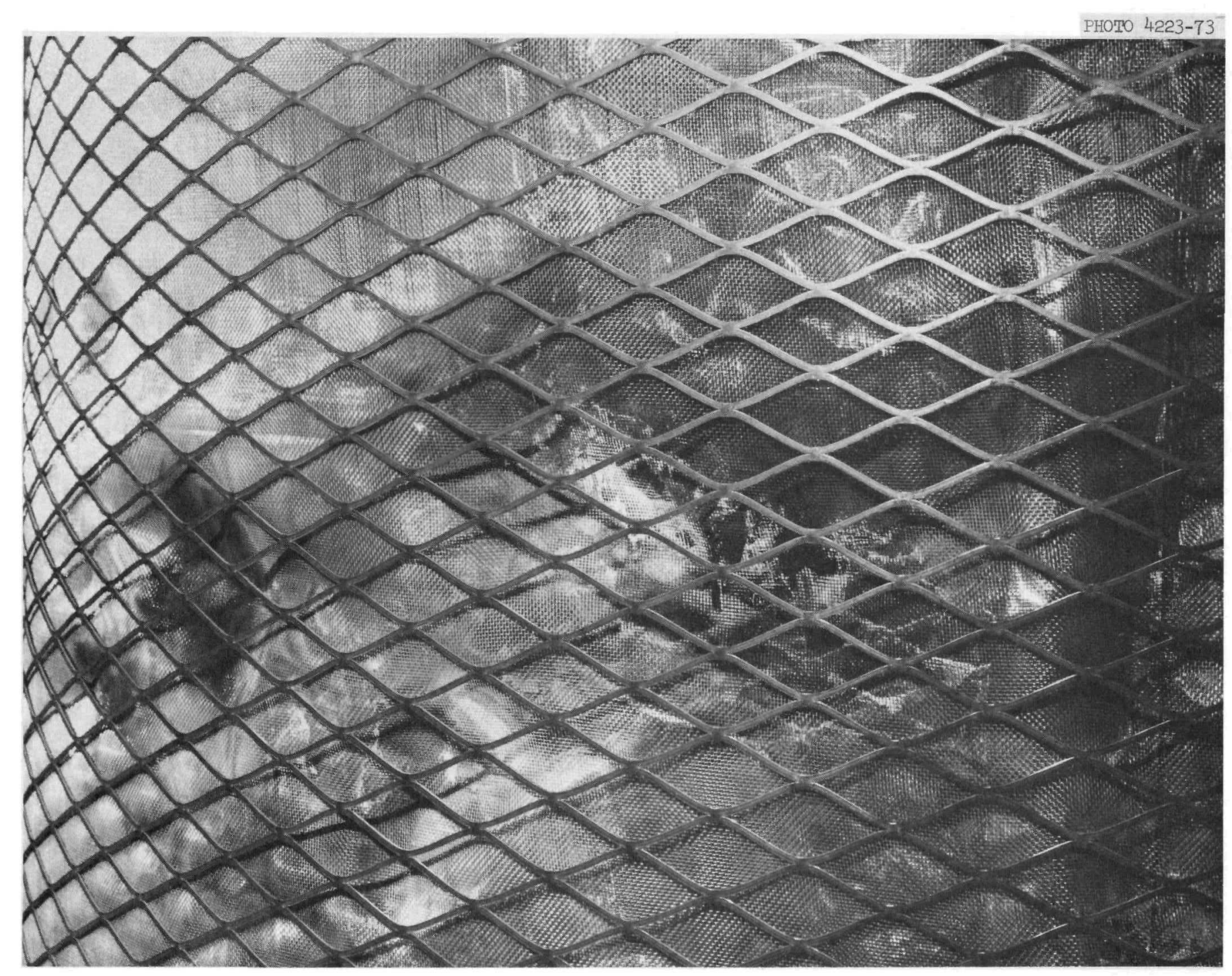

Fig. 26. Close-up view of a radial fusion complete except for the outer screen layer. 


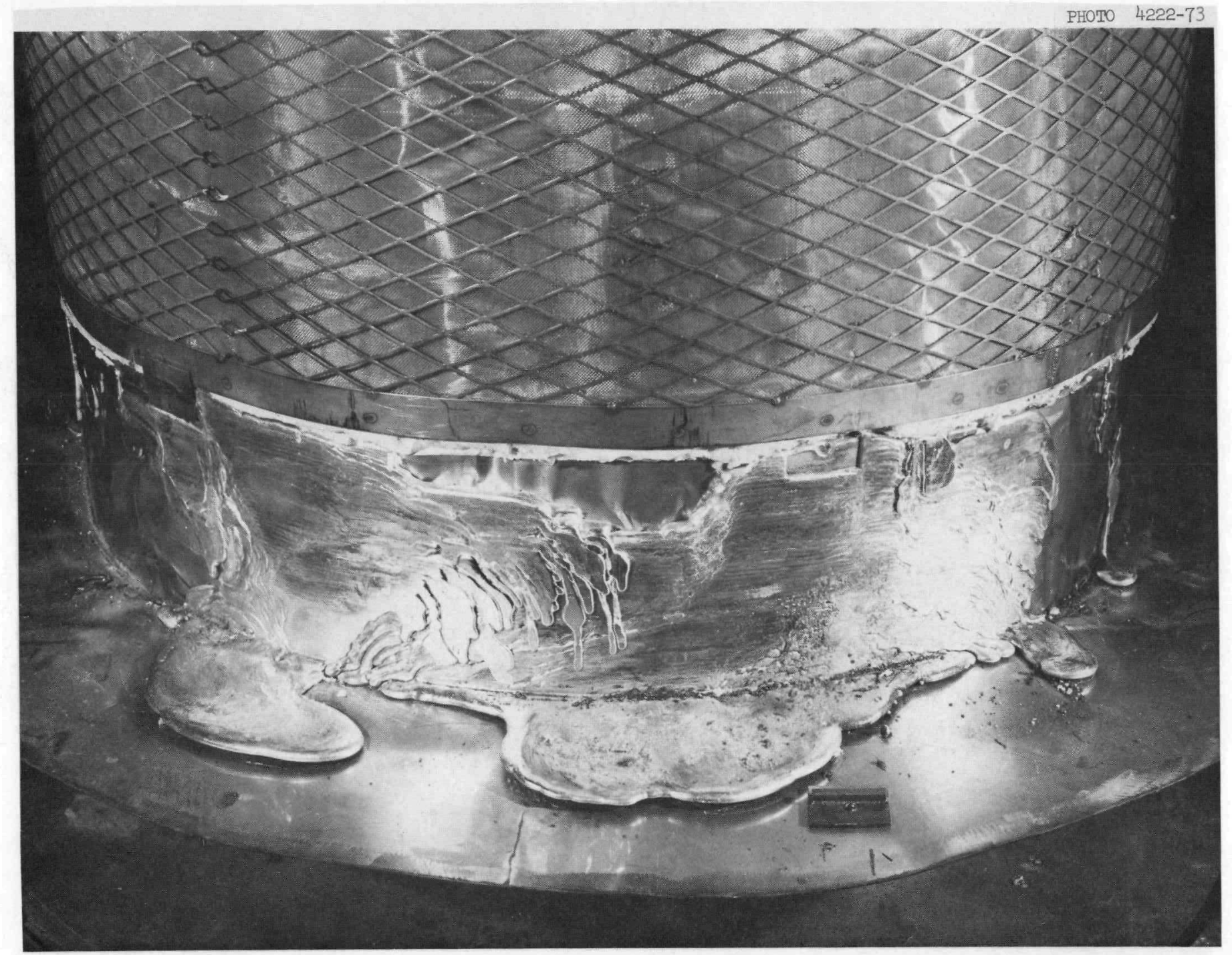

Fig. 27. Molten aluminum spillover occuring at approximately 13 hours into the meltdown. 


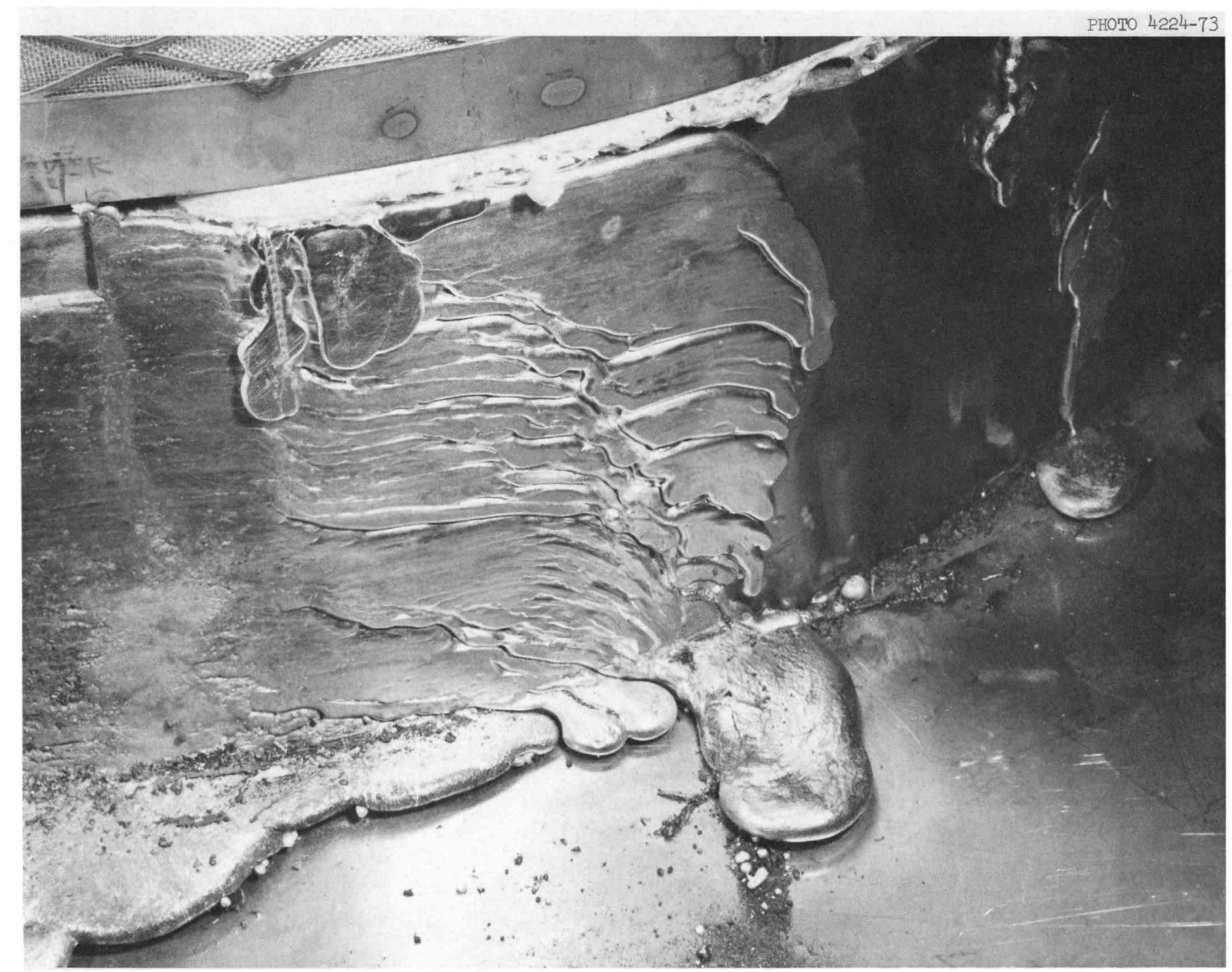

Fig. 28. Close-up of the 13-hour spillover showing a layering effect indicating successive spillover. 


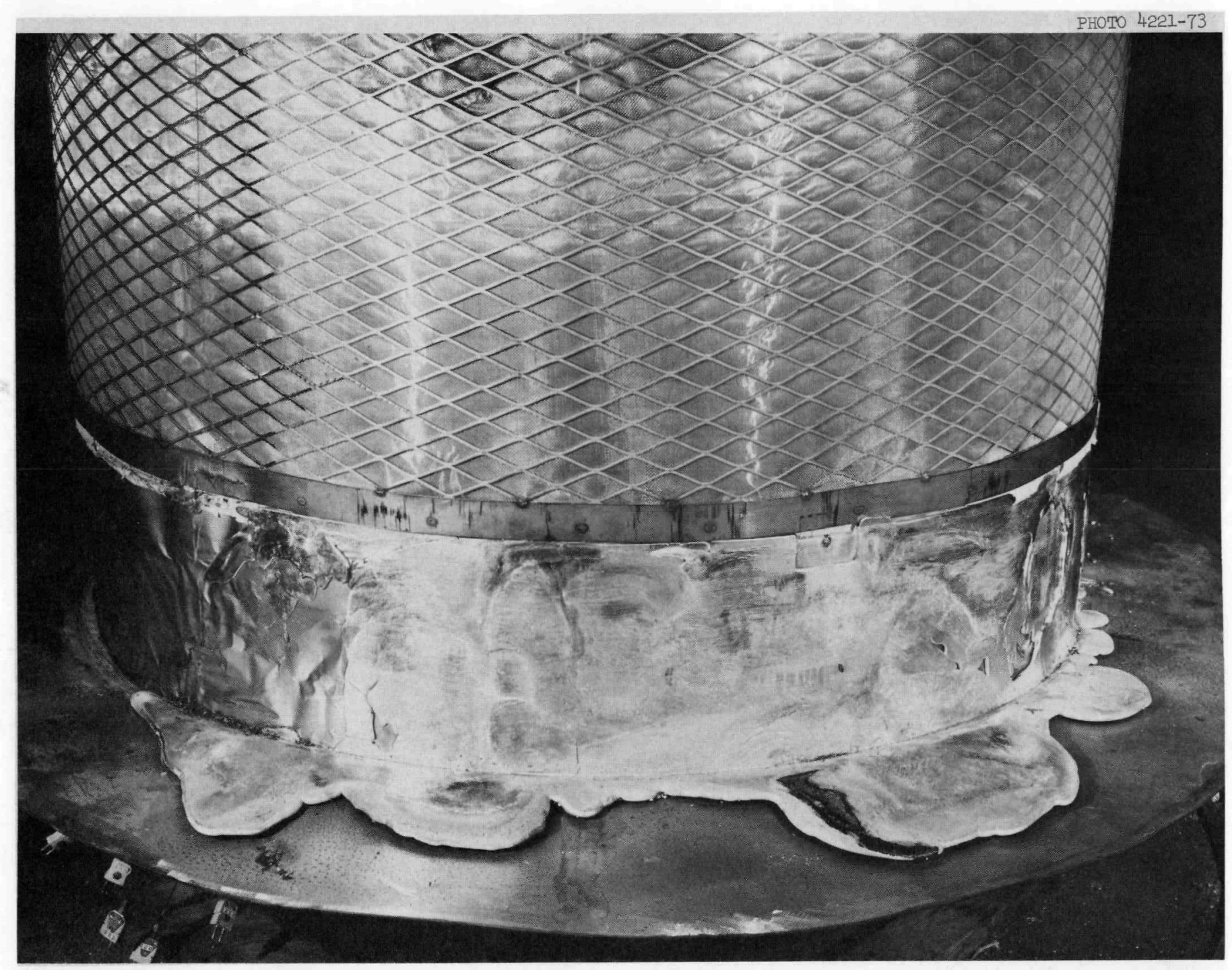

Fig. 29. Molten aluminum spillover occuring at approximately 40 hours into the meltdown. 


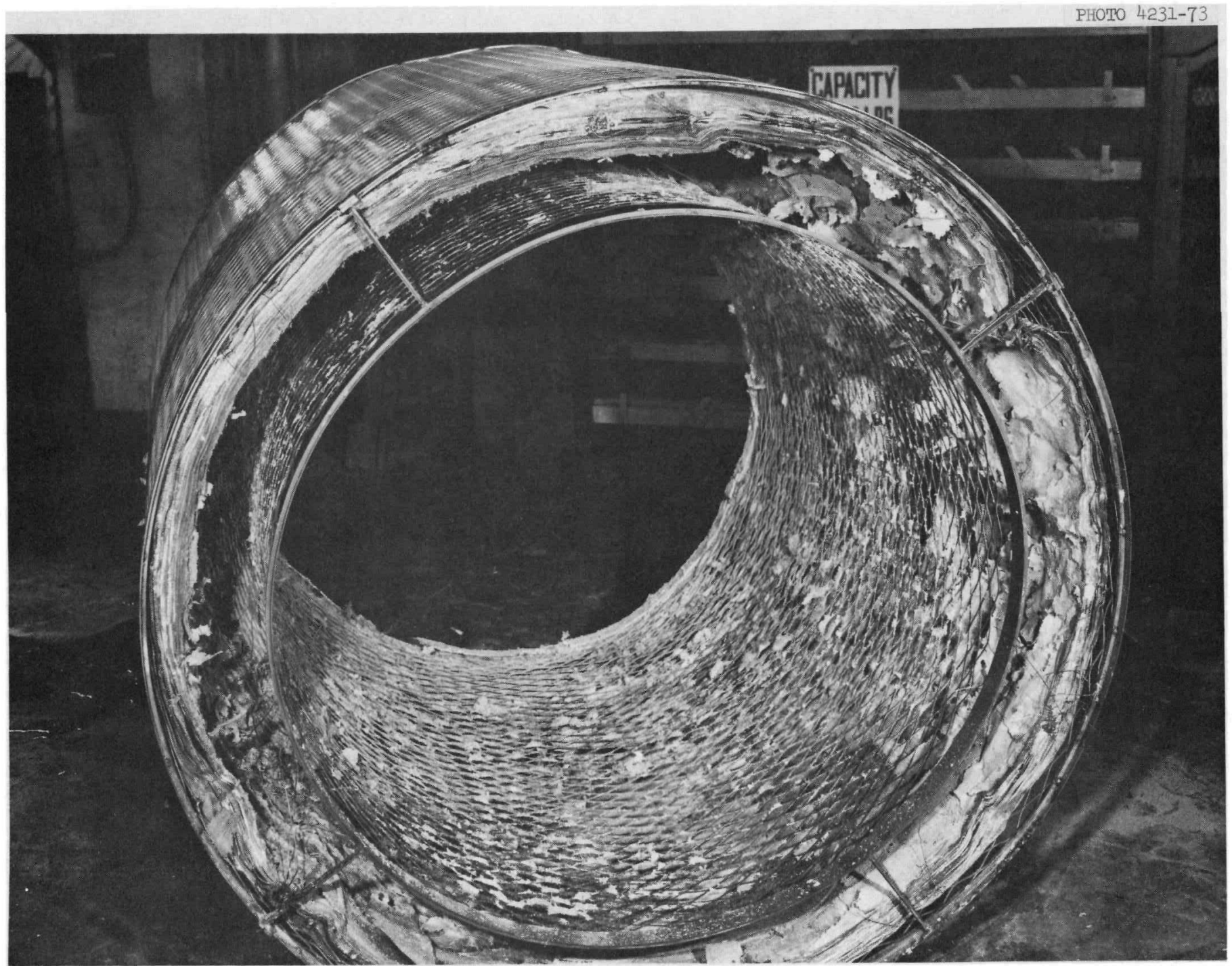

Fig. 30. Top view of the fusible insulation bundle after removal from the heat block-shield. 


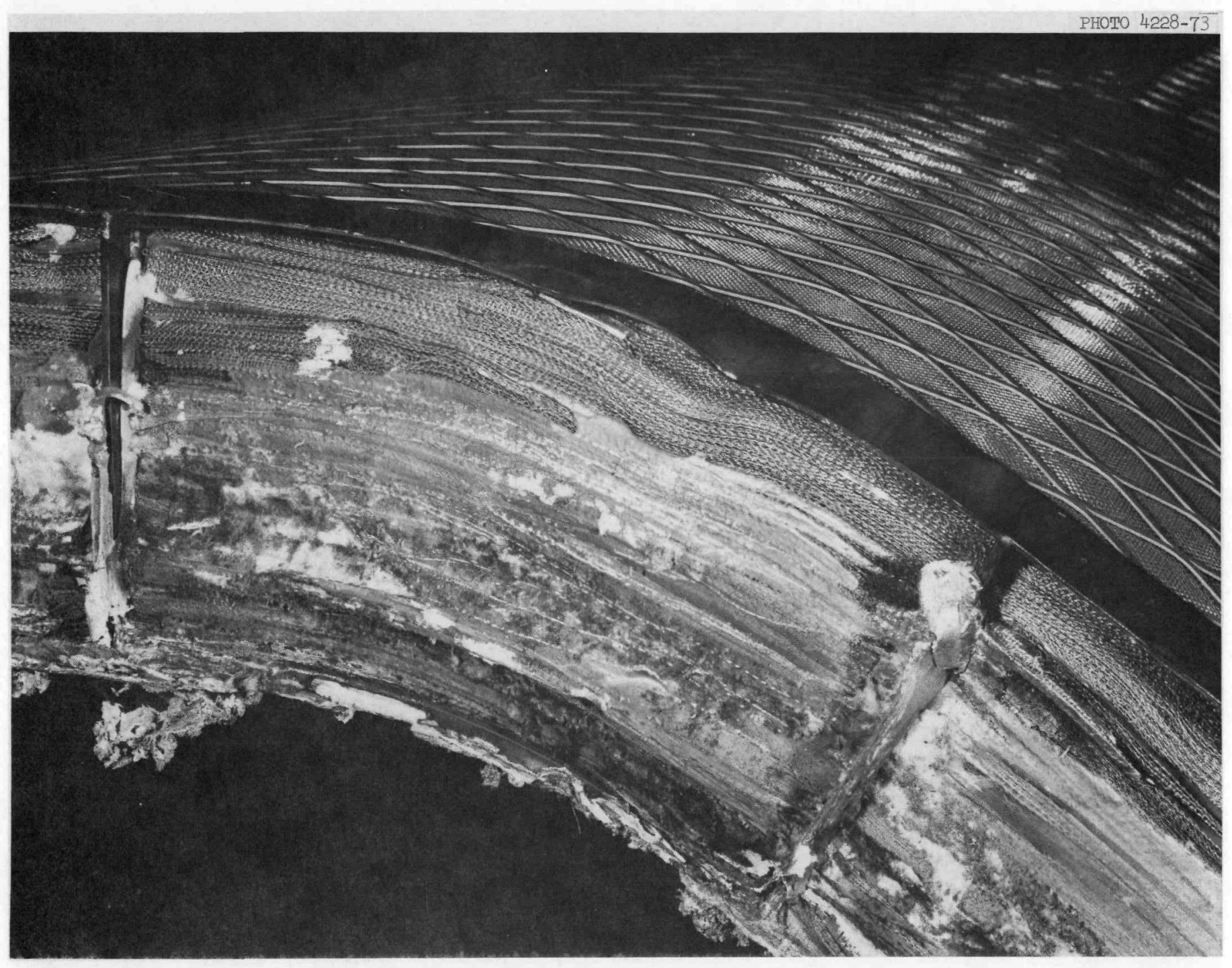

Fig. 31. Bottom biew of the fusible insulation bundle after removal from the heat block-shield. 
the bottom of the insulation. This photograph shows the build up of melted aluminum in the bottom section of the insulation. This solid aluminum portion covers approximately $80 \%$ of the bottom area. Figure 32 shows an end view of the bottom of the insulation bundle. The debris from the melting at the top can be seen as well as large chunks of aluminum and debris mixture. This mixed region extends upward from the bottom for about $25 \%$ of the height of the insulation bundle.

After the insulation bundle was removed from the heat block-shield, the insulation and the stainless insulation retainer (see Fig. 14) were removed. Figure 33 shows the distribution of the aluminum in the bottom section of heat block-shield. The molten aluminum ran over the deflection cone and formed a cylinder of aluminum at the outer circumference of the cone approximately $1.0 \mathrm{in}$. thick. A section of the cone was cut and turned up to show the thickness of the cylinder and the insulation between the cylinder and the heat biock-shield bottom skirt. A second cylinder of aluminum that formed just inside of stainless insulation retainer can be seen in Fig. 33. Figure 34 shows the inner aluminum cylinder that formed at the outer circumference of the deflector cone. The cone is in good condition and shows essentially no attack from the aluminum (see Figs. 7 and 8).

Figure 35 gives a view of the bottom section of the heat block-shield showing that the maximum elevation reached by the molten aluminum was approximately $1.0 \mathrm{ft}$. This is probably the elevation attained before the "breakthrough" that occured after approximately $13 \mathrm{hr}$ into the test run. A secondary level of approximately $2.0 \mathrm{in}$. can be observed at the point of the damaged thermocouple sheathing that is shown in the lower center of Fig. 35. This was probably the lower level of the $13 \mathrm{hr}$ "breakthrough" which was maintained until the $40 \mathrm{hr}$ "breakthrough" occured. No evidence of further buildup of a liquid level was noted.

\section{GENERAL ANALYSIS AND CONCLUSIONS}

\section{Heat Loss Test}

The thermal conductivity of the $6.5 \mathrm{in}$. thick combined aluminum foil-screen insulation operating in 1 psig argon (see Fig. 13) was found 


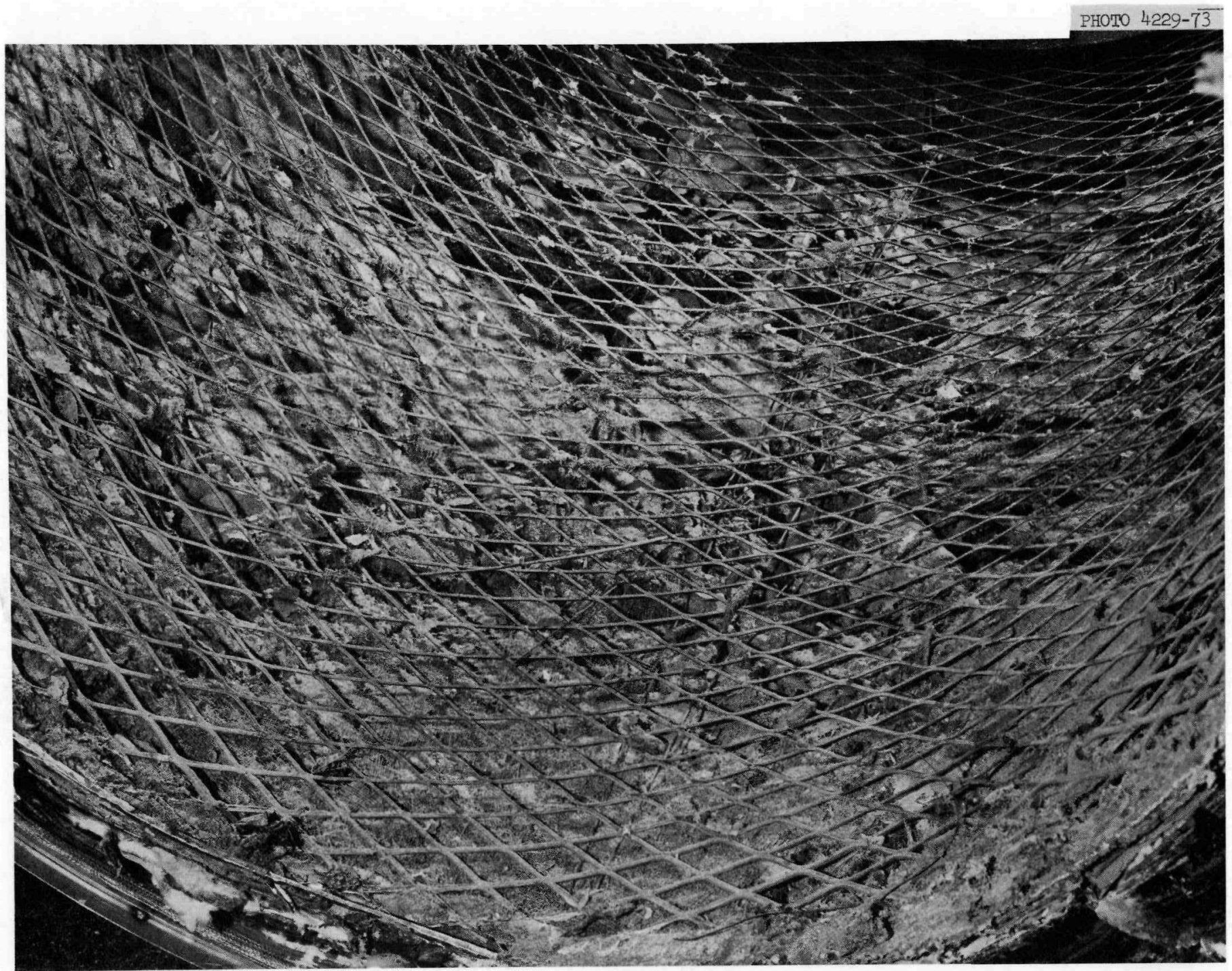

Fig. 32. Bottom view of the fusible insulation bundle showing the debris buildup. 


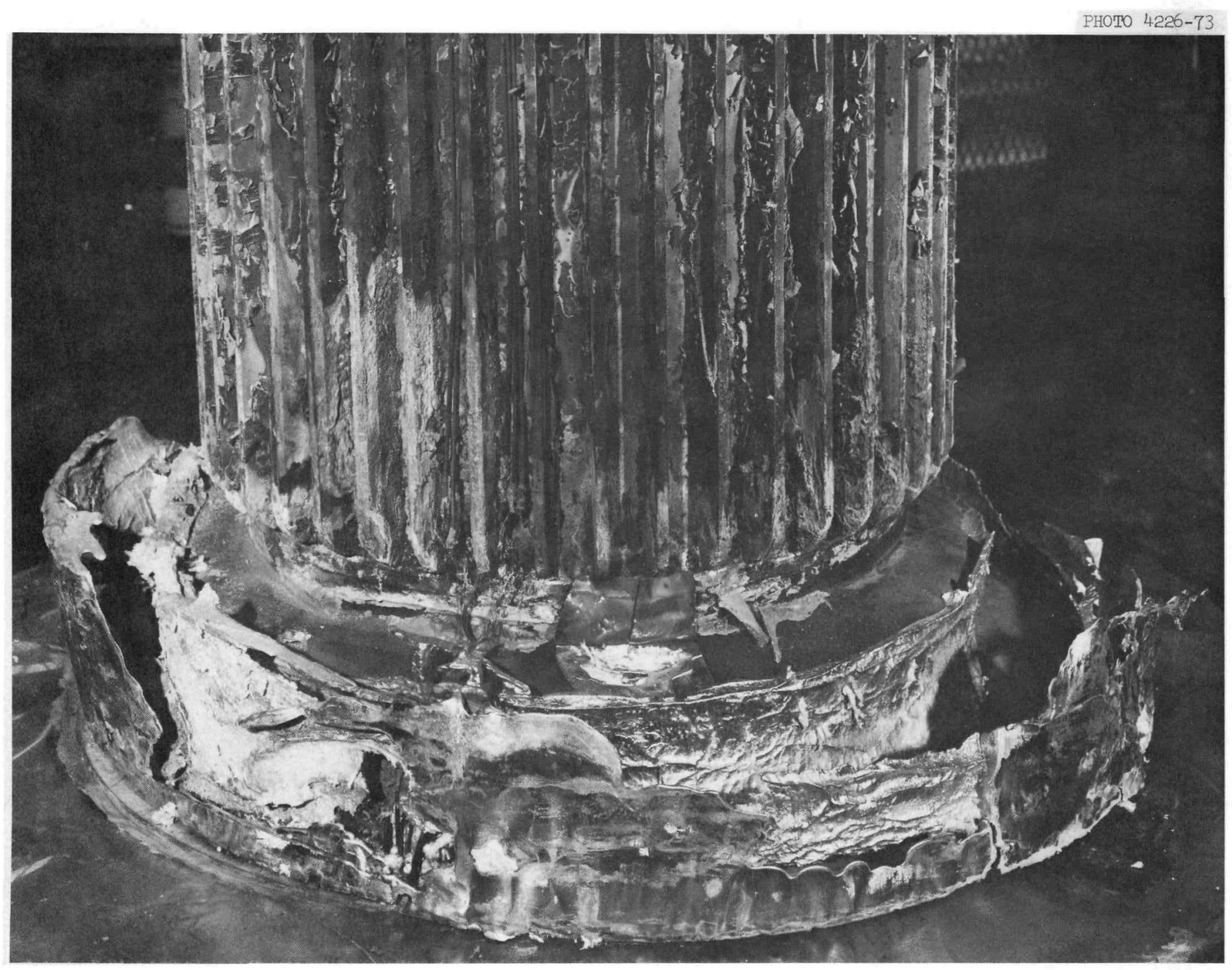

Fig. 33. Bottom section of the heat block-shield after the removal of the fusible insulation bundle. 


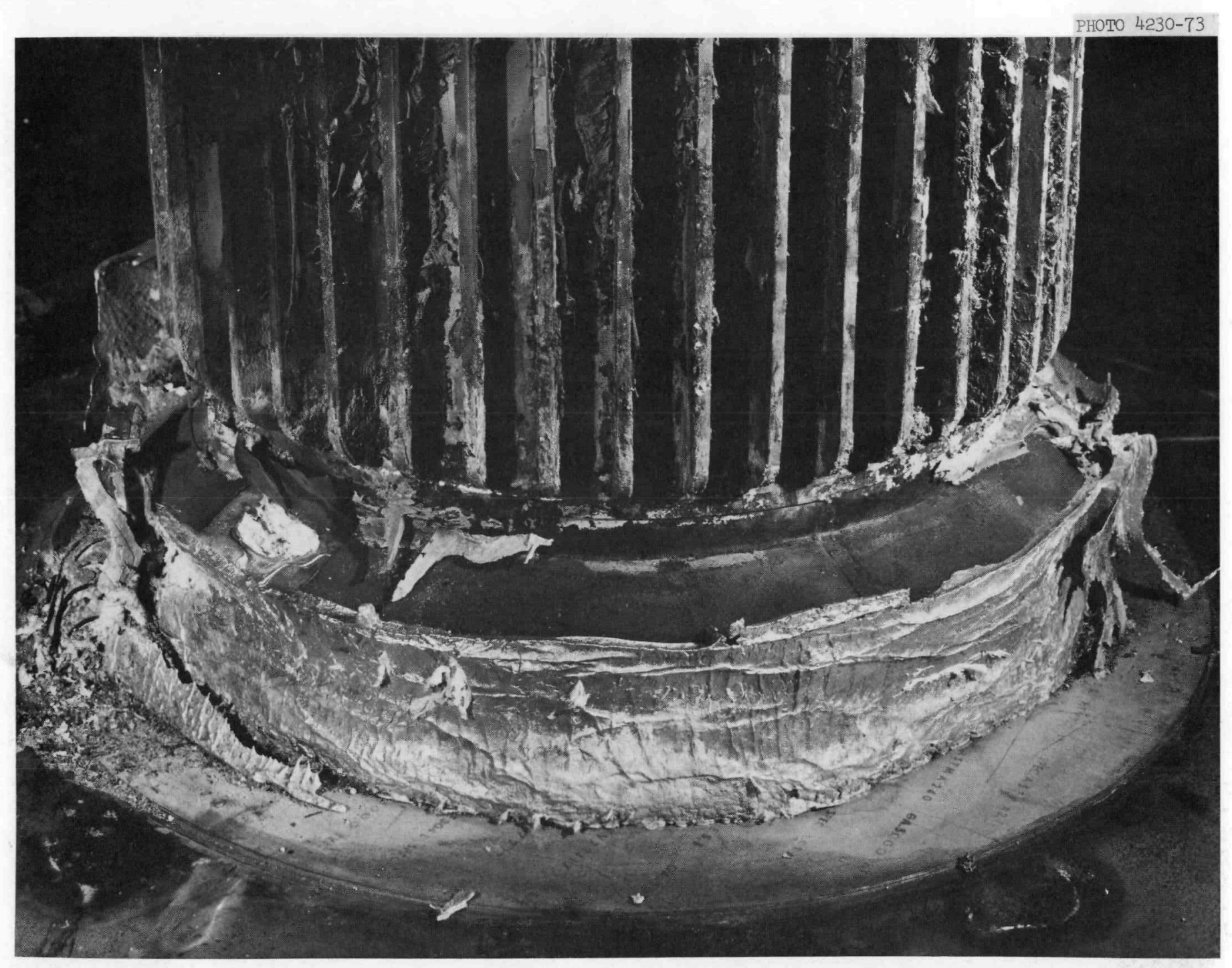

Fig. 34. Deflector cone after the removal of the fusible insulation bundle. 


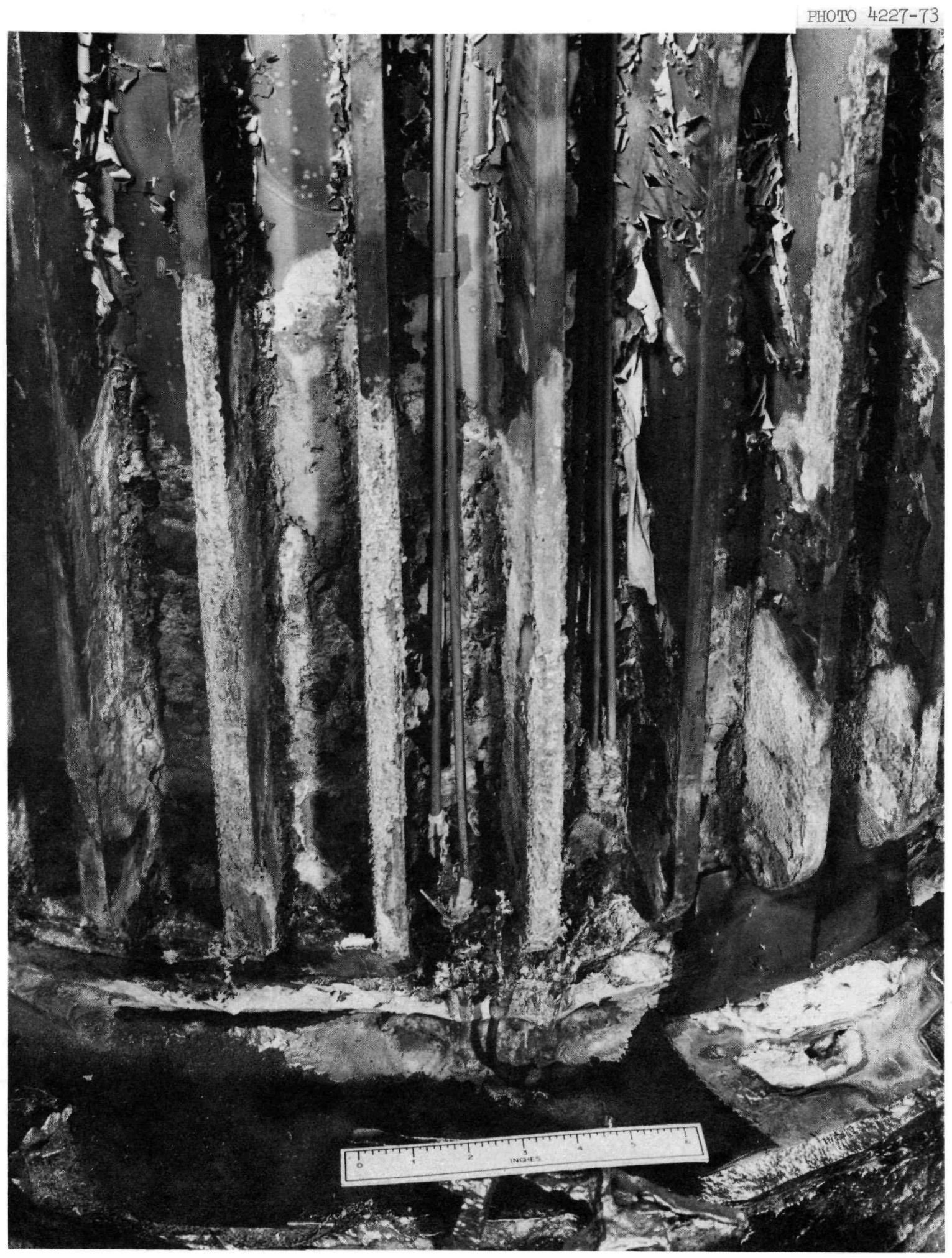

Fig. 35. Bottom section of the heat block-shield showing the maximum height of the molten aluminum to be approximately one foot. 
to be in substantial agreement with the conductivity obtained from the previously tested 3.0 in. thick specimen (Ref。6.) This agreement in the thermal conductivity obtained for the two bundles indicates that the insulation fabrication technique gives reproducible results. The 6.5 in. thick combined aluminum foil-screen insulation had an adjusted heat loss of $9.1 \%$ for the specified normal operation of the thermoelectric radioisotope power system at a heat block-shield surface temperature of $1100^{\circ} \mathrm{F}$ in argon at a pressure of $1 \mathrm{psig}$.

\section{Heat Pipe Coupling Test}

During the Phase I testing of the heat block-shield (Ref. 4), the surfaces of the thermoelectric heat pipe holes rusted. In preparation for the test of the heat block-shield with 12 heat pipes in place, these holes were cleaned and inspected. The holes were tested for dimensional acceptance by insertion of the dummy heat pipe used for the Phase I insertion test. The dummy pipe would not go into the holes more than 9 to 10 in. without heavy resistance. The holes were reamed and honed to allow free insertion of the dummy pipe. This increased the average diameter of the 12 holes by approximately 0.002 in., thereby giving a cold diametral clearance of 0.007 in. between the heat pipes and the walls of the holes.

The data from a heat loss test, reported as Run 4 in Table A-1 of Appendix A, were extrapolated to the conditions of the heat pipe coupling test reported as Run 7 in Table A-2 of Appendix A to give the surface temperature of the heat pipe hole. Figure 36 shows the heat pipe vapor temperature and the heat pipe hole surface temperature distribution in the heat block-shield when operating at a power input to the heater elements of $34 \mathrm{~kW}$. Also shown in Fig. 36 is the temperature difference between the heat pipe hole surface and the heat pipe vapor.

Integration of the curve for the temperature difference between the heat block and the vapor in the heat pipe gave an average value of 93. $7^{\circ} \mathrm{F}$ over the effective length of the heat pipe. A total power input to the 12 heat pipes of $30.76 \mathrm{~kW}$ was obtained after adjusting for system 


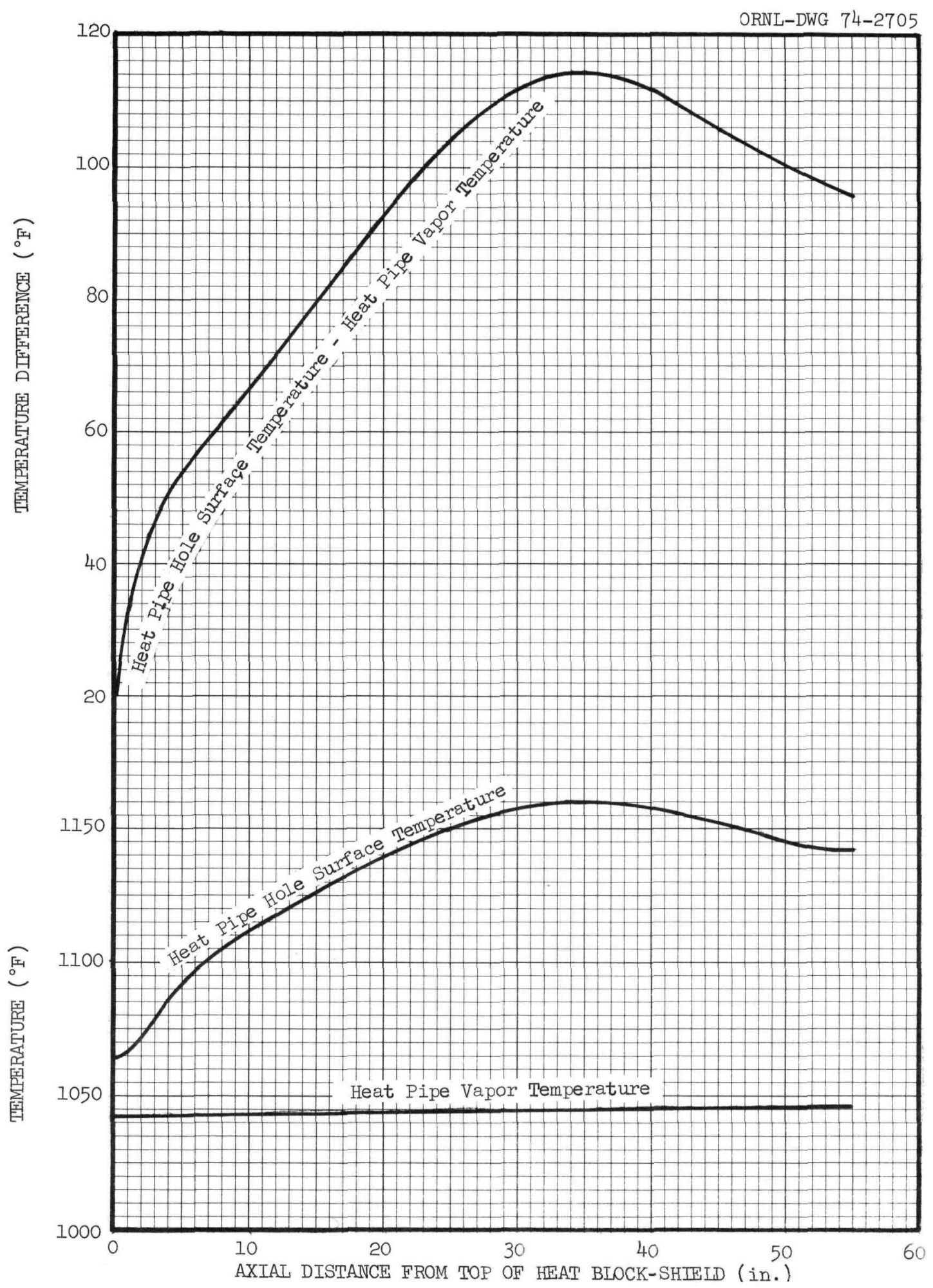

Fig. 36. The temperature difference, the heat pipe vapor and the heat pipe hole surface temperature distribution in the heat block-shield at a power level of $34 \mathrm{~kW}$. 
heat losses. The $30.76 \mathrm{~kW}$ input was equilivalent to a heat flux of $8012 \mathrm{Btu} / \mathrm{hr}^{-\mathrm{ft}^{2}}$ which results in an average temperature drop between the heat pipe vapor and the heat pipe outside surface of $3.9^{\circ} \mathrm{F}$ to give an average temperature drop between the heat pipe hole surface and the heat pipe outside surface of $89.8^{\circ} \mathrm{F}$. An emissivity value of 0.6 taken for the surfaces gave an average value of the radiation heat flux of $1003 \mathrm{Btu} / \mathrm{hr}-\mathrm{ft}^{2}$. Analytical work indicates that a diametral gap of approximately $0.007 \mathrm{in}$. would conduct the remaining of $7009 \mathrm{Btu} / \mathrm{hr}-\mathrm{ft}^{2}$ through the argon gas in the gap. The hot diametral gap was also estimated from the measured cold gap, the expansion coefficients of the heat pipe and the heat block-shield, and the temperature distribution shown in Fig. 36. This procedure, gave a hot diametral clearance of $0.006 \mathrm{in.}$, which checks closely with the value of 0.007 in. calculated from heat transfer considerations.

Using an average of the above two valves for the hot diametral clearance results in a value of $0.0065 \mathrm{in}$. If the cold clearance had not been increased $0.002 \mathrm{in}$. by reaming, the hot clearance would have been approximately $0.004 \mathrm{in}$. which would have reduced the temperature drop between the heat pipe and the heat block-shield by approximately $28^{\circ} \mathrm{F}$. This $28^{\circ} \mathrm{F}$ decrease would in turm be reflected throughout the heat block-shield, and would give a midplane block surface temperature of approximately $1122^{\circ} \mathrm{F}$ as compared to the measured value of $1150^{\circ} \mathrm{F}$.

\section{Loss-of-Coolant Accident Test}

In the experiment designed to simulate abrupt cessation of cooling of the heat block-shield by the power conversion system working fluid, the maximum midplane surface temperatures in the course of the transient while the aluminum insulation was melting were found to be $2175^{\circ} \mathrm{F}$ and $1690^{\circ} \mathrm{F}$ respectively for the central simulated fuel capsule and the heat block-shield. Corresponding equilibrium values for these temperatures after completion of the insulation meltdown were found to be $2067^{\circ} \mathrm{F}$ and $1570^{\circ} \mathrm{F}$. 
The time-temperature data set shown in Fig. 17 was replotted and is shown in Fig. 37 along with an extrapolation of the curve beginning at the $13 \mathrm{hr}$ slope change that is postulated had the molten aluminum not spilled over the deflector cone. It is believed that, if the deflector cone were made to extend to the simulated pressure vessel diameter, no spillover would occur and the extrapolated peak and equilibrium values for the heat block-shield midplane surface temperatures would be $1525^{\circ} \mathrm{F}$ and $1430^{\circ} \mathrm{F}$ respectively.

Replacement of the SAE-1010 steel heat block-shield with a nickel heat block-shield would result in a decrease in the fuel capsule surface temperature. The calculated effects of a nickel heat block-shield upon the fuel capsule surface temperature under various operating conditions are given in Table 6.

Comparison of the central fuel capsule maximum surface temperatures when operating with an SAE-1010 steel and a nickel heat block-shield under loss-of-coolant accident conditions.

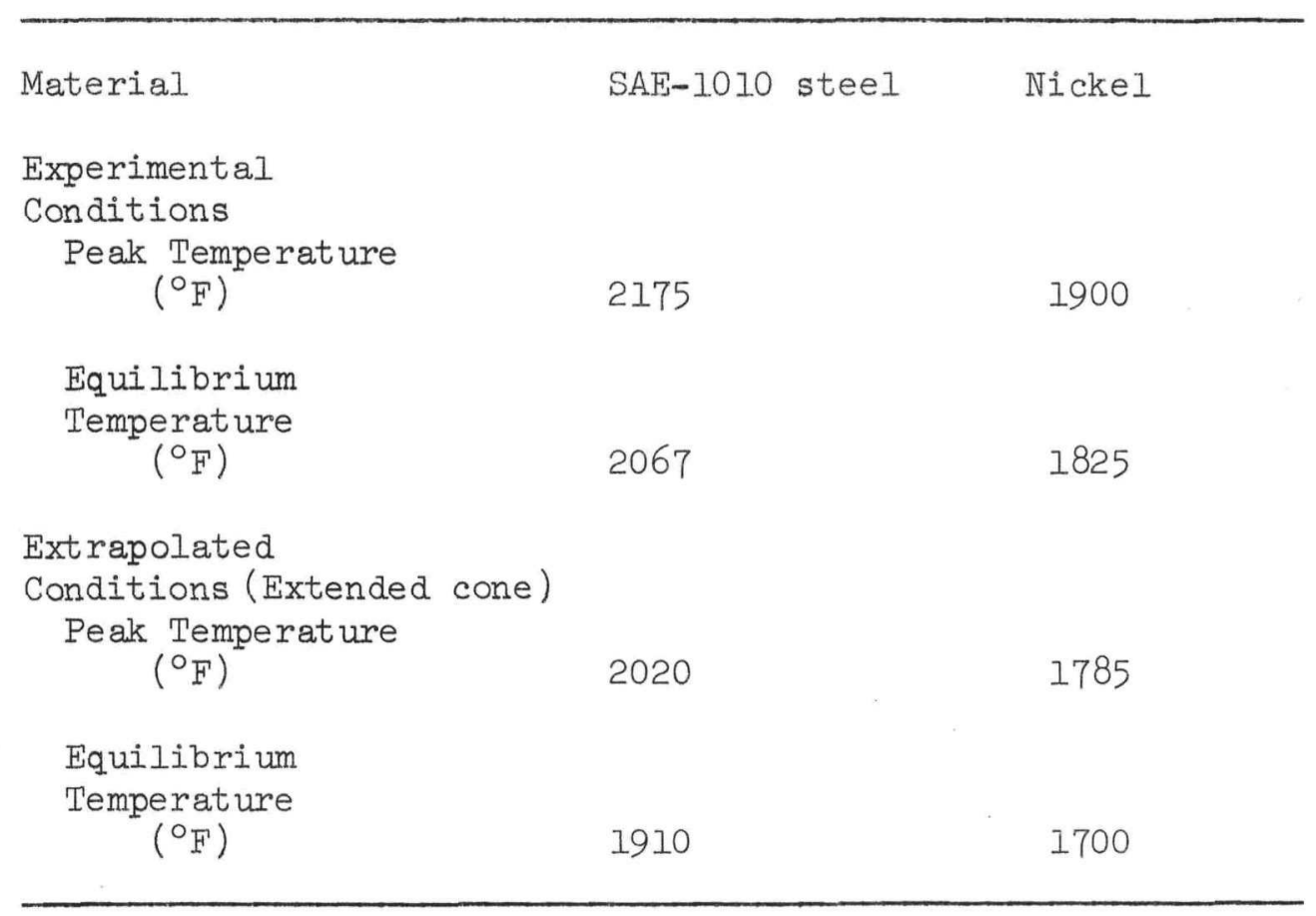


ORNL-DWG 74-2706

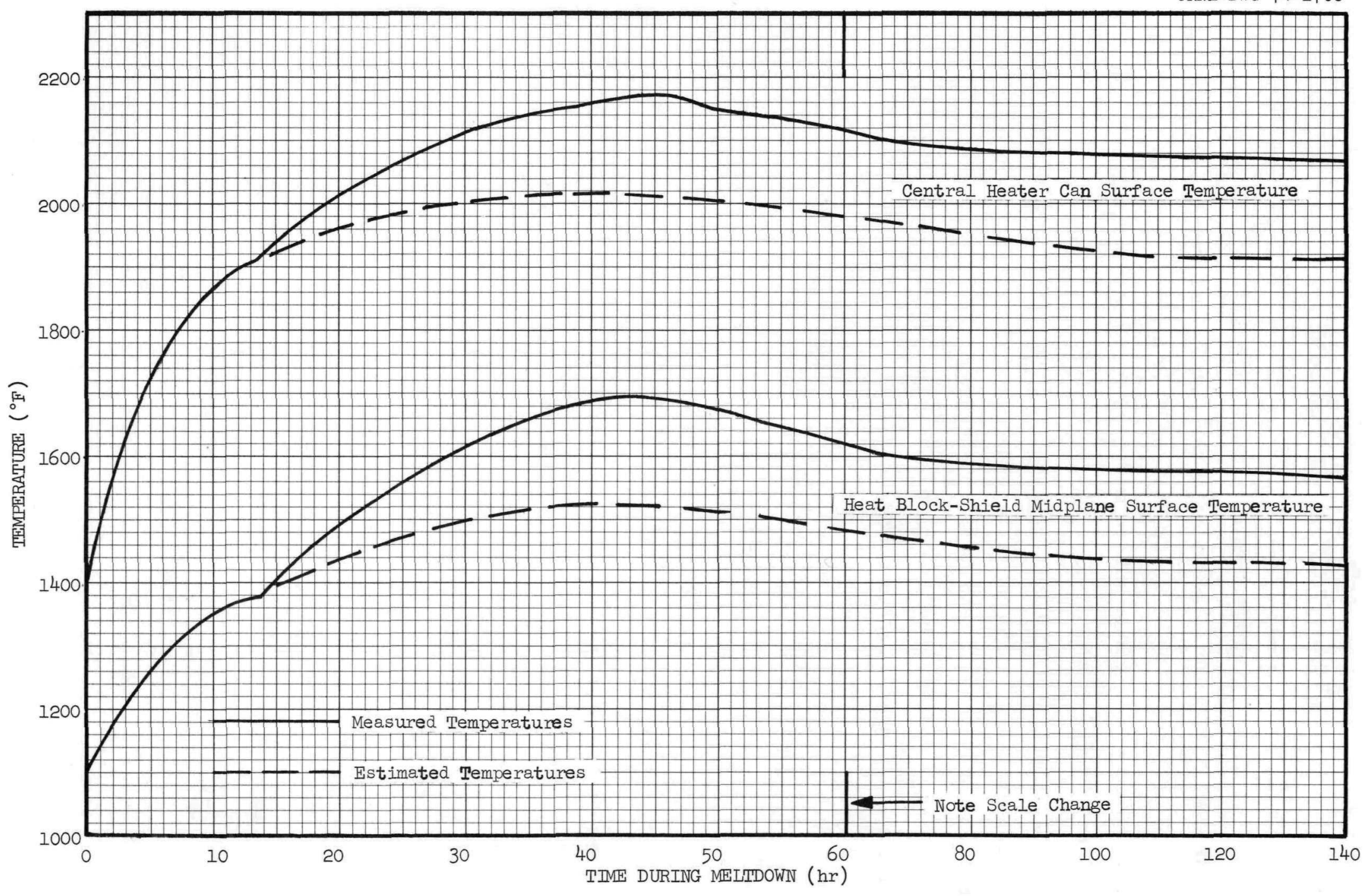

Fig. 37. Estimated time-temperature history of the full scale meltdown. 
APPENDICES 
Blank Page 
The data for the heat loss tests with the fusible insulation in place are given in Table A-I. The data for the heat pipe coupling tests are given in Table A-2, and the data for the loss-of-coolant accident test are given in Table $\mathrm{A}-3$.

The locations of the thermocouples are given in $X, R$, and $\theta$ coordinates. The reference conditions are shown in Fig. A-l where $X=0$ is located at the top surface of the heat block-shield, $R=0$ is located at the center, and $\Theta$ is measured clockwise. The location of the thermocouples on the heater element surface is shown in Fig. A-I where $\theta$ is used to designate the orientation of the heater element relative to the center of the heat block-shield and $\theta^{\prime}$ is used to designate the orientation of the thermocouple relative to the center of the heater element.

The location of the thermocouples in the fusible insulation is shown in Fig. A-2 relative to the insulation surface. The dimensions given in Tables $A-1, A-2$ and $A-3$ are $X, R$, and $\theta$ as designated in Fig. A-l. 

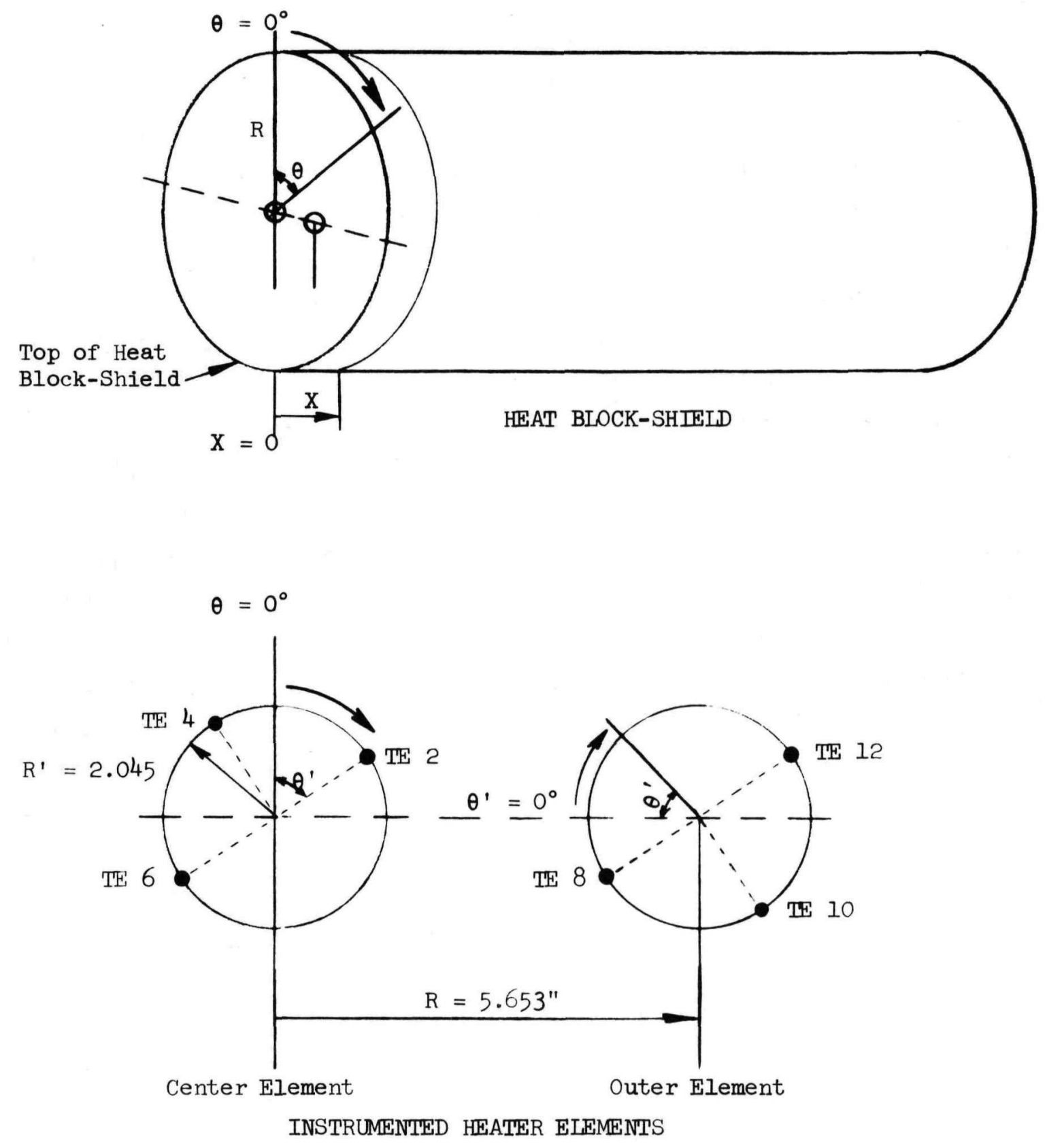

Fig. A.1. Thermocouple coordinate system. 
ORNL-DWG $\quad 74-2707$

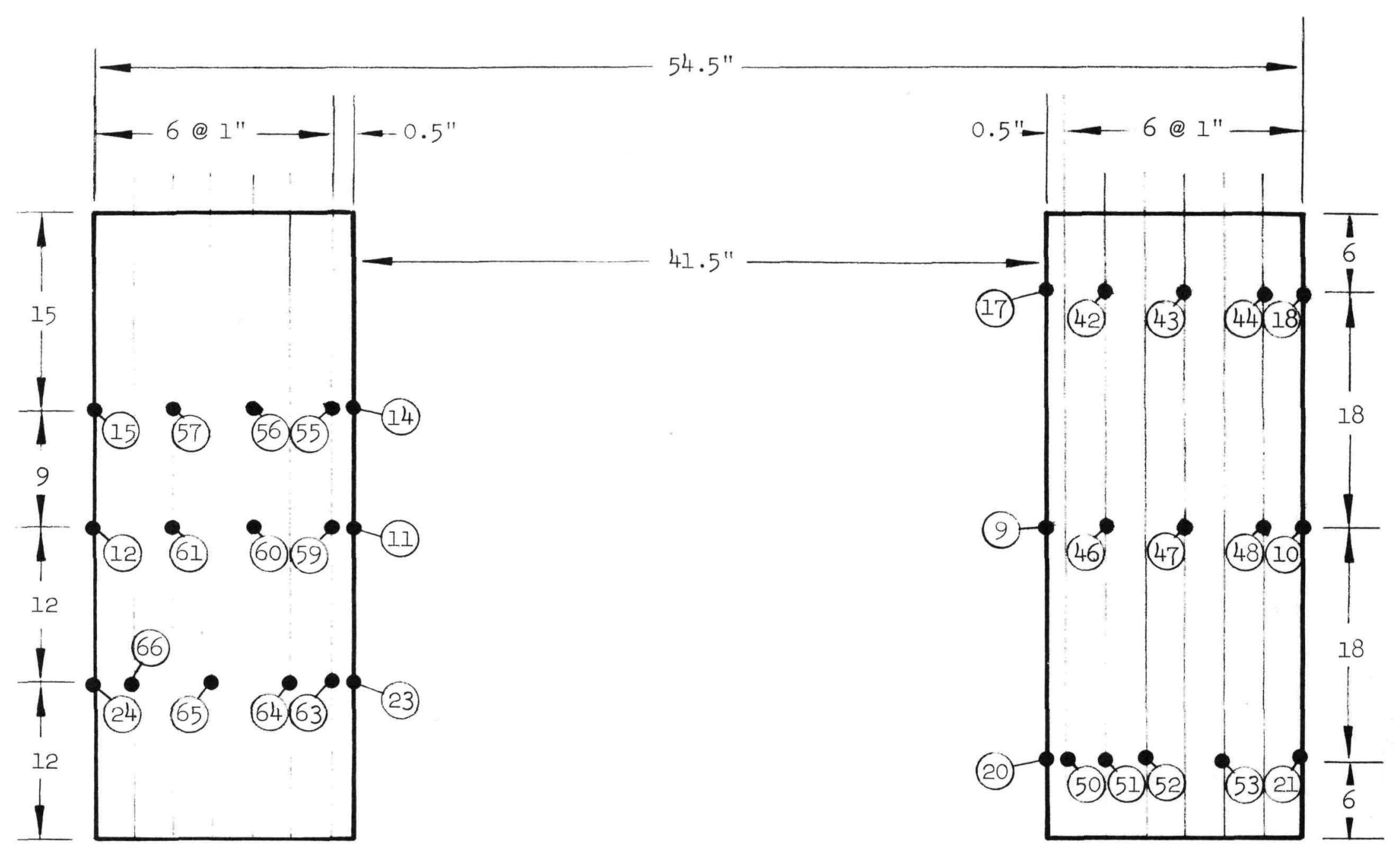

Fig. A.2. Location of the thermocouples in the fusible insulation. 
Table A-1. Heat Loss Test Data

\begin{tabular}{|c|c|c|c|c|c|c|c|c|}
\hline & & Test & umber & & 1 & 2 & 3 & 4 \\
\hline & & Numk & of Ele & & 7 & 7 & 7 & 7 \\
\hline & & Powe & Level, & & 1.079 & $\begin{array}{c}1.490 \\
\text { Temperature }\end{array}$ & $\begin{array}{l}2.217 \\
\left({ }^{\circ} \mathrm{F}\right)\end{array}$ & 3.386 \\
\hline & & Locatic & & & & & & \\
\hline טل & $\begin{array}{c}X \\
\text { (in.) }\end{array}$ & $\begin{array}{c}R \\
\text { (in.) }\end{array}$ & $\stackrel{\theta}{(\operatorname{deg})}$ & $\begin{array}{c}\theta^{\prime} \\
(\mathrm{deg})\end{array}$ & & & & \\
\hline 1 & 30.125 & 5.653 & 330 & 90 & 507.7 & 703.3 & 904.9 & 1137.0 \\
\hline 2 & 30.125 & 0 & 0 & 180 & 510.3 & 707.2 & 909.5 & 1148.0 \\
\hline 3 & 30.125 & 5.653 & 330 & 0 & 512.1 & 707.6 & 910.8 & 1147.0 \\
\hline 4 & 30.125 & 0 & 0 & 90 & 511.7 & 709.7 & 911.2 & 1149.0 \\
\hline 5 & 30.125 & 5.653 & 330 & 270 & 506.0 & 701.6 & 902.3 & 1135.0 \\
\hline 6 & 30.125 & 0 & 0 & 0 & 510.3 & 705.0 & 910.8 & 1151.0 \\
\hline 7 & 30.125 & 17.750 & 288 & & 489.3 & 679.7 & 872.0 & 1092.0 \\
\hline 8 & 30.125 & 17.750 & 112 & & 489.3 & 679.3 & 872.0 & 1092.0 \\
\hline 9 & 30.125 & 20.750 & 288 & & 481.8 & 672.9 & 865.6 & 1082.0 \\
\hline 10 & 30.125 & 27.250 & 288 & & 90.4 & 107.5 & 127.8 & 156.7 \\
\hline 11 & 30.125 & 20.750 & 112 & & 476.5 & 666.9 & 857.6 & 1077.0 \\
\hline 12 & 30.125 & 27.250 & 112 & & 97.9 & 111.9 & 134.4 & 187.8 \\
\hline 13 & 21.000 & 17.750 & 112 & & 486.6 & 677.2 & 869.4 & 1089.0 \\
\hline 14 & 21.000 & 20.750 & 112 & & 479.1 & 669.9 & 863.1 & 1082.0 \\
\hline 15 & 21.000 & 27.250 & 112 & & 97.5 & 120.6 & 148.3 & 188.6 \\
\hline 16 & 12.000 & 17.750 & 288 & & 485.7 & 674.2 & 864.4 & 1082.0 \\
\hline 17 & 12.000 & 20.750 & 288 & & 479.6 & 669 & 860.2 & 1079.0 \\
\hline 18 & 12.000 & 27.250 & 288 & & 89.9 & 108.8 & 133.1 & 167.5 \\
\hline 19 & 48.000 & 17.750 & 288 & & 482.7 & 670.3 & 859.7 & 1075.0 \\
\hline 20 & 48.000 & 20.750 & 288 & & 476.6 & 663.8 & 854.2 & 1068.0 \\
\hline 21 & 48.000 & 27.250 & 288 & & 93.5 & 113.6 & 137.4 & 173.6 \\
\hline 22 & 42.000 & 17.750 & 112 & & 486.6 & 676.3 & 867.3 & 1084.0 \\
\hline 23 & 42.000 & 20.750 & 112 & & 472.9 & 662.6 & 852.5 & 1067.0 \\
\hline 24 & 42.000 & 27.250 & 112 & & 101.1 & 123.9 & 149.1 & 191.0 \\
\hline 25 & 6.000 & 10.625 & 285 & & 486.8 & 677.9 & 867.7 & 1086.0 \\
\hline 26 & 11.875 & 10.625 & 285 & & 489.0 & 680.9 & 872.7 & 1092.0 \\
\hline 27 & 24.250 & 10.625 & 285 & & 491.7 & 684.3 & 879.1 & 1104.0 \\
\hline 28 & 30.125 & 10.625 & 285 & & 491.7 & 683.5 & 878.2 & 1103.0 \\
\hline 29 & 36.000 & 10.625 & 285 & & 491.2 & 682.2 & 876.5 & 1100.0 \\
\hline 30 & 48.375 & 10.625 & 285 & & 486.0 & 675.3 & 866.4 & 1083.0 \\
\hline 31 & 55.000 & 10.625 & 285 & & 483.3 & 671.0 & 860.5 & 1074.0 \\
\hline 32 & 6.000 & 15.500 & 285 & & 482.9 & 672.7 & 863.5 & 1079.0 \\
\hline 33 & 11.875 & 15.500 & 285 & & 487.3 & 677.5 & 868.5 & 1086.0 \\
\hline 34 & 24.250 & 15.500 & 285 & & 489.0 & 680.5 & 874.0 & 1095.0 \\
\hline 35 & 30.125 & 15.500 & 285 & & 489.5 & 680.0 & 873.2 & 1094.0 \\
\hline 36 & 36.000 & 15.500 & 285 & & 489.0 & 679.2 & 872.7 & 1092.0 \\
\hline 37 & 48.375 & 15.500 & 285 & & 484.6 & 671.9 & 863.0 & 1077.0 \\
\hline 38 & 55.000 & 15.500 & 285 & & 482.0 & 668.0 & 856.7 & 1068.0 \\
\hline 39 & 3.500 & 17.750 & 112 & & 486.4 & 674.5 & 864.3 & 1081.0 \\
\hline 40 & 3.500 & 17.750 & 288 & & 485.5 & 671.9 & 860.5 & 1076.0 \\
\hline 41 & 12.000 & 20.250 & 288 & & 485.1 & 674.9 & 864.7 & 1082.0 \\
\hline 42 & 12.000 & 22.250 & 288 & & 437.7 & 610.7 & 783.2 & 976.1 \\
\hline 43 & 12.000 & 24.250 & 288 & & 341.9 & 477.1 & 609.3 & 740.5 \\
\hline 44 & 12.000 & 26.250 & 288 & & 174.4 & 237.1 & 303.3 & 378.9 \\
\hline 45 & 30.125 & 20.250 & 288 & & 488.2 & 678.3 & 870.2 & 1090.0 \\
\hline 46 & 30.125 & 22.250 & 288 & & 439 & 613.8 & 788.7 & 985.8 \\
\hline 47 & 30.125 & 24.250 & 288 & & 338.3 & 470.9 & 601.9 & 737.1 \\
\hline 48 & 30.125 & 26.250 & 288 & & 178.1 & 241.3 & 307.9 & 388.9 \\
\hline 49 & 48.000 & 20.250 & 288 & & 485.3 & 672.4 & 861.1 & 1074.0 \\
\hline 50 & 48.000 & 21.250 & 288 & & 462.8 & 645.4 & 829.3 & 1035.0 \\
\hline 51 & 48.000 & 22.250 & 288 & & 439.3 & 612.6 & 784.2 & 975.4 \\
\hline 52 & 48.000 & 23.250 & 288 & & 394.2 & 549.6 & 702.8 & 866.5 \\
\hline 53 & 48.000 & 25.250 & 288 & & 243.1 & 338.8 & 431.0 & 533.0 \\
\hline 54 & 21.000 & 20.250 & 112 & & 486.2 & 677.2 & 867.5 & 1086.0 \\
\hline 55 & 21.000 & 21.250 & 112 & & 463.7 & 650.1 & 837.0 & 1049.0 \\
\hline 56 & 21.000 & 23.250 & 112 & & 404.5 & 564.4 & 721.2 & 893.5 \\
\hline 57 & 21.000 & 25.250 & 112 & & 242.6 & 337.5 & 430.5 & 529.7 \\
\hline 58 & 30.125 & 20.250 & 112 & & 487.5 & 677.6 & 869.6 & 1088.0 \\
\hline 59 & 30.125 & 21.250 & 112 & & 459.3 & 644.5 & 830.6 & 1043.0 \\
\hline 60 & 30.125 & 23.250 & 112 & & 405.8 & 565.7 & 724.6 & 900.6 \\
\hline 61 & 30.125 & 25.250 & 112 & & 239.1 & 332.9 & 425.2 & 527.1 \\
\hline 62 & 42.000 & 20.250 & 112 & & 484.9 & 673.3 & 862.8 & 1078.0 \\
\hline 63 & 42.000 & 21.250 & 112 & & 458.4 & 641.9 & 827.2 & 1037.0 \\
\hline 64 & 42.000 & 22.250 & 112 & & 445.1 & 621.2 & 799.6 & 995.7 \\
\hline 65 & 42.000 & 24.250 & 112 & & 337.2 & 467.5 & 597.4 & 733.0 \\
\hline 66 & 42.000 & 26.250 & 112 & & 178.5 & 243.4 & 313.9 & 402.3 \\
\hline 67 & 51.500 & 17.750 & 112 & & 479.6 & 664.7 & 851.4 & 1063.0 \\
\hline 68 & 51.500 & 17.750 & 288 & & 480.9 & 666.0 & 853.9 & 1066.0 \\
\hline 69 & 11.875 & 3.364 & 0 & & 491.9 & 683.6 & 878 & 1105.0 \\
\hline 70 & 24.250 & 3.364 & 0 & & 497.2 & 691.3 & 890.2 & 1127.0 \\
\hline 71 & 36.000 & 3.364 & 0 & & 495.5 & 689.6 & 888.5 & 1124.0 \\
\hline 72 & 55.500 & 17.750 & 288 & & 446.8 & 620.6 & 799.4 & 998.2 \\
\hline 73 & 60.000 & 17.750 & 288 & & 260 & 365 & 498 & 595.0 \\
\hline 74 & 65.500 & 17.750 & 288 & & 100 & 120 & 205 & 168.0 \\
\hline 75 & 0 & 15.500 & 300 & & 483 & 668 & 855 & 1070.0 \\
\hline 76 & 0 & 10.625 & 300 & & 485 & 670 & 858 & 1075.0 \\
\hline 77 & 0 & 8.500 & 300 & & 485 & 672 & 861 & 1078.0 \\
\hline
\end{tabular}




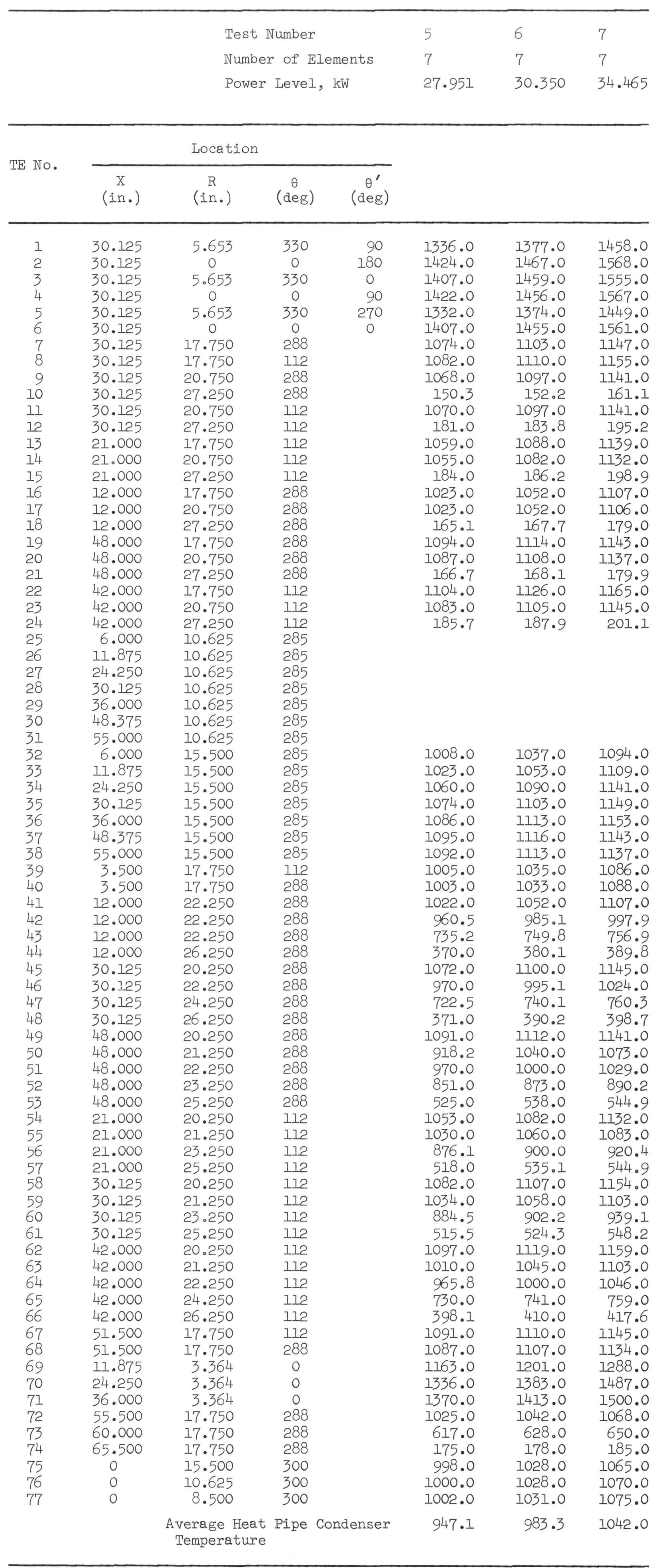


Table A-3. Loss-of-Coolant Accident Tests

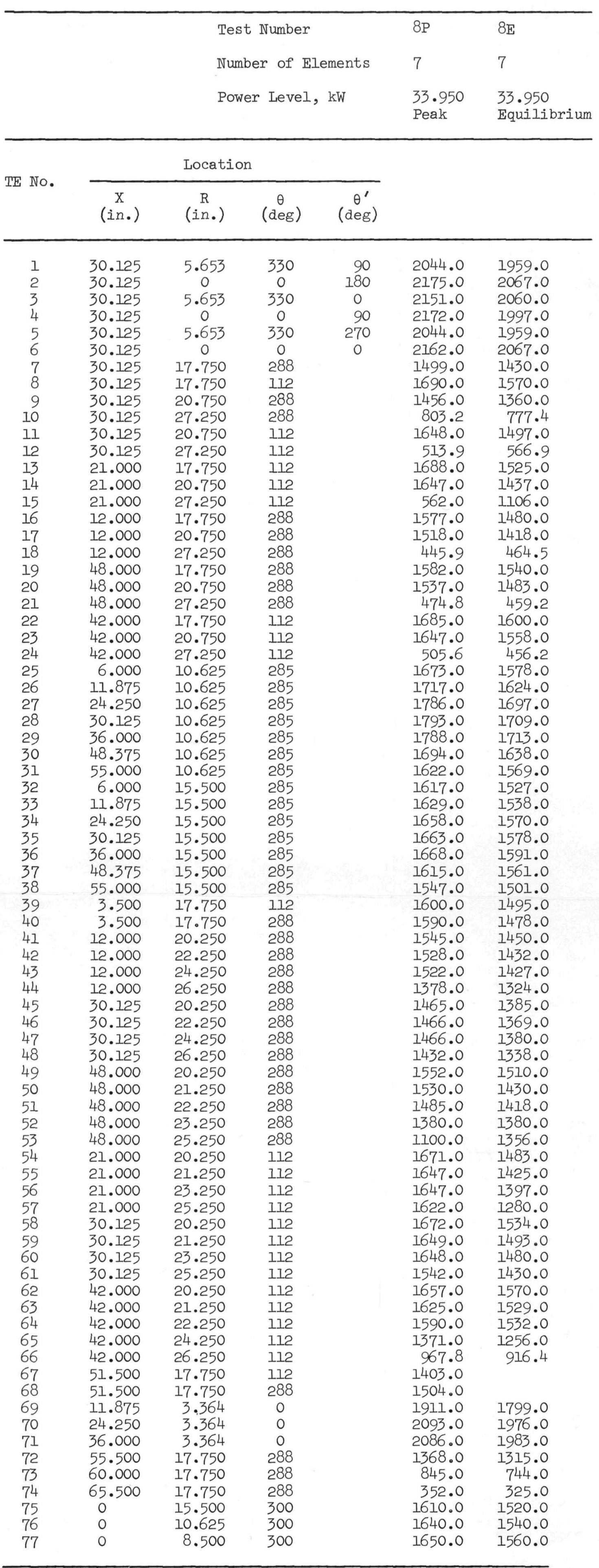




\section{APPENDIX B}

HEAT PIPE DESIGN, FABRICATION, AND TESTING

D. B. Lloyd

The heat pipes used in this test were a modification of the type used in the earlier phase of the Thermoelectric Isotope Power Program (Ref. 5). The heat pipes are 79 in. long, have a 1.0 in. diameter, and use potassium as the working fluid.

The major cost component in the heat pipes used earlier was the wick structure. This structure had extremely fine pores and was theoretically capable of performance far in excess of that required for this test. The method of fabrication is reported in Ref.5. Figure 11 in Ref. 5 shows that, for a potassium heat pipe of this general configuration operated in a vertical position with the evaporator end down, the capillary pumping limit (which is a function of pore size and annulus width) exceeds the sonic flow limit (which is a function of the vapor channel diameter) until very large pore sizes are achieved. Accordingly, it was decided that. a less expensive wick structure would be tested in a heat pipe and, if found to be workable, would be used in the heat pipes for the full-scale fusible insulation evaluation test. The method of fabrication of the wick is shown in Fig. B-l. When the wick structure is removed from the mandrel around which it is formed, it is essentially a tubular sandwich with 400-mesh wire cloth held between inner and outer layers of 200-mesh wire cloth. The 200-mesh cloth is substantially more rigid than the 400-mesh cloth and is a factor of 10 less expensive. In addition to a substantial saving in material costs, this wick design also eliminates many of the time-consuming operations required by the earlier structure. Measurements indicated that the effective pore diameter of this type of wick was about $134 \mu \mathrm{m}$. A heat pipe incorporating the modified wick was build and tested and was judged to be acceptable for use in the full-scale fusible insulation evaluation test. 


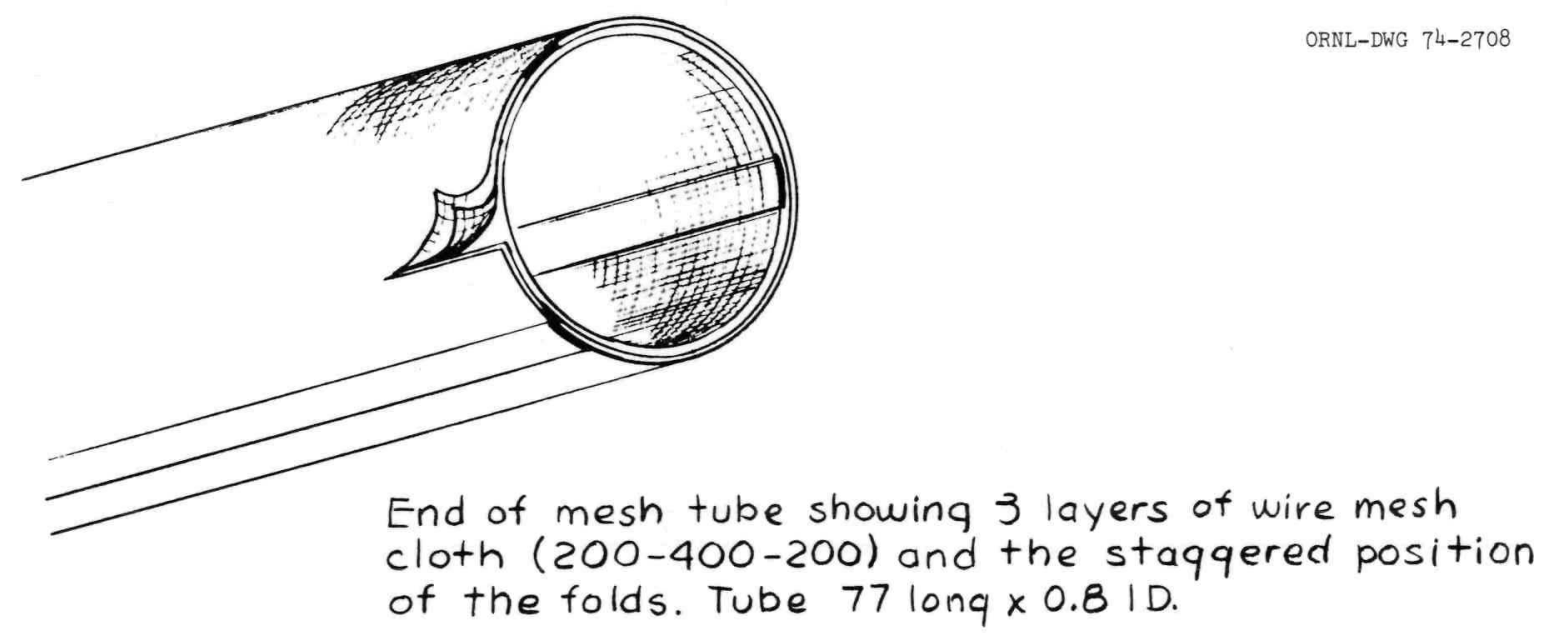

End of mesh tube showing 3 layers of wire mesh th (200-400-200) and the stagqered position of the folds. Tube 77 long $\times 0.8$ ID.
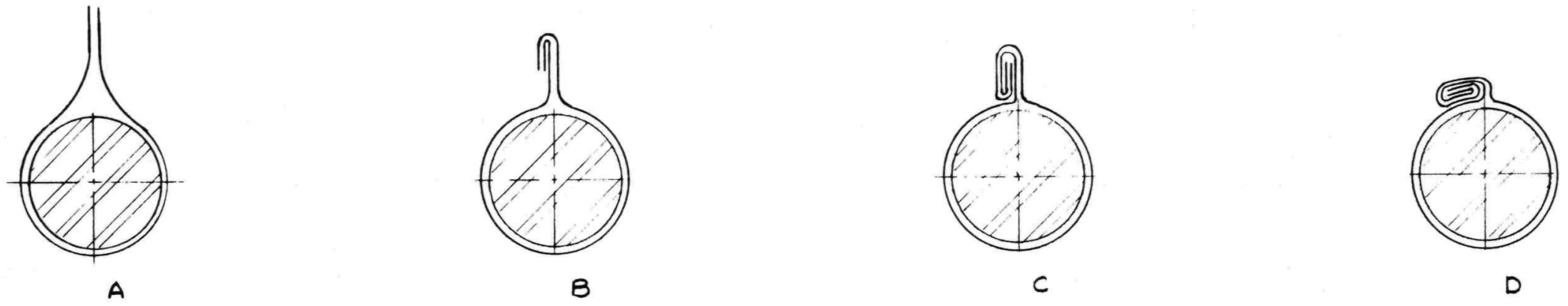

Fig. B.1. Fabrication technique for a 200-400-200 mesh wick. 
Reference 5 refers to operational problems encountered with earlier heat pipes which were thought to be caused by a build-up of impurities in the potassium during operation of the heat pipe. (The source of these impurities was postulated to be the surface of the wick structure). As a rule, the addition of impurities to a liquid tends to reduce the surface tension of the liquid. If that occurs in a heat pipe, the potential capillary pumping forces are correspondingly reduced. In an attempt to minimize this buildup, an in situ cleanup system was incorporated in the heat pipes. This system consisted of a $\mathrm{Zr}$ foil getter located in the evaporator end of the heat pipe as shown in Figure B-2. As the heat pipe operates, the potassium vapor (generated in the evaporator) flows to the heat removal section where it is condensed. If there are any oxides present, they will be dissolved in the newly condensed liquid and returned to the evaporator. There will be a tendency for these impurities to concentrate in the evaporator where the return liquid. flow ceases, that is, where the last of it is reevaporated. At the proposed operating temperature of the heat pipes $\left(1050^{\circ} \mathrm{F}\right.$ ) the $\mathrm{Zr}$ metal will reduce the potassium oxide and form zirconium oxide (which is insoluble in potassium) thereby removing it from solution in the potassium.

At the time the heat pipes were fabricated it was decided to build two of the heat pipes with external rather than internal Zr foil hot traps. These are shown in Figure B-3. One of the two simply had an extermal hot trap located in the fill tube, while the second had both a hot trap and a cold trap. The purpose of these variations was to determine if there were any observable differences in their mode of operation.

After the heat pipes had been fabricated and connected to the distillation pot, they were leak-checked with a sensitive mass spectrometer helium leak detector. They were then connected to a potasium storage tank and vacuum system, as shown in Figure B-4. This assembly was evacuated for approximately $18 \mathrm{hr}$ to a pressure of less than 1.0 torr. The heat pipe and distillation pot were heated to about $200^{\circ} \mathrm{F}$ during this period. 
ORNL-DWG 74-2709

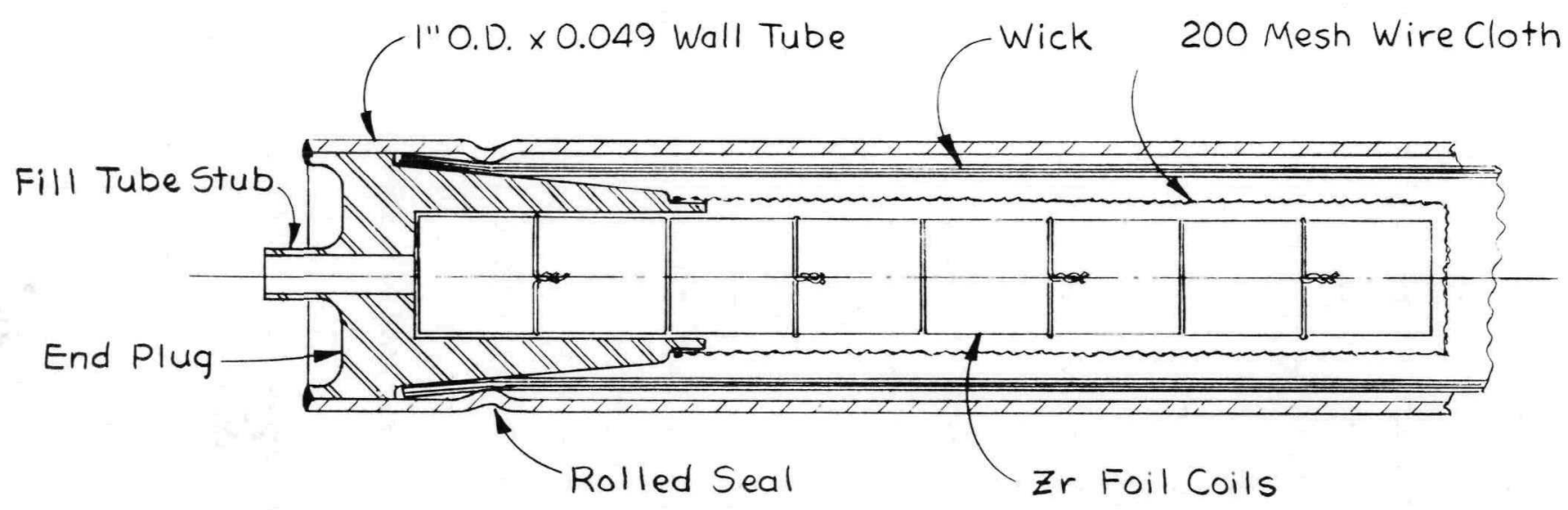

Fig. B.2. Internal cleanup system in the evaporator end of a heat pipe. 
ORNL-DWG $74-2710$

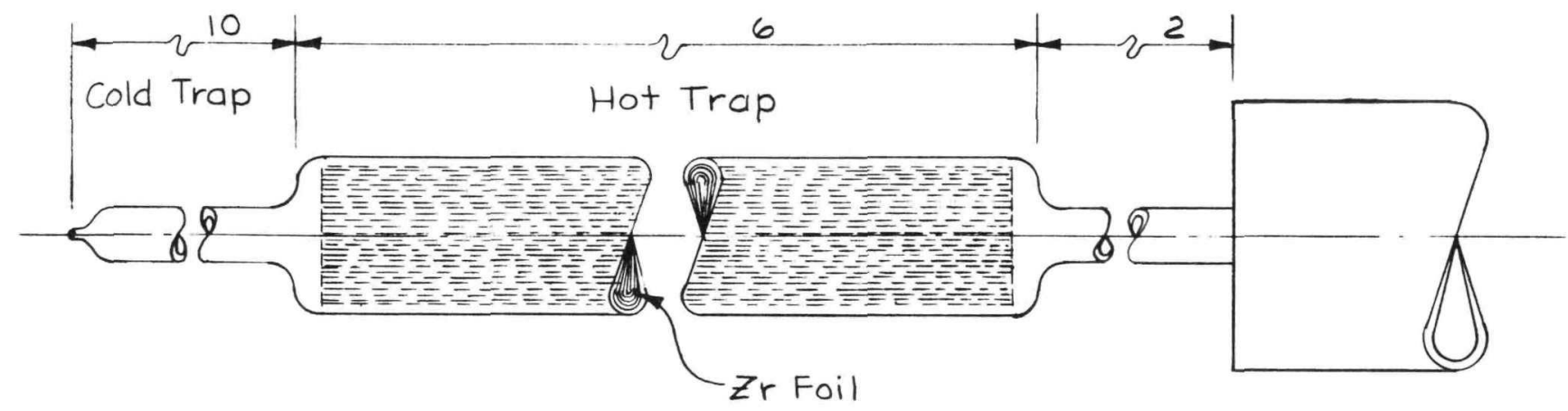

Fig. B.3. External cleanup system on the evaporator end of a heat pipe. 


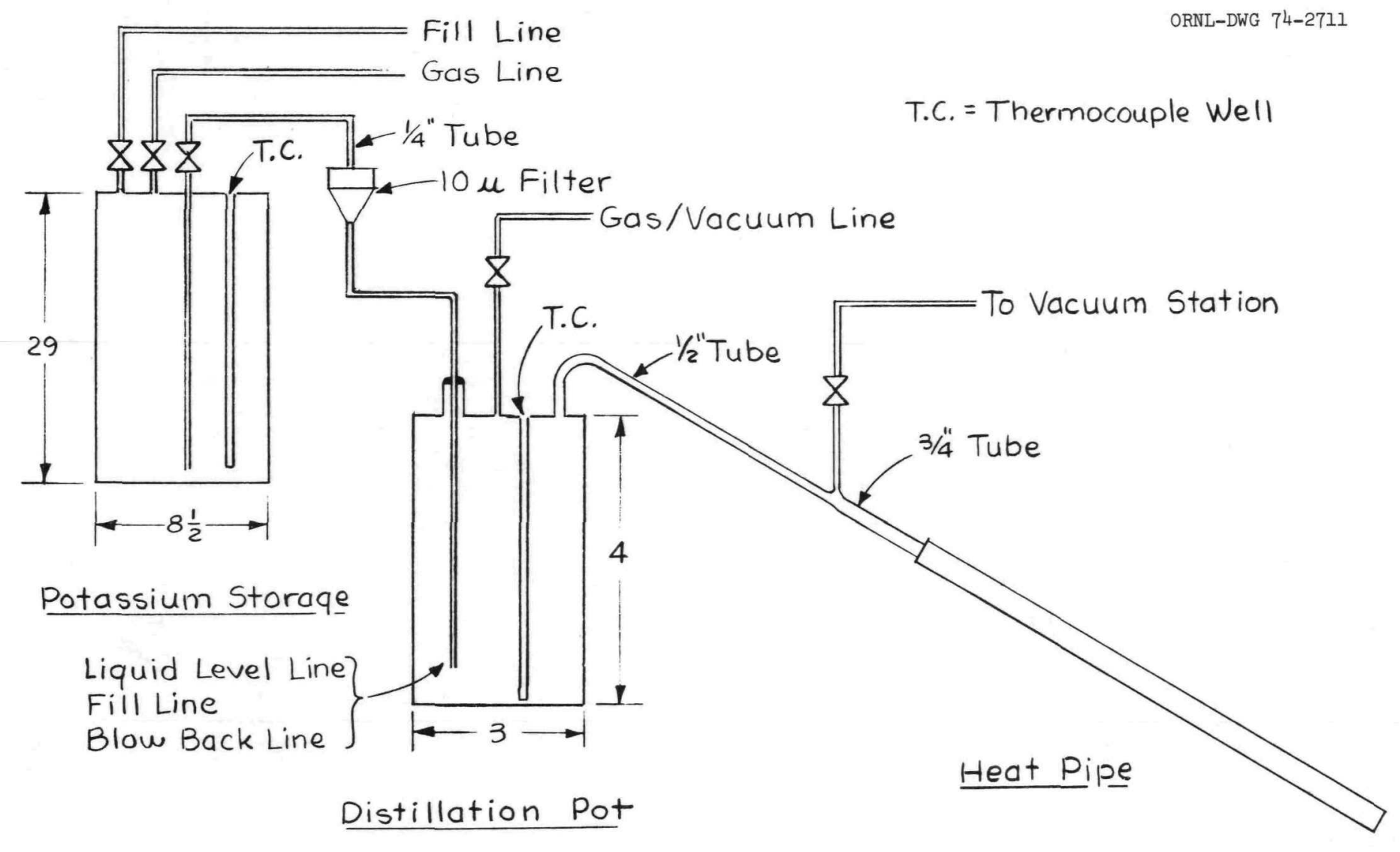

Fig. B.4. Potassium charging system. 
The potassium in the storage tank was heated to $300^{\circ} \mathrm{F}$, and the heat pipe was backfilled to atmospheric pressure with high-purity argon. An argon pressure of 5 psig was applied to the storage tank, and when the intermediate valve was opened, the potassium was transferred to the distillation pot. After a predetermined amount had been transferred, the flow was stopped, and the argon pressure in the distillation pot was increased to force the potassium back into the storage tank. The level of the fill line insured leaving the proper amount of potassium in the distillation pot. The heat pipe distillation pot assembly was disconnected from the storage tank. The assembly was evacuated to a pressure of $2 \times 10^{-7}$ torr or less and the heat pipe heated to $932^{\circ} \mathrm{F}$ for a minimum of $18 \mathrm{hr}$.

At the end of the out-gassing period the heat pipe was cooled to about $800^{\circ} \mathrm{F}$. The potassium was transferred from the pot to the pipe in about 25 min under these conditions. A dynamic vacuum was maintained on the system during the transfer. After the transfer, the tube between the heat pipe and the distillation pot was flame heated to a red heat to assure a potassium-free inner surface and then pinched shut, cut, and seal welded. When all of the heat pipes had been filled and sealed, they were placed in a vacuum furnace and heated to $1250^{\circ} \mathrm{F}$ for about $9 \mathrm{hr}$ to allow them to"wet in" before testing.

At this time the two heat pipes with the external hot traps and one of those with an internal trap were instrumented and placed in a tube furnace to initiate the potassium cleanup.* Figure B-5A shows schematically the arrangement of the heat pipes in the furnace. The heat pipes were operated in this manner for one week at a temperature of $1250^{\circ} \mathrm{F}$. Figure B-5B shows the temperature distribution during this period.

At the end of the potassium cleanup operation the heat pipes were removed from the furnace and the thermocouples removed. The external

*Note: While some cleanup of the potassium occurred during the "wetting in" period, the heat pipes were entirely within the heated zone of the furnace and, therefore, it is doubtful if there was much circulation of the potassium within the heat pipes. 


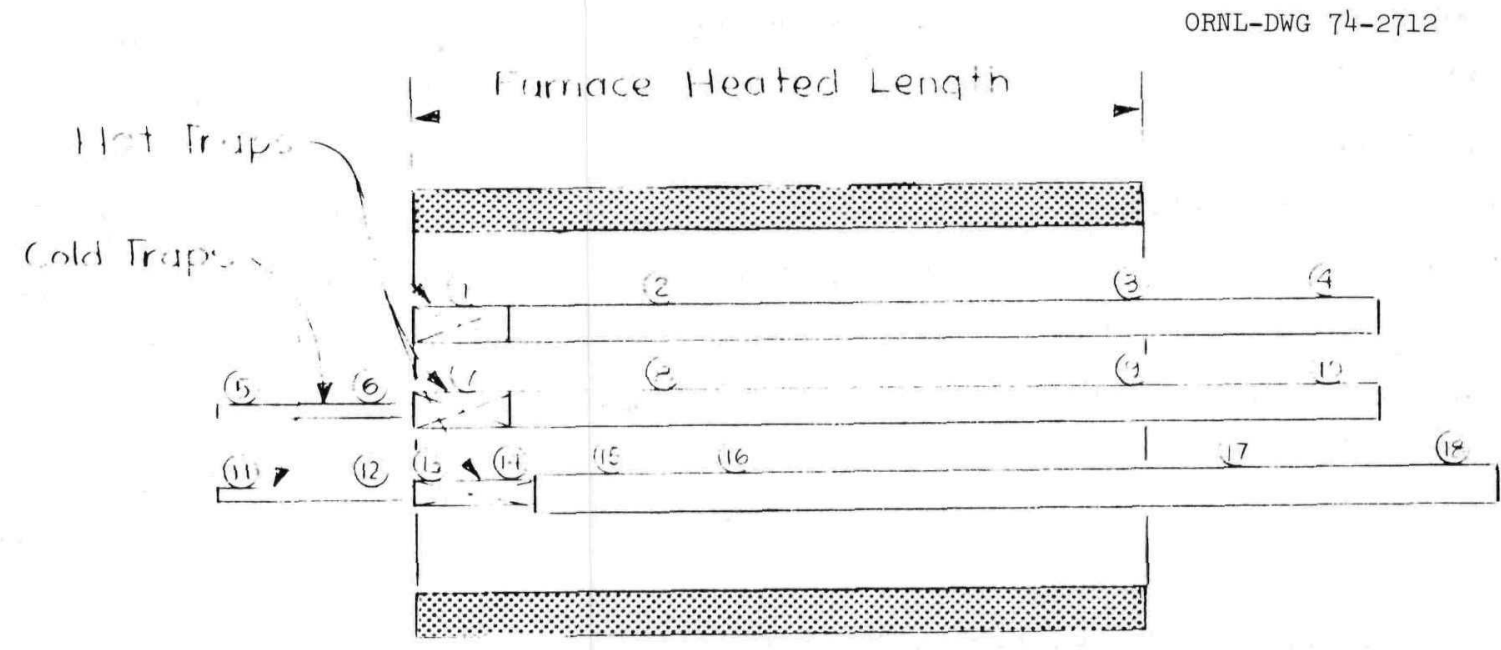

() - Thermocomples

Fig. B.5a. Heat pipe arrangement in the furnace during cleanup.

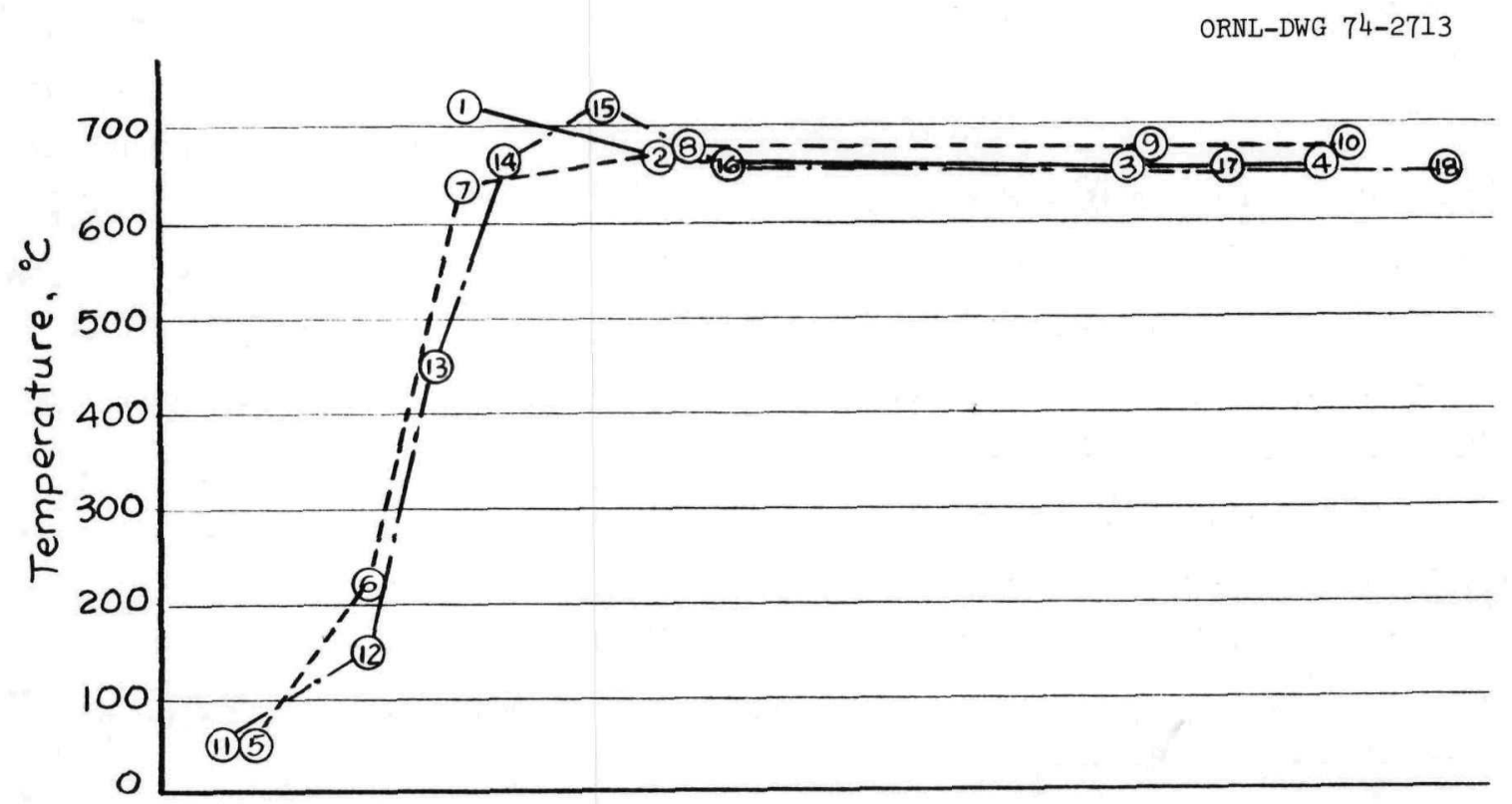

Fig. B.5b. Heat pipe temperature distribution during cleanup. 
traps were removed from the two heat pipes and the fill tubes were closed and seal welded.

A small, single hole, heat block was built and installed in the test fixture used in the earlier heat pipe studies (Ref. 5). This system not only simulated the method of heat input from the heat block-shield more closely than the radiant heaters used in the previous testing, but it also made the insertion and withdrawal of the heat pipes less time consuming than before. This configuration is shown in Fig. B-6. Prior to installing the heat pipes in the test fixture, the system was baked out at $600^{\circ} \mathrm{F}$ for $24 \mathrm{hr}$ under vacuum in order to remove as much water vapor as possible from the Kaowool insulation.

The three heat pipes were operated in turn and were found to operate satisfactorily. During the course of the tests the following observations were made:

1. The heat transfer characteristics of the heat block-heat pipe system are such that the system does not operate well under vacuum. There was a divergence and rather erratic temperature distribution along the length of the heat block until I psia of argon was admitted to the system. When this was done, the temperature distribution almost immediately leveled out, and the temperature differences between the heat block and the heat pipe were reduced.

2. In vertical operation at low power inputs there was a cyclic, opposing fluctuation of the temperatures in the evaporator and condenser sections of the heat pipe. This situation is similar to that which occurs in pool boiling and is apparently caused by superheating of the potassium in the evaporator region. The effect becomes less pronounced as the power input to the heat block is increased and disappears completely when the system is tilted toward the horizontal. The probable cause of this behavior is the relatively long length of the evaporator section and the inability of the wick structure to keep the annulus between the wick and the wall full of potassium. The magnitude of this temperature fluctuation was small $\left(20^{\circ} \mathrm{F}\right)$ and was not judged to interfere with proper operation of the test.

3. No significant variations in the performance of the three pipes could be assigned to the three different methods of oxygen gettering that were employed in the manufacturing of the pipes. 


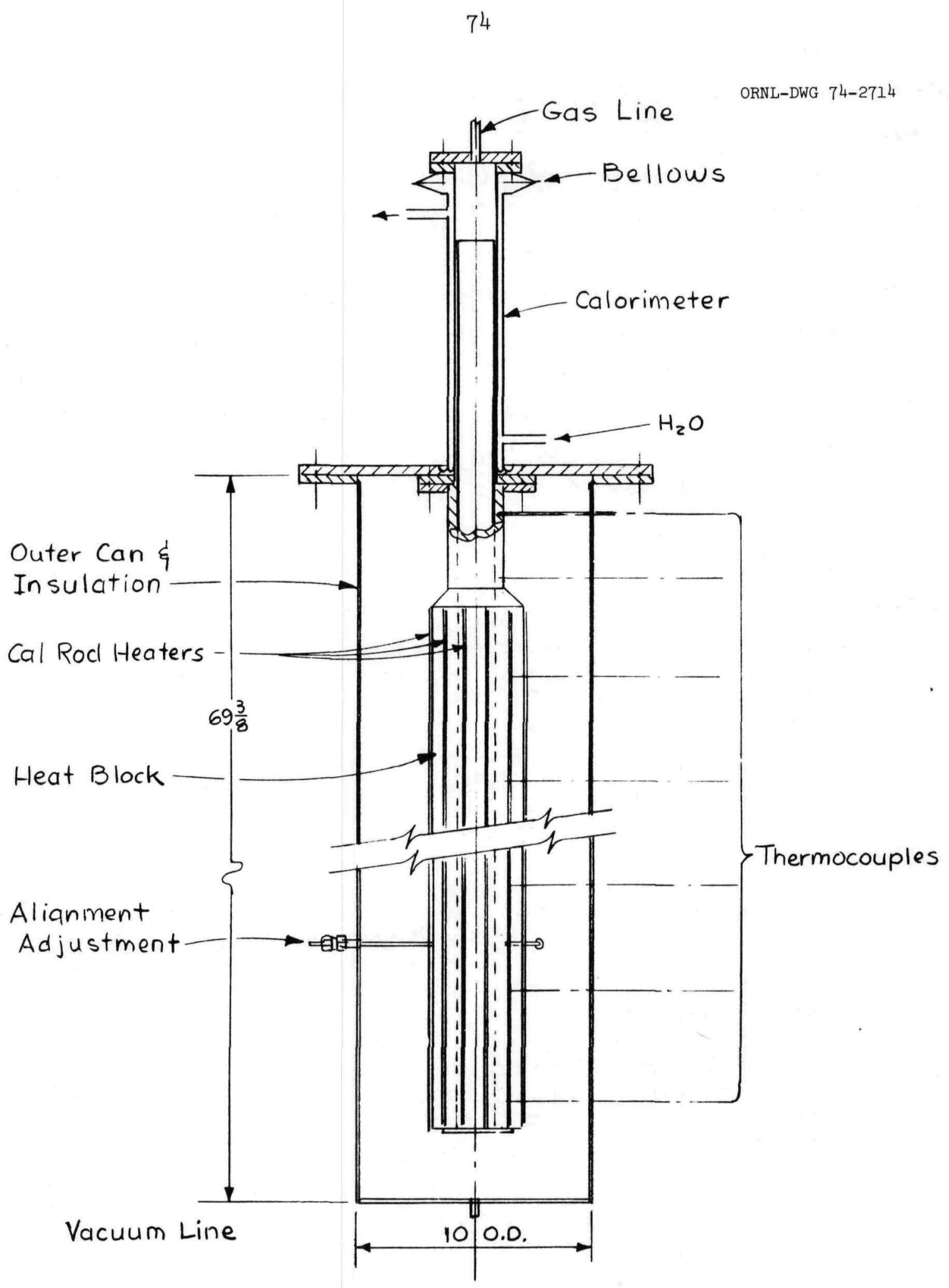

Fig. B.6. Cross-section of heat pipe test assembly . 
1. A. P. Fraas and M. E. Laverne, Reference Design for a Thermoelectric Isotope Power Unit Employing Heat Pipe Modules, USAEC Report ORNLTM-2959, Oak Ridge National Laboratory, November 1971.

2. A. P. Fraas, Reference Design of a $3 \mathrm{~kW}(\mathrm{e})$ Steam Rankine Cycle System for an Isotope Power Plant, USAEC Report ORNL-TM-2961, Oak Ridge National Laboratory, November 1971.

3. G. Samuels and R. S. Holcomb, Reference Design for an Isotope Power Unit Employing an Organic Rankine Cycle, USAEC Report ORNL-TM-2960, Oak Ridge National Laboratory, January 1971.

4. M. E. Lackey, Thermal Test of the Heat Block-Shield for the Isotope Kilowatt Program, USAEC Report ORNL-TM-3806, Oak Ridge National Laboratory, March 1973.

5. D. B. Lloyd, Test of a Combined Heat Pipe Thermoelectric Module, USAEC Report ORNL-TM-4012, Oak Ridge National Laboratory, April 1973.

6. Isotope Kilowatt Program Quarterly Progress Report for Period Ending June 30, 1972, USAEC Report ORNL-TM-3922, Oak Ridge National Laboratory, August 1972 . 
Blank Page 
ORNL-TM-4422

Internal Distribution

1. S. E. Beall

2. T. A. Butler

3. W. B. Cottrell

4. W. C. Cox

5. F. L. Culler

6. R. G. Donnelly

7-11. A. P. Fraas

12. J. H. Gillette

13. A. G. Grindell

14. K. W. Haff

15. H. W. Hoffman

16. R. S. Holcomb

17. P. R. Kasten

18-23. M. E. Lackey

24. E. Lamb

25. D. B. Lloyd

26. R. N. Lyon

27. R. E. MacPherson

28. H. C. McCurdy

29. A. J. Miller

30. A. M. Perry
31. H. Postma

32. R. A. Robins on

33. M. W. Rosenthal

34-39。G. Samuels

40. M. R. Sheldon

41. A. C. Schaffhauser

42. M. J. Skinner

43. A. M. Smith

44. I. Spiewak

45. D. A. Sundberg

46. D. B. Trauger

47. J. J. Tudor

48. J. R. Weir

49. G. D. Whitman

50. J. V. Wilson

51. H. C. Young

52. Biology Library

53-54. Central Research Library

55. Document Reference Section

56-80. Laboratory Records Department

81. Laboratory Records (RC)

\section{External Distribution}

82. D. F. Cope, RRD Site Office, ORNL

83. W. M. Crim, Jr., Technical Director, U.S. Army Engineer Power Group, Ft. Belvoir, Va. 22060

84. R. E. English, NASA, Lewis Research Center, Cleveland, Ohio 44135

85. E. E. Fowler, Division of Applied Technology, USAEC, Washington, D.C. 20545

86. D. S. Gabriel, Division of Space Nuclear Systems, USAEC, Washington, D.C. 20545

87. I. R. Jones, TRW, Redondo Beach, Califormia 90277

88. T. G. Kirkland, Acting Technical Director, U.S. Army Mobility Equipment Research and Development Center, Ft. Belvoir, Va. 22060

89. J. Pidkowicz, RRD Site Office, ORNL

90-95. J. G. Whiteaker, Division of Reactor Research and Development, USAEC, Washington, D.C. 20545 
96-100. Nuclear Engineering Division, Naval Facilities Engineering Command, Washington, D.C. 20545

101-103. Directorate of Licensing, USAEC, Washington, D.C. 20545

104-105. Directorate of Regulatory Standards, USAEC, Washington, D.C. 20545

106-122. Manager, Technical Information Center, AEC (for ACRS Members)

123. Research and Technical Support Division, AEC, ORO

124-125. Technical Information Center, AEC 